\author{
UNIVERSIDADE DE SÃO PAULO \\ INSTITUTO DE ASTRONOMIA, GEOFÍSICA E CIÊNCIAS ATMOSFÉRICAS \\ DEPARTAMENTO DE CIÊNCIAS ATMOSFÉRICAS
}

Andrea Salomé Viteri López

Caracterização da chuva estimada pelo radar durante eventos de alagamento na cidade de São Paulo

São Paulo

2018 
Andrea Salomé Viteri López

\title{
Caracterização da chuva estimada pelo radar durante eventos de alagamento na cidade de São Paulo
}

\author{
Versão Corrigida
}

Dissertação apresentada ao Departamento de Ciências Atmosféricas do Instituto de Astronomia, Geofísica e Ciências Atmosféricas da Universidade de São Paulo como requisito parcial para obtenção do título de Mestre em Ciências.

Área de concentração: Ciências Atmosféricas

Orientador: Prof. Dr. Carlos Augusto Morales Rodriguez

São Paulo

2018 


\section{FOLHA DE APROVAÇÃO}

VITERI, A. S. Caracterização da chuva estimada pelo radar durante eventos de alagamento na cidade de São Paulo. 2018. Dissertação (Mestrado em Meteorologia) - Instituto de Astronomia, Geofísica e Ciências Atmosféricas, Universidade de São Paulo, São Paulo, 2018.

Aprovado em:

Banca Examinadora

Prof. Dr.

Instituição:

Julgamento:

Prof. Dr.

Instituição:

Julgamento:

Prof. Dr.

Instituição:

Julgamento: 
“lo más lindo de los sueños no es llegar hasta el final, es vivirlos, superar cada desafio" Aniko Villalba 


\section{AGRADECIMENTOS}

Quero agradecer imensamente a todos aqueles que direta ou indiretamente contribuíram neste processo que tem mudado minha vida. Agora, todas as pessoas que conheci no Brasil são parte da minha evolução pessoal e profissional e desta inesquecível experiência.

Primero eu gostaria agradecer a meu orientador o Prof. Dr. Carlos Augusto Morales pela paciência, exigência, seus conselhos e diretrizes no desenvolvimento desta dissertação, e principalmente pelo incentivo, amizade e suas palavras reconfortantes quando eu mais precisei.

A minha família, meus pais Francisco e Myrian e meus irmãos Kate e Esteban, que tem sido a principal motivação e força para não me dar por vencida e continuar com meus projetos e sonhos. Obrigada por sempre confiar em mim.

A minha família cubana e colombiana, Darsys, Dayana, Dayne, Janet, Jose, Keyla, Maciel, Puig e Ramón, sou muito afortunada por tê-los conhecido. Obrigada vocês por me adotar com uma irmã e por me brindar sua ajuda, seus ânimos, companhia e boa comida. A minha amiga incondicional, minha irmã Yus, por seu apoio nos momentos mais difíceis, nos dias longos e de muito trabalho, e por me alentar para não desistir. A meus amigos do IAG, com quem compartilhamos conhecimentos, experiências, problemas e alegrias.

Obrigada a todos os professores do IAG, IME e PHA pelos conhecimentos adquiridos, em particular a Adalgiza por ser exemplo de pessoa e uma amiga, obrigada estar presente nos momentos precisos, e também as professoras Beti e Lane do IME que foram guia no desenvolvimento da pesquisa.

Obrigada também ao suporte técnico do IAG pela ajuda e amizade incondicional.

Finalmente, este projeto tivera sido impossível sem a infraestrutura fornecida pelo IAG/USP e o financiamento de CAPES. 


\section{RESUMO}

VITERI, A. S. Caracterização da chuva estimada pelo radar durante eventos de alagamento na cidade de São Paulo. 2018. 114f. Dissertação (Mestrado em Meteorologia) - Instituto de Astronomia, Geofísica e Ciências Atmosféricas, Universidade de São Paulo, São Paulo, 2018.

Este projeto de mestrado apresenta uma caracterização das chuvas estimadas pelo radar meteorológico Doppler de dupla polarização banda S (SPOL) do Departamento de Águas e Energia Elétrica (DAEE) e Fundação Centro Tecnológico de Hidráulica (FCTH) durante eventos com ou sem alagamento para cada bairro da cidade de São Paulo durante o ano de 2015. A caracterização foi determinada a partir da função densidade de probabilidade (PDF) da chuva acumulada e da taxa de precipitação, duração da chuva e fração da área de cada bairro onde ocorreu a chuva. Na média, os eventos de alagamento estavam associados com um volume de chuva maior que $30 \mathrm{~mm}$ e taxa precipitação máxima maior que $30 \mathrm{~mm} / \mathrm{h}$. Com relação à duração não foi possível encontrar um padrão médio, pois a chuva teve duração mínima de 20 minutos e máxima de 23 horas. Por outro lado, eventos de alagamento tinham alcançado mais de $27 \%$ da área do bairro com taxa de precipitação maior que $30 \mathrm{~mm} / \mathrm{h}$ e 50 $\mathrm{mm} / \mathrm{h}$. Destaca-se ao longo desta análise que os bairros localizados próximos aos rios Tietê e Pinheiros e a região central da cidade de São Paulo apresentaram maior probabilidade de ocorrência de alagamento com volumes de chuva mais baixos do que a média de $30 \mathrm{~mm}$ por dia e também registraram maior recorrência de pontos alagados. Por último foi desenvolvido um método de regressão logística binária para calcular a probabilidade de ocorrência de alagamentos nos diversos bairros da cidade São Paulo. Este modelo utiliza como parâmetros de entrada a duração da chuva, a taxa de precipitação máxima e a chuva acumulada nas últimas 24 horas. O modelo apresentou uma probabilidade de detecção (POD) média de 1\% e uma taxa de falso alarme média (FAR) de 0,6 para os eventos de alagamento, já para eventos sem alagamento o POD médio foi de $96 \%$ e a FAR foi de $2,5 \%$. Portanto o modelo consegue prever os casos sem alagamento.

Palavras - chave: alagamento, radar meteorológico, PDF, Modelo de Regressão Logística Binaria, São Paulo. 


\begin{abstract}
VITERI, A. S. Characterization of precipitation estimated by radar during flooding events in São Paulo. 2018. 114f. Dissertation (Master in Meteorology) - Institute of Astronomy, Geophysics and Atmospheric Sciences, University of São Paulo, 2018.
\end{abstract}

This dissertation project presents a characterization of the rainfall estimated from a dualpolarization S-band Doppler meteorological radar (SPOL) of the Department of Water and Electric Energy (DAEE) and Foundation Technological Center of Hydraulics (FCTH) during with or without flooding events for each neighborhood of the city of São Paulo over the year 2015. The characterization was determined by the probability density function (PDF) of the accumulated rainfall and the precipitation rate, rainfall duration and rainfall-area fraction in the neighborhoods. In average, flood events were associated with a rainfall volume greater than $30 \mathrm{~mm}$ and a maximum rainfall rate greater than $30 \mathrm{~mm} / \mathrm{h}$. Regarding the duration, it was not possible to find an average pattern, because the rain had a minimum duration of 20 minutes and a maximum of 23 hours. On the other hand, flood events had reached more than $27 \%$ of the neighborhood's area with a precipitation rate greater than $30 \mathrm{~mm} / \mathrm{h}$ and $50 \mathrm{~mm} / \mathrm{h}$. It is highlighted throughout this analysis that the neighborhoods located near the Tietê and Pinheiros rivers and central region of the city of São Paulo presented a higher probability of flood occurrence with rainfall volumes lower than the average of $30 \mathrm{~mm}$ per day and also recorded higher recurrence of flooded spots. Finally, a binary logistic regression method was developed to estimate the probability of occurrence of flooding in the various neighborhoods of the city of São Paulo. This model uses as input parameters rainfall duration, maximum rainfall rate and accumulated rainfall in the last 24 hours. The model presented a mean probability of detection (POD) of $1 \%$ and a mean false alarm rate (FAR) of 0,6 for flood events. On the other hand, for events without occurrence of flood a mean POD was $96 \%$ and FAR 2,5. Therefore the model can predict the events without flooding.

Key - words: flooding, meteorological radar, PDF, Binary Logistic Regression Model, Sao Paulo 


\section{LISTA DE FIGURAS}

Fig. $\quad$ Descrição

Pág.

3.1 Mapa das regiões administrativas e bairros da cidade de São Paulo. Fonte: Andrea Viteri.

3.2 Mapa de localização dos postos pluviométricos da cidade de São Paulo. Fonte: Andrea Viteri.

3.3 Esquema do controle de qualidade para os dados dos pluviômetros...............

3.4 Relação entre o cociente do raio de uma esfera pelo comprimento de onda do pulso do radar com a secção transversal de retro espalhamento normalizada pela área de um circulo. Adaptado de Yuter, 2003.

3.5 Mapa de localização e alcance do radar Banda S de Dupla Polarização da SELEX. Fonte: Andrea Viteri.

3.6 Mapa de localização dos pontos de alagamento registrados em 2015 pelo CGE. Fonte: Andrea Viteri.

4.1 Matriz de confusão e medidas usadas comumente para seu cálculo. Adaptado de Fawcett (2006)

5.1 Ajustes lineares entre precipitação acumulada pelo pluviômetro e o radar para as escalas temporais de (a) 10 minutos, (b) 1 hora e (c) 1 dia na cidade de São Paulo.

5.2 Mapa do número total de ocorrências de alagamento no ano 2015 para os bairros da cidade de São Paulo. Fonte: Andrea Viteri.

5.3 Mapa da chuva acumulada no ano 2015 estimada pelo radar para a cidade de São Paulo. Fonte: Andrea Viteri.

5.4 Comparação dos dias com e sem alagamento nos bairros de a) Campo Limpo, b) República e c) Sacomã: (ESQUERDA) Função Densidade de Probabilidade para os dias com alagamento (linha azul) e sem alagamento (linha preta), as linhas ponteadas representam as intensidades médias. (DIREITA) Comparação das propriedades da chuva acumulada dos dias com e sem alagamento, o ponto vermelho representa o valor médio, a linha preta em cada caixa marca a mediana, as bordas da caixa baixa e superior representam os quartis ao $25 \mathrm{e} 75 \%$, respectivamente, e os pontos pretos fora das caixas representam os valores extremos.

5.5 Gráfico de frequência e dispersão entre a chuva acumulada e a duração da chuva por dia ano 2015 para os bairros de Belém, Cursino e Morumbi..........

5.6 Gráfico de frequência e dispersão entre a chuva acumulada e a taxa de precipitação máxima por dia - ano 2015 nos bairros de Barra Funda, Butantã e Itaim Bibi.

5.7 Comparação da fração da área de chuva nos bairros de (a) Agua Rasa, (b) Ipiranga e (c) Santana em relação à chuva acumulada média na escala temporal de 10 minutos.

5.8 Função Densidade de Probabilidade da fração da área de chuva para os bairros de Agua Rasa com precipitações maiores a $30 \mathrm{~mm} / \mathrm{h}$ (a) e $50 \mathrm{~mm} / \mathrm{h}$ (b), Ipiranga (c) e (d) e Santana (e) e (f) para os instantes com alagamento 
(linha azul) e sem alagamento (linha preta); as linhas ponteadas representam as intensidades médias.

5.9 Mapa do padrão médio da probabilidade de ocorrência de alagamento de acordo com a taxa de precipitação máxima para o ano 2015 nos bairros da cidade de São Paulo. Fonte: Andrea Viteri.

5.10 Mapa de localização dos pontos alagados e a frequência de ocorrência de alagamento durante o ano 2015 na cidade de São Paulo. Fonte: Andrea Viteri

5.11 Distribuição da precipitação para os dias 25, 26,27 e 28 de janeiro e 46, 47 e 48 de fevereiro do ano 2015

5.12 Distribuição da precipitação do bairro de Bom Retiro para o mês de novembro nos dias 304, 305, 306, 307 e dezembro os dias 353, 354, 355, 356 do ano 2015.

5.13 Distribuição da precipitação do bairro de Santana para o mês de outubro nos dias 294, 295 e 296, e o mês de novembro nos dias 305, 306, 307 e 308 do ano 2015 .....

5.14 Diagrama de frequências de ocorrência de eventos de alagamento e da chuva acumulada média antes do alagamento.

5.15 Esquema do modelo de investigação para o prognóstico de alagamentos nos bairros da cidade de São Paulo.

5.16 Tabela gráfica de seleção de subconjuntos para o bairro de Santana.

5.17 Mapa de variáveis ajustadas no modelo de regressão logística binária nos bairros da cidade de São Paulo. Fonte: Andrea Viteri.

5.18 Mapas do índice de validação POD para eventos a) com alagamento e b) sem alagamento nos bairros da cidade de São Paulo.

5.19 Mapas do índice de validação FAR para eventos a) com alagamento e b) sem alagamento nos bairros da cidade de São Paulo. 


\section{LISTA DE TABELAS}

Tab. Descrição

Pág.

3.1 Frequência e comprimento de onda dos radares meteorológicos...................

3.2 Características técnicas do radar banda $\mathrm{S}$ de dupla polarização da SELEX, modelo METEOR 600S. Fonte SAISP

3.3 Tabela de contingencia para o radar (Rradar) e o pluviômetro (Rpluviômetro). Fonte: Adaptado de Oliveira (2017)

3.4 Lista das métricas estatísticas utilizadas na validação das estimativas de precipitação. Fonte: Adaptado de Oliveira (2017)

5.1 Características do controle de qualidade dos postos pluviométricos

5.2 Análise estatístico da validação dos pluviômetros em relação ao radar a escalas temporais de 10 minutos, 1 hora e 1 dia.

5.3 Média e desvio padrão (em parênteses) das propriedades espaciais e temporais das chuvas e dos eventos de alagamento no ano 2015 para os bairros de Campo Limpo, Republica e Sacomã

5.4 Média e desvio padrão (em parênteses) das propriedades espaciais e temporais das chuvas e dos eventos de alagamento no ano 2015 para os bairros de Belém, Cursino e Morumbi.

5.5 Média e desvio padrão (em parênteses) das propriedades espaciais e temporais das chuvas e dos eventos de alagamento no ano 2015 para os bairros de Barra Funda, Butantã e Itaim Bibi...

5.6 Propriedades espaciais e temporais das chuvas e dos eventos de alagamento para os bairros de Agua Rasa, Ipiranga e Santana no ano 2015 para os bairros de Agua Rasa, Ipiranga e Santana.

5.7 Resumo dos padrões diários de cada analise para os bairros da cidade de São Paulo - por dia.

5.8 Resumo das características dos pontos de alagamento mais recorrentes........

5.9 Coeficientes do modelo de Regressão Logística Binária para os bairros de São Paulo

A1.1 Características dos resultados obtidos no controle de qualidade dos postos pluviométricos da cidade de São Paulo durante o ano 2015.

A2.1 Características estadísticas gerais para escala temporal de 10 minutos..........

A2.2 Características estadísticas gerais para escala temporal de 1 hora..................

A2.3 Características estadísticas gerais para escala temporal de 1 dia....................

A3.1 Características espaciais e temporais das chuvas e eventos de alagamento dos bairros da cidade de São Paulo durante o ano 2015.

A3.2 PDF da Taxa de precipitação dos bairros da cidade de São Paulo no ano 2015

A3.3 PDF da chuva acumulada nos bairros da cidade de São Paulo no ano 2015...

A3.4 PDF da fração da área de chuva para precipitações maiores que $30 \mathrm{~mm} / \mathrm{h}$ e $50 \mathrm{~mm} / \mathrm{h}$ dos bairros da cidade de São Paulo durante o ano 2015.

A4.1 Características de avaliação do modelo de regressão logística binária para eventos com e sem alagamento nos bairros da cidade de São Paulo 


\section{LISTA DE SIGLAS E VARIÁVEIS}

\begin{tabular}{|c|c|c|}
\hline Item & $\begin{array}{c}\text { Siglas e } \\
\text { variáveis }\end{array}$ & Descrição \\
\hline 1 & CEPED & Centro de Estudos e Pesquisas em Desastres \\
\hline 2 & CEMADEN & $\begin{array}{l}\text { Centro Nacional de Monitoramento e Alertas de Desastres } \\
\text { Naturais }\end{array}$ \\
\hline 3 & CGE & Centro de Gerenciamento de Emergências Climáticas \\
\hline 4 & DAEE & Departamento de Águas e Energia Elétrica \\
\hline 5 & DPSRI & Dual Polarization Surface Rainfall Intensity \\
\hline 6 & EM & Energia eletromagnética \\
\hline 7 & FCTH & Fundação Centro Tecnológico de Hidráulica \\
\hline 8 & LI & Linhas de instabilidade \\
\hline 9 & PDF & Função Densidade de Probabilidade \\
\hline 10 & PPS & Precipitation Preprocessing Subsystem \\
\hline 11 & RMSP & Região Metropolitana de São Paulo \\
\hline & SAISP & Sistema de Alerta a Inundações do Estado de São Paulo \\
\hline 12 & SIGNURB & Sistema de Gestão da Infra-estrutura Urbana \\
\hline 13 & USP & Universidade de São Paulo \\
\hline 14 & VRP & Perfil vertical de refletividade \\
\hline 15 & ZCAS & Zona de Convergência do Atlântico Sul \\
\hline 16 & DSD & Distribuição de tamanho de gotas \\
\hline 17 & $\mathrm{~N}(\mathrm{D})$ & Concentração de gotas por $\mathrm{m}^{3}$ \\
\hline 18 & $\mathrm{P}_{\mathrm{T}}$ & Potência Transmitida \\
\hline 19 & $P_{R}$ & Potência de Retorno \\
\hline 20 & $\sigma$ & Secção transversal de retro-espalhamento \\
\hline 21 & $\lambda$ & Comprimento de onda do radar \\
\hline 22 & $D$ & Diâmetro da partícula \\
\hline 23 & $\mathrm{~V}_{\mathrm{T}}$ & Velocidade terminal de queda dos hidrometeoros \\
\hline 24 & $\mathrm{~W}$ & Velocidade vertical \\
\hline 25 & $\mathrm{R}$ & Taxa de precipitação \\
\hline 26 & $\mathrm{Z}$ & Refletividade de radar \\
\hline 27 & $Z_{D R}$ & Refletividade Diferencial \\
\hline 28 & $\mathrm{~K}_{\mathrm{DP}}$ & Diferencial de fase especifica \\
\hline 29 & $\phi \mathrm{DP}$ & Fase Diferencial \\
\hline 30 & $\mu$ & Média da distribuição \\
\hline 31 & $\mathrm{p}(\mathrm{x})$ & Probabilidade de que o evento suceda \\
\hline 32 & POD & Probabilidade de Detecção \\
\hline 33 & FAR & Taxa de Falso Alarma \\
\hline 34 & ROC & Receiver Operating Characteristic \\
\hline
\end{tabular}




\section{SUMÁRIO}

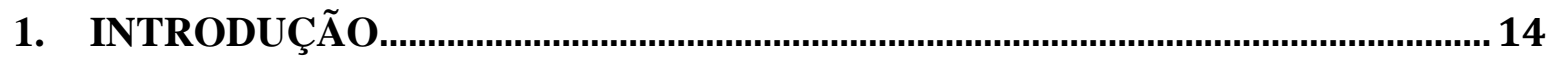

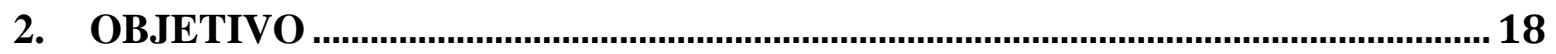

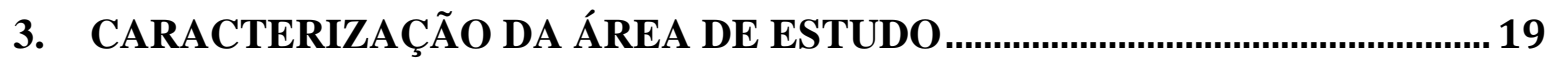

3.1. Características da Região Metropolitana de SÃo PaUlo............................... 19

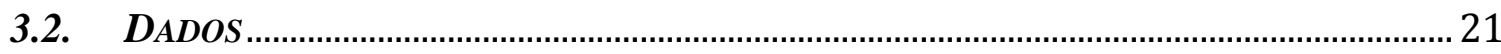

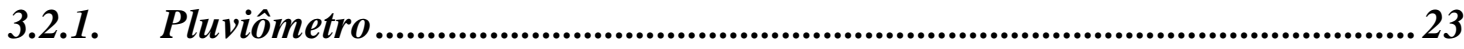

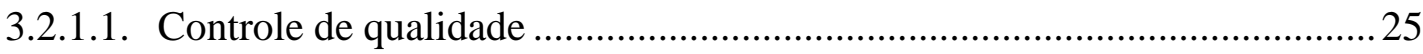

3.2.2. Radar Meteorológico .....................................................................................26

3.2.2.1. Radar meteorológico banda $\mathrm{S}$ de dupla polarização ..................................... 31

3.2.2.2. Algoritmo de estimativa de Precipitação do SPOL ........................................33

3.2.3. Estatísticas de validação das estimativas de precipitação .................................34

3.2.4. Gestão de alagamentos .......................................................................................35

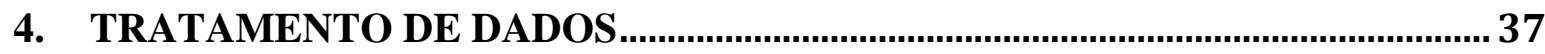

4.1. FUNÇÃO DENSIDADE DE PROBABILIDADE - PDF ………....................................... 37

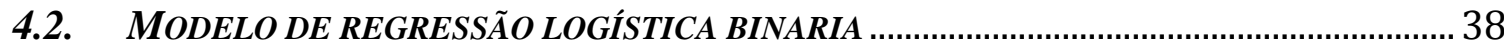

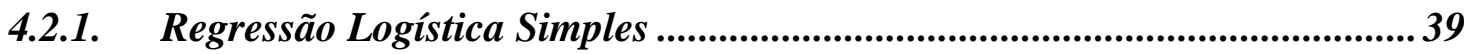

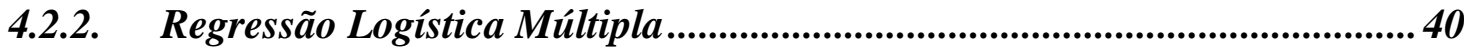

4.2.3. Validação do Modelo de Regressão Logística ...................................................40

5. CARACTERIZAÇÃO DA CHUVA OBSERVADA EM SÃO PAULO PELO

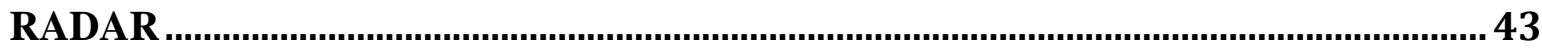

5.1. CONTROLE DE QUALIDADE DOS PLUVIÔMETROS ..................................................... 44

5.2. VARIAÇÃO DA CHUVA ESTIMADA PELO RADAR ……….......................................... 45

5.3. ANÁLISES DOS BAIRROS DA CIDADE DE SÃO PAULO ............................................... 48

5.3.1. Função Densidade de Probabilidade - PDF ..................................................52

5.3.2. Duração da chuva vs Chuva acumulada .........................................................56

5.3.3. Taxa de precipitação vs Chuva acumulada .....................................................59

5.3.4. Fração da área de chuva vs Chuva acumulada .............................................62

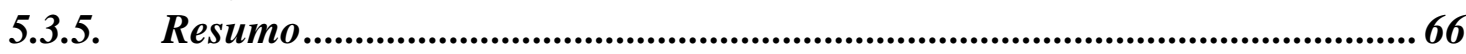

5.4. ANÁLISES DOS PONTOS ALAGADOS NOS BAIRROS DA CIDADE DE SÃO PAULO........... 71

5.5. ANÁLISES DO MODELO DE REGRESSÃO LOGÍSTICA BINÁRIA..................................... 77

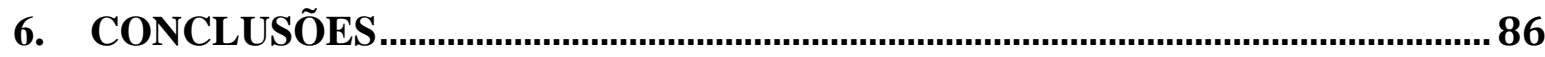

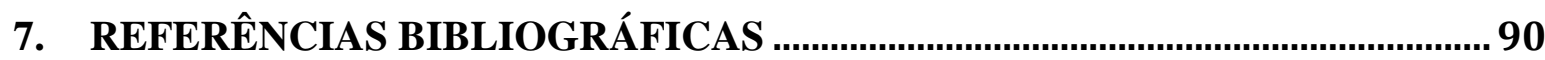

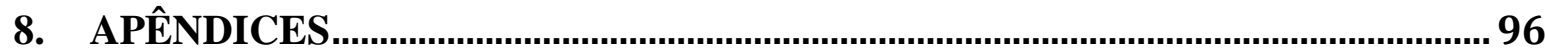




\section{Introdução}

Nos últimos anos a previsão dos alagamentos tem sido uma das prioridades nas cidades densamente povoadas no Brasil, como por exemplo a Região Metropolitana de São Paulo (RMSP) (Barros \& Conde, 2017; Farias \& Filho, 2013; C. P. M. Oliveira et al., 2014). A RMSP é periodicamente sujeita a eventos convectivos severos (Barros \& Conde, 2017; Silva, Pereira Filho, \& Hallak, 2009), que causam precipitações intensas. Este efeito é agravado devido à topografia da região e às diferentes ocupações do solo, que agravam os efeitos negativos para a população causando alagamentos ou enchentes na cidade (Larser, Vasquez Conde \& Clark, 1999).

No verão é registrado o maior número de alagamentos e enchentes na cidade de São Paulo (Pereira Filho, 1999). De acordo com Pereira Filho, Haas, \& Ambrizzi (2002) que analisaram os eventos de enchentes na cidade entre 1999 e 2002 e Pereira Filho et al. (2004) durante os anos 2002 e 2004, a grande maioria dos eventos ocorrem por grandes colunas de precipitação ocasionado pelo forte aquecimento diurno e pela interação da brisa marítima (injeção de umidade), que gera sistemas precipitantes mais profundos e com maior volume de precipitação. Geralmente, na RMSP, a entrada da brisa marítima ocorre entre o meio e fim da tarde com o aumento da temperatura do ponto de orvalho (Naccarato, 2006; Pereira Filho, et al., 2004; Vemado, 2012) e coincide com a hora de máximo aquecimento da atmosfera.

Já do ponto de vista de alagamentos, Rocha Filho et al. (2013), mostraram que 35 a $60 \mathrm{~mm}$ de chuva acumulada em um período de 30 a 80 minutos podem causar alagamentos na maior parte da cidade. Neste estudo, também afirma-se que a cidade não tem uma solução economicamente viável para resolver o problema de alagamentos, sendo necessário o estabelecimento de métodos de coexistência com a água urbana.

A grande maioria dos estudos na previsão de alagamentos e enchentes está baseada em modelos hidrológicos ou hidráulicos (Ávila et al., 2007; Boni et al., 2007). Em modelos de simulação que reproduzem os principais mecanismos de geração de alagamentos, 
incluindo a dinâmica da umidade do solo, a sazonalidade da precipitação e a intermitência, a concentração de descarga, etc. (Fiorentino, Manfreda, \& Iacobellis, 2007).

Os modelos hidrológicos, além de antecipar a ocorrência de alagamentos, ajudam a compreender e representar o comportamento da bacia hidrográfica (Gonçalves, 2009). Segundo Tucci (2005), podem ser classificados em: 1) modelos concentrados, quando não levam em conta a variabilidade espacial da bacia, 2) em modelos distribuídos, quando consideram as variáveis de espaço e tempo, 3) em modelos estocásticos, quando a probabilidade é introduzido na formulação do modelo, 4) em modelos determinísticos, quando para uma mesma entrada o modelo produz uma mesma saída, 5) em modelos conceituais, quando consideram as características físicas dos processos hidrológicos e 6) em modelos empíricos, quando são baseados em analises estatísticas.

Entretanto estes modelos requerem calibração e validação, que por sua vez dependem da localização ou do aumento de parâmetros estimados para a diminuição dos erros (Collier, 2007; Santos, 2009) e mesmo assim não são suficientes para melhorar o ajuste e o prognóstico de um sistema de alertas (Zhu, Xuan, \& Cluckie, 2014). C. P. M. Oliveira et al. (2014), mostraram a importância da qualidade dos dados na aplicação de um modelo hidrológico, do controle ou manutenção das estruturas hidráulicas, estações pluviométricas e fluviométricas e de ter um melhor reporte dos alagamentos na cidade de São Paulo.

Neste sentido, a definição e o estabelecimento de um sistema de alertas podem diminuir os efeitos negativos dos alagamentos na cidade e assim permitir uma rápida resposta na prevenção e preparação para os alagamentos. Pensando nisso, o DAEE (Departamento de Águas e Energia Elétrica) e FCTH (Fundação Centro Tecnológico de Hidráulica) instalaram um radar meteorológico banda S da McGill em Salesópolis em 1989 (Pisani, 1995) com o objetivo de melhorar o monitoramento da precipitação na RMSP e das bacias hidrográficas vizinhas. Posteriormente, início de 2014, o radar da McGill foi atualizado por um radar Doppler banda S de dupla polarização da SELEX que proporciona melhores estimativas de precipitação (Rocha Filho, Conde, \& Andrioli, 2015). Por exemplo, este novo radar realiza varreduras até $240 \mathrm{~km}$ com uma resolução de $250 \mathrm{~m}$, a cada 5 minutos, viabilizando a caracterização da precipitação e da probabilidade de ocorrência de alagamentos ou enchentes na cidade (Barros \& Conde, 2017). 
Em vista de melhorar o sistema de alertas, o Centro Nacional de Monitoramento e Alertas de Desastres Naturais (CEMADEN), que gerencia e prevê eventuais desastres naturais como os alagamentos no Brasil, envia constantemente alerta de riscos de desastres naturais quando sejam observadas condições que produzam riscos de ocorrência de processos geodinâmicos (movimentos de massa) e hidrológicos (inundações ou enxurradas) e estes a sua vez são enviados para os órgãos de Defensa Civil Estadual e Municipal (CEMADEN, 2018). Do mesmo modo, o Sistema de Alerta a Inundações do Estado de São Paulo (SAISP), que faz o monitoramento das variáveis hidrometeorológicas e níveis dos rios e reservatórios e a previsão da chuva e a vazão em tempo real (C. P. M. Oliveira et al., 2014), utiliza a metodologia do modelo SWMM (Modelo de Gerenciamento de Águas Pluviais da Agência de Proteção Ambiental dos Estados Unidos). Este modelo gera mapas de previsão dos níveis de agua e alagamentos em diferentes áreas da RMSP (Barros \& Conde, 2017) e permite a apreensão da intensidade das chuvas das estacoes hidrológicas e do radar meteorológico.

No ano de 1999, a cidade de São Paulo teve um alagamento de grandes proporções que gerou enormes impactos econômicos e humanos. Em resposta, a Prefeitura de São Paulo (PMSP) criou o Centro de Gerenciamento de Emergências Climáticas (CGE) da Cidade de São Paulo (https://www.cgesp.org/v3/quem-somos.jsp). Este centro conta com a cooperação da FCTH, que em parceria com outras instituições, viabiliza o monitoramento dos pontos onde ocorreram alagamentos na RMSP em conjunto com medidas de chuva em tempo real, a partir da rede telemétrica e um radar meteorológico. Portanto, o monitoramento e previsão da precipitação com poucas horas de antecedência permite desenvolver um sistema de alertas de alagamentos e enchentes, capaz de reduzir os impactos em diversas escalas (Ávila, Pinto, \& Nery, 2007).

Farias \& Filho (2013), mediante um modelo de previsão de chuva de curtíssimo prazo acoplado ao radar meteorológico de São Paulo, previram a precipitação na RMSP para um período de 3 horas e identificou cinco tipos de sistemas precipitantes que seriam possíveis de prever a magnitude da chuva: brisa marítima, convecção isolada, linhas de instabilidade, bandas dispersas e frentes frias. Já (Ávila et al., 2007), através do uso de radar meteorológico conseguiram identificar áreas propensas a chuvas fortes. 
Posteriormente, em Dezembro de 2012, a USP, o governo do estado de São Paulo e o Ministério de Integração Nacional celebraram um convênio e criaram o Centro de Estudos e Pesquisas em Desastres (CEPED) da USP. O CEPED por sua vez, responde a uma demanda da Defesa Civil do Estado de São Paulo e cria o projeto ChuvaOnline para desenvolver novas metodologias de monitoramento de precipitação com alta resolução espacial/temporal para cidades de pequeno e médio porte. Este projeto foi inserido dentro do programa inovador de cidades inteligentes e resilientes Sistema de Gestão da Infra-estrutura Urbana (SIGNURB).

O ChuvaOnline composto por uma rede de 3 radares meteorológicos banda $\mathrm{X}$ com alta resolução espacial (Morales, 2015; Morales et al., 2017) que cobrem essencialmente a RMSP e conta com a parceria da Climatempo e FCTH. Ao usar a tecnologia de um radar banda $X$ foi possível obter uma resolução espacial de 75 a 90 m e amostrar temporalmente a cada 1 e 5 minutos (Morales et al., 2017). Logo, pretende-se complementar as medidas de precipitação do radar banda $\mathrm{S}$ do DAEE/FCTH e assim inferir a precipitação com mais precisão a ponto de identificar ruas e bairros.

Sendo São Paulo uma cidade que tem frequentes ocorrências de alagamentos, por exemplo, no verão de 2014/2015 foram identificados 183 pontos de alagamento, dos quais 130 ocorreram entre janeiro e março de 2015. Os bairros da região central de São Paulo (Sé e República) e da zona norte (Santana e Limão) apresentaram maior ocorrência de alagamentos, entretanto os maiores índices pluviométricos observados durante o verão estavam concentrados na zona oeste e leste da cidade de São Paulo. À vista disso, é importante caracterizar as chuvas a partir de um radar meteorológico com o menor erro de forma que seja possível identificar padrões de ocorrência de eventos de alagamentos. Assim, características geomorfológicas, hidrológicas, demográficas e de infra-estrutura de cada bairro podem ser levadas em consideração para prever os alagamentos. Conjuntamente com a caracterização das chuvas na cidade e com o propósito de prever os alagamentos em cada um dos bairros, se estabeleceu um modelo de regressão logística binária baseado nas medidas do radar, com o propósito de definir se o bairro entra em estado de atenção ou não. 


\section{Objetivo}

Diferentemente dos estudos que visam prever alagamentos e enchentes a partir de modelos hidrológicos, neste estudo pretende-se caracterizar pela primeira vez as chuvas estimadas pelo radar meteorológico Doppler de dupla polarização Banda S (SPOL) do DAEE/FCTH durante eventos de alagamento ou não para cada Bairro da cidade de São Paulo.

Portanto, os seguintes objetivos específicos serão desenvolvidos:

a) Estimar os padrões estatísticos da distribuição de probabilidade de chuva para cada bairro da cidade de São Paulo associado ou não com alagamentos e identificar se o bairro poderia entrar em estado de atenção ou não relativo à ocorrência de alagamentos.

b) Desenvolver um modelo de regressão logística binária para calcular a probabilidade de ocorrência de alagamento nos bairros da cidade de São Paulo. 


\section{Caracterização da Área de estudo}

\subsection{Características da Região Metropolitana de São Paulo}

A Região Metropolitana de São Paulo (RMSP) faz parte da bacia hidrográfica do Alto Tietê e possui uma área de $5985 \mathrm{~km}^{2}$ (Silva et al., 2009). Atualmente concentra 39 municípios. O município de São Paulo é um dos municípios da RMSP que abrange 32 prefeituras regionais e 96 bairros agrupados em 9 zonas administrativas (Figura 3.1). O município de São Paulo tem aproximadamente 12.1 milhões de habitantes (IBGE, [s.d.]), enquanto que a RMSP tem 21,1 milhões de habitantes (IBGE, 2017).

A cidade encontra-se a uma altitude de 760 m na bacia do rio Tietê, que dá passo às sub bacias como do Rio Pinheiros. A cidade de São Paulo conta com mais de 300 rios (superficiais ou canalizados), que modelam o relevo de cada bairro. Consequentemente, as características dos rios existentes e o modo como se deu a ocupação urbana podem aumentar ou não a probabilidade de ocorrência de alagamento na cidade.

A cidade é caracterizada por um inverno (Junho - agosto) seco e frio com valores de temperatura média mensal entre $16.5^{\circ} \mathrm{C}$ e $17.1^{\circ} \mathrm{C}$, e um verão (dezembro - março) úmido e quente com valores de temperatura média entre $21.1^{\circ} \mathrm{C}$ e $21.7^{\circ} \mathrm{C}$. No período de chuvas dezembro a março, a cidade de São Paulo registrou totais de chuva que variam entre $450 \mathrm{~mm}$ e $700 \mathrm{~mm}$, para este último período. As chuvas variam em função da atuação das frentes frias, linhas de instabilidade, brisas marítimas e convecções locais (Pereira Filho et al., 2002).

Os sistemas frontais associados às frentes frias atuam durante o ano inteiro, sendo mais convectivos no verão do que no inverno. As frentes apresentam faixas de precipitação de largura variável com direção noroeste a sudeste e deslocamento de sudoeste para nordeste (Farias, 2009; Silva et al., 2009). No verão a umidade proveniente da região Amazônica induz a formação de zonas baroclínicas que se tornam estacionárias e geram bandas de precipitação mais intensas (Silva et al., 2009). Em geral, as chuvas associadas às frentes frias têm características estratiforme, ou seja, tem longa duração e abrangem grandes áreas (Anagnostou, 2004; Libertino et al., 2015; Steiner \& Smith, 1998). 
Quando as frentes frias estão acopladas à Zona de Convergência do Atlântico Sul (ZCAS) as precipitações são mais intensas e de longa duração (Farias, 2009), portanto com maiores acumulados de precipitação.

Pereira et al. (2004) observaram também que na RMSP os eventos de precipitação intensa se desenvolvem rapidamente sobre a ilha de calor urbano. A ilha de calor está associada a grandes centros urbanos, como é o caso da RMSP, e resulta do contraste de temperatura entre o meio urbano e as áreas vizinhas formando uma circulação em direção a cidade, o que leva a uma temperatura maior no centro urbano que nas redondezas (Vemado, 2012). Geralmente no inverno, a ilha de calor é mais evidente devido a suas condições climáticas (seco), ou seja ventos fracos e condições de céu claro (Vemado, 2012).

As linhas de instabilidade (LI) são bandas de precipitação que consistem de nuvens cumulonimbus organizadas em linha ou em curva, e se deslocam uniformemente durante poucas horas até um dia (Reboita, Gan, Rocha, \& Ambrizzi, 2010). As LI mais significativas estão associadas a linhas de células convectivas profundas a cerca de 200$300 \mathrm{~km}$ das frentes frias em áreas mais quentes (Reboita et al., 2010). Além disso, podem estar associadas a sistemas frontais sendo predominantes na tarde, de 14:00 a 18:00 HL com período de 4 a 15 horas (Farias, 2009; Pereira Filho \& Silva, 2005). As linhas de instabilidade se movem em qualquer direção, perpendicular e paralela ao movimento de sistemas frontais (Silva et al., 2009). Pereira Filho et al. (2000) observaram que eventos de chuva significativos estavam associados às linhas de instabilidade na primavera, que normalmente se formam no Mato Grosso do Sul (Queiroz, 2008)

Além disso, segundo A. P. Oliveira \& Silva Dias (1982), os fluxos de massa e calor na RMSP são mais intensos devido ao aquecimento diurno, expansão urbana, poluição e penetração da circulação da brisa marítima. Pereira Filho (1999) observou que a ilha de calor associada à penetração da brisa marítima contribui para eventos de precipitação mais frequentes na RMSP, e estão associados com eventos de alagamento mais profundos que cobrem maior área e com maior volume de precipitação (Pereira Filho et al., 2004). Em geral, estes eventos convectivos induzidos pela brisa marina desenvolvem-se entre 14:30 HL e 19:00 HL formando células convectivas ao longo da costa do litoral paulista favorecidas pela Serra do Mar (Silva et al., 2009). 
Sistemas convectivos formados no Paraguai e associados aos jatos de baixos níveis naquela região também afetam a RMSP (Queiroz, 2008). Além disso, células convectivas isoladas e sem orientação se formam a tarde e seguem o aquecimento diurno (Silva et al., 2009). Durante a fase de dissipação, estes sistemas levam a formação de grandes áreas de precipitação estratiforme (Farias, 2009).

Assim, pode-se concluir que a morfologia e evolução de cada um destes sistemas na cidade de São Paulo depende de fatores como a topografia, circulação associada e processos de mistura induzidos pelo aquecimento diurno (Silva et al., 2009).

\subsection{Dados}

A região conta com uma rede telemétrica de pluviômetros e fluviômetros sob a responsabilidade do DAEE desde 1976 (Barros \& Braga JR, 1992). Os dados pluviométricos e fluviométricos são coletados a cada 10 minutos e enviados para a FCTH. Na bacia do Alto - Tietê estão distribuídos 94 postos pluviométricos e fluviográficos conforme ilustrado na figura 3.2. É possível observar que nem todos os bairros da cidade de São Paulo tem medidas pluviométricas, portanto somente um radar meteorológico pode suprir estas informações.

O DAEE e FCTH também operam um radar meteorológico de dupla polarização, que está instalado em Ponte Nova, a 60-70 km da cidade de São Paulo. A partir das varreduras volumétricas realizadas a cada 5 minutos, o software de SELEX gera campos de precipitação com resolução espacial regular de 500 x 500 m até 2 x 2 km, que são utilizados para descrever a distribuição de chuva na região onde os pluviômetros não medem. Por exemplo, este procedimento do software da SELEX foi utilizado anteriormente para caracterizar a chuva na cidade de São Paulo (Barros \& Conde, 2017; Farias \& Filho, 2013; Pereira Filho, 1999; Pereira Filho et al., 2002; Silva et al., 2009).

A seguir são apresentadas com detalhe as técnicas de cada instrumento utilizado neste estudo. 


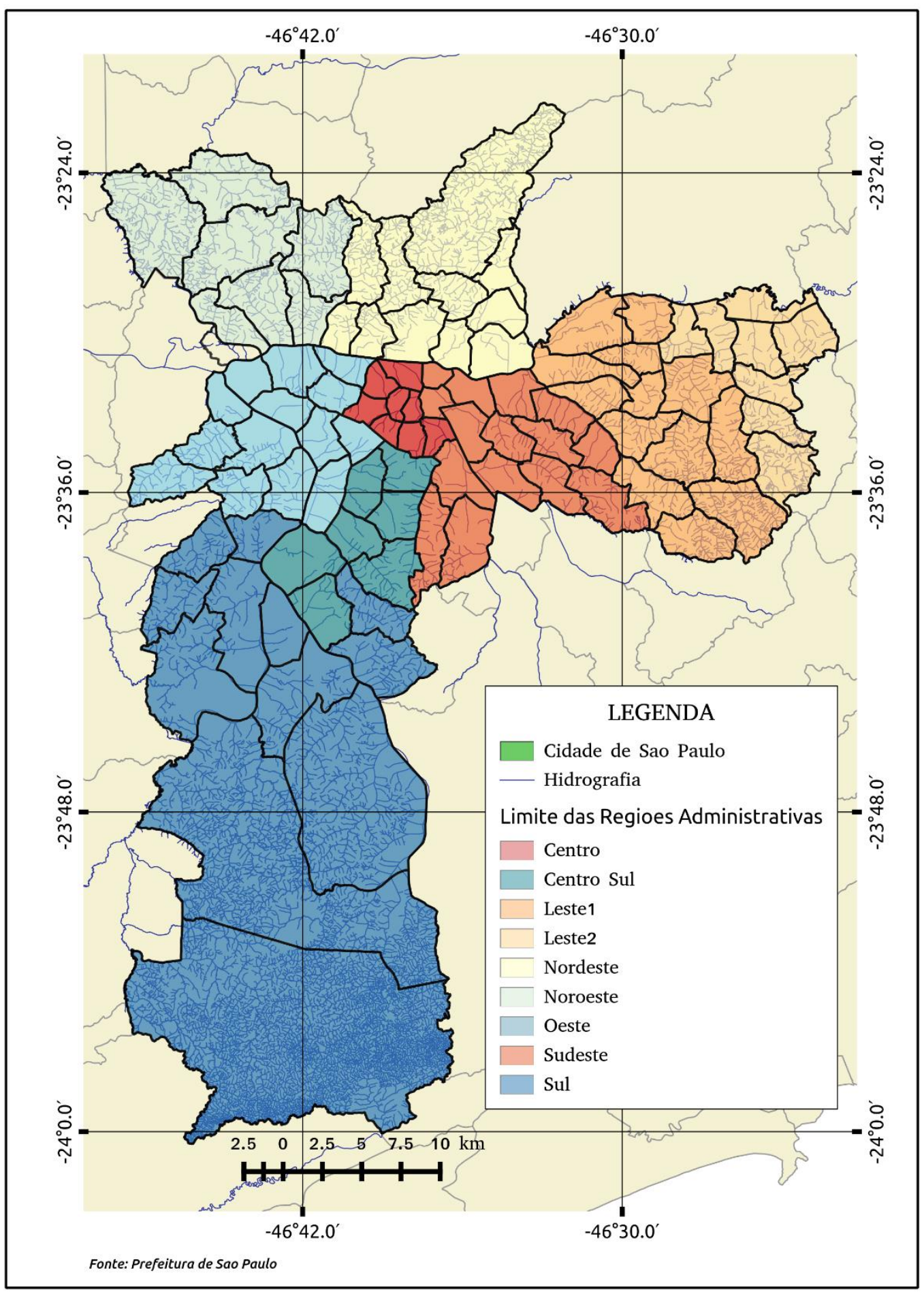

Figura 3. Mapa das regiões administrativas e bairros da cidade de São Paulo. Fonte: Andrea Viteri 


\subsubsection{Pluviômetro}

O pluviômetro é um instrumento de medição quantitativa do acumulado de precipitação $(\mathrm{mm})$ e intensidade $(\mathrm{mm} / \mathrm{h})$ direta, ou seja, ele coleta a chuva em um funil que possui uma báscula (caçamba) normalmente com volume proporcional a 0,252 $\mathrm{mm}$ de chuva ou 0,1 polegadas no caso de pluviômetros americanos. Este tipo de pluviômetro é conhecido como pluviógrafo de báscula ou "tipping bucket". A cada basculhada um pulso de duração de 0,1 segundos é criado e assim é possível contar o número de básculadas por tempo. $\mathrm{O}$ número de pulsos registrados em um intervalo de tempo é transformado em volume de chuva neste período de tempo (Cyr, 2014; Dutta et al., 2012; Ulbrich \& Lee, 1999). Assume-se que estas medidas representam a verdadeira medida da precipitação ao nível do solo (Richards \& Crozier, 2010). 


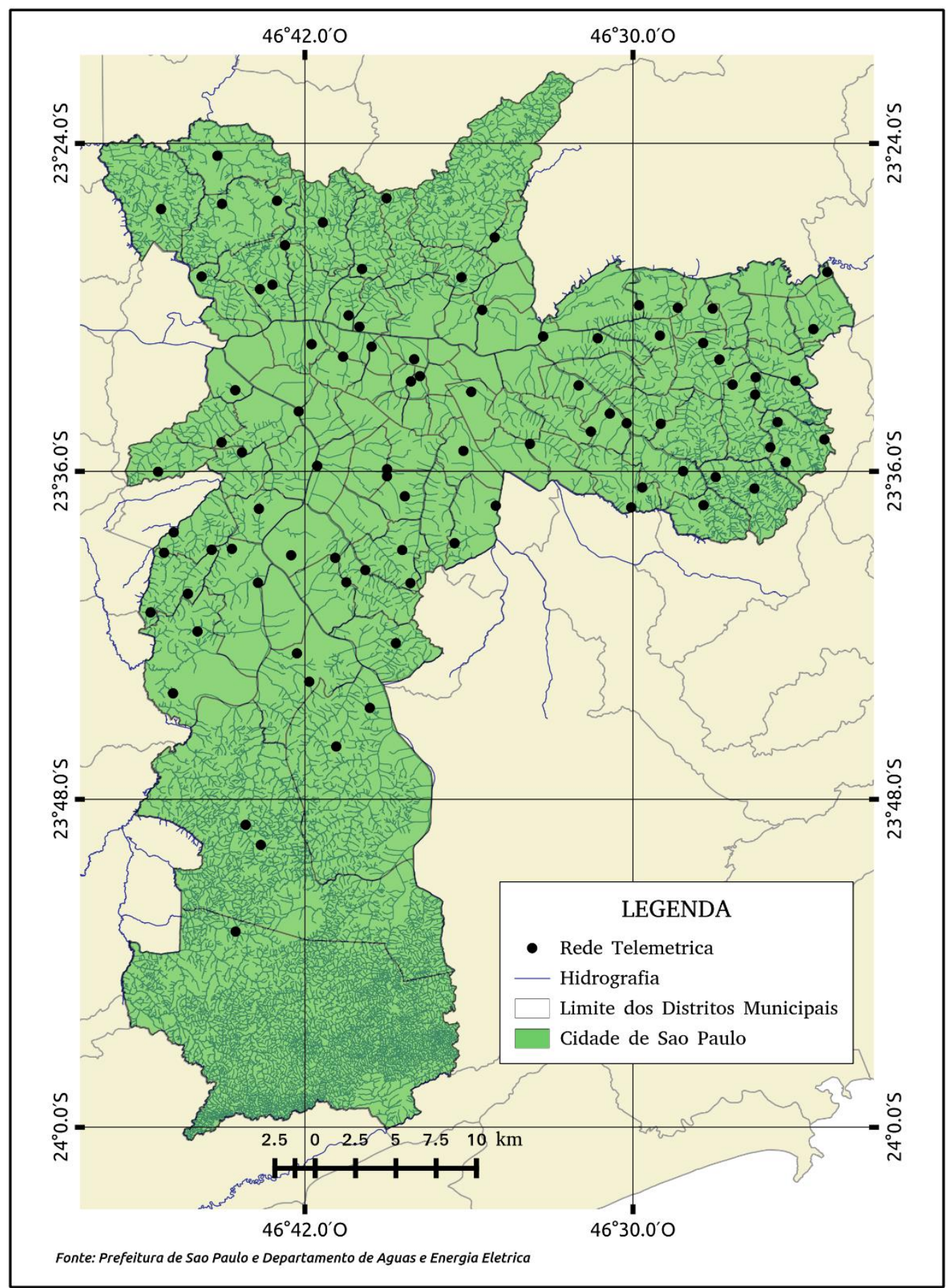

Figura 3. Mapa de localização dos postos pluviométricos da cidade de São Paulo. Fonte: Andrea Viteri 


\subsubsection{Controle de qualidade}

$\mathrm{Na}$ análise dos dados é importante minimizar e quantificar as incertezas obtidas nas observações. Steiner et al. (1999) demostraram que os dados de medição dos pluviômetros quando não passaram por um controle de qualidade afetam substancialmente a validação estatística das estimativas de precipitação por radar.

Hamada et al. (2011), propôs alguns métodos para avaliação dos dados dos pluviômetros como a detecção de outliers, dados duplicados, repetição de zeros ou valores constantes, valores maiores que não correspondem com a localização, homogeneidade ou erros por unidades de medição.

Assim como se observa na figura 3.3, neste estudo foram analisados as series de dados dos pluviômetros. Se eles não tiveram uma continuidade nas suas medições, o pluviômetro foi desconsiderado para posteriores analises estatísticos. Do mesmo modo, detectaram-se os zeros ou registros sem informação, valores negativos e os valores constantes, principalmente se eram maiores a $10 \mathrm{~mm} / \mathrm{h}$ por mais de 2 dias. Logo, se detectaram os outliers, o qual é a detecção de quanto uma medida se afasta da média ou do dado anterior. Os outliers podem ser medições errôneas ou valores extremos corregidos (González-Rouco et al., 2001). 


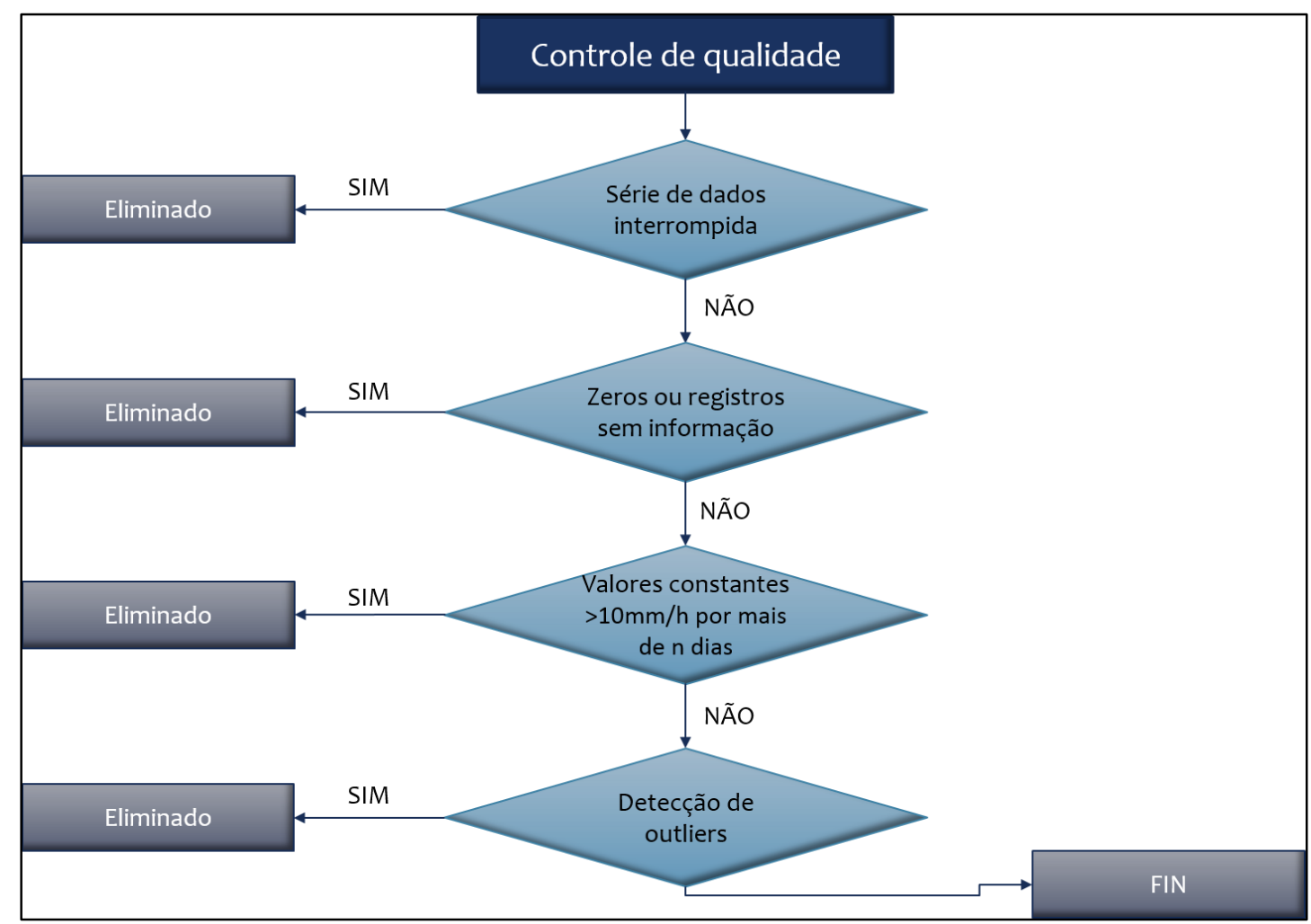

Figura 3. Esquema do controle de qualidade para os dados dos pluviômetros

\subsubsection{Radar Meteorológico}

O radar meteorológico é uma ferramenta capaz de caracterizar a chuva em áreas maiores que a dos pluviômetros que estão restritas a medidas pontuais. O radar (Radio Detection And Ranging) é essencialmente um transmissor de energia eletromagnética (EM) que a capta energia através de um receptor e visualiza em um display (Rinehart, 1997). A partir da emissão de ondas EM na faixa de frequência de microondas, tabela 3.1, é possível caracterizar alvos ao longo do caminho. Durante a propagação do feixe do radar, a potência transmitida $\left(\mathrm{P}_{\mathrm{T}}\right)$ interage com os alvos de diversas formas (absorção, espalhamento, difração e reflexão) e uma fração desta energia pode ao retornar $\left(\mathrm{P}_{\mathrm{R}}\right)$.

Caso os alvos interceptados pelo radar sejam hidrometeoros, a interação se dá através do processo da absorção e espalhamento, que re-irradia energia em todas as direções no mesmo comprimento da onda incidente uma vez que a água é um dielétrico e uma molécula 
polar. Esta energia, definida como secção transversal de retro-espalhamento $(\sigma)$ é utiliza para estimar a chuva. Na verdade se analisarmos a equação do radar, temos que a potência de retorno é proporcional à secção transversal de retro-espalhamento e pode ser expresso pela equação abaixo (Rinehart, 1997).

$$
P_{r}=\frac{P_{t} G^{2} \theta \phi c \tau \lambda^{2}}{2^{10} \cdot \ln (2) \pi^{2} r^{2}} \sum_{i=0}^{n} \sigma_{i}
$$

Onde, $\mathrm{G}$ é o ganho da antena, $\theta$ e $\varphi$ são os ângulo de abertura da antena, h a largura do feixe, $\lambda$ o comprimento de onda do radar, $r$ a distância do feixe e $\sigma$ a secção transversal de retro-espalhamento.

Para detalhar a chuva espacialmente, o radar utiliza um modulador que regula o envio de pulsos discretos através do transmissor (Yuter, 2003), assim é possível definir a resolução espacial do volume a ser amostrado (gate ou bin) (h).

Por outro lado, temos que o espalhamento da EM pelos hidrometeoros depende da polarização da onda incidente, do tamanho e da respectiva concentração de gotas e do comprimento de onda do radar. Esta dependência é extremamente importante para inferir a chuva, pois dependendo do regime de espalhamento não é possível relacionar potência de retorno com volume de chuva.

O espalhamento pode ser divido em três regimes: Rayleigh, Mie e Ótico (Figura 3.4). No regime de espalhamento Rayleigh, secção transversal de retro-espalhamento normalizada pela área da partícula aumenta com a quarta potência do parâmetro de forma ( $\alpha$ $=$ razão entre o perímetro da gota $-2 \pi \mathrm{a}-$ pelo comprimento da onda incidente $-\lambda)$. Já quando o diâmetro da partícula é maior que $\sim \lambda / 16$ temos espalhamento Mie e para valores ainda maiores temos espalhamento ótico (Montopoli \& Marzano, 2011). No regime de espalhamento Rayleigh as partículas espalham isotropicamente em todas as direções, já no regime de espalhamento Mie é direcional (Bohren \& Clothiaux, 2006). Logo, no regime de espalhamento Rayleigh é possível ter uma relação única entre potência e tamanho da partícula, o que não é o mesmo para os regimes de espalhamento Mie e ótico, pois a absorção tende a ser maior que o espalhamento. 


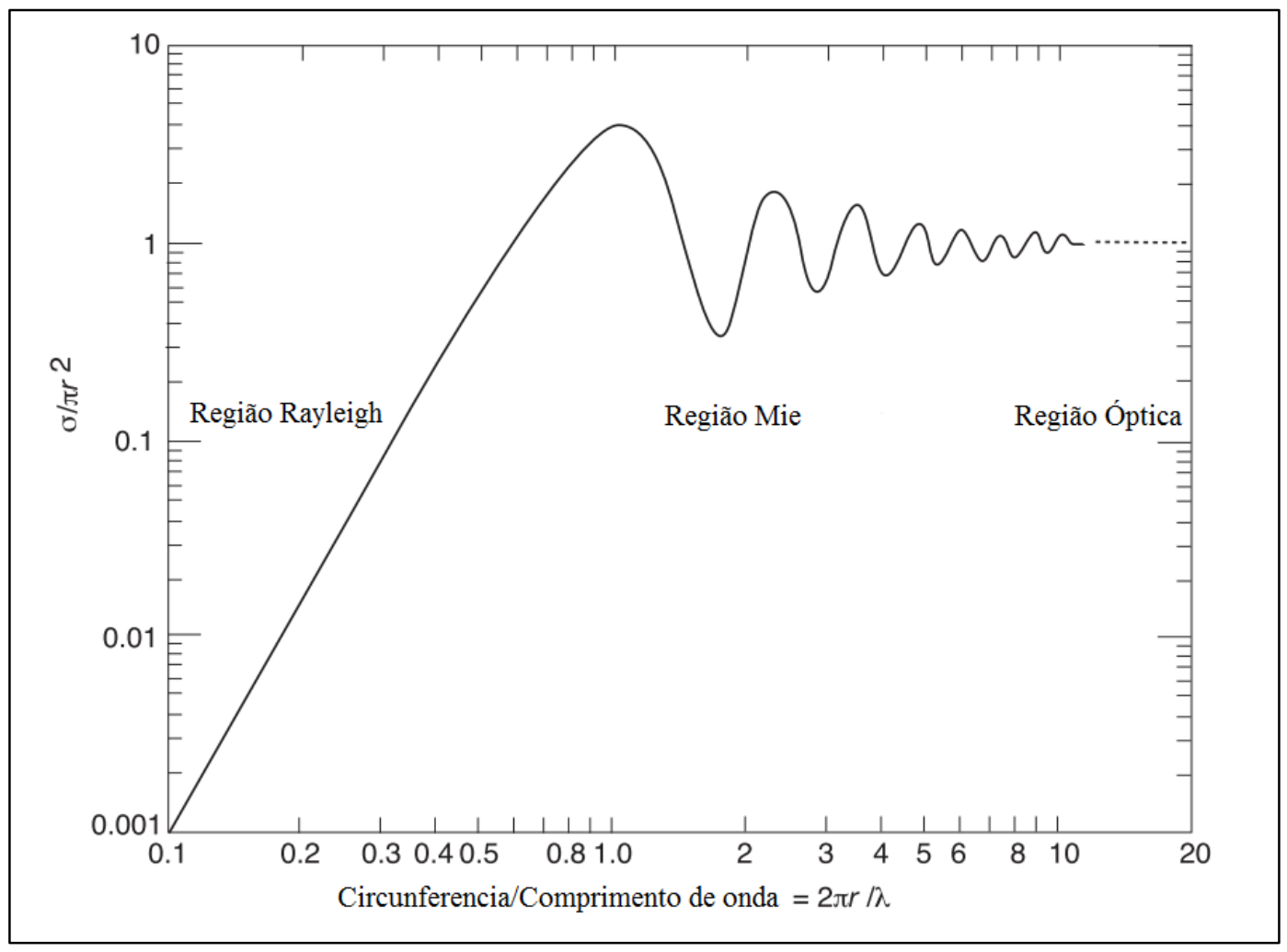

Figura 3. Relação entre o cociente do raio de uma esfera pelo comprimento de onda do pulso do radar com a secção transversal de retro espalhamento normalizada pela área de um curculo. Adaptado de Yuter, 2003

Analisando a secção transversal de retro-espalhamento do radar $(\sigma)$ é possível entender com ela varia em função do comprimento de onda, do tamanho da partícula e estado (líquido ou sólido). De acordo com Rinehart (1997), a secção transversal de um espalhador isotrópico que retornaria a mesma potência para o radar pode ser expressa por:

$$
\sigma=\frac{\lambda^{2}}{4 \pi}\left|\sum_{n=1}^{\infty}(-1)^{n}(2 n+1)\left(a_{n}+b_{n}\right)\right|^{2}
$$

Onde $a_{n}$ e $b_{n}$ são os coeficientes Mie magnético e elétrico respectivamente, que dependem do diâmetro e do índice de refração complexo (m) da partícula. Quando o raio da gota é muito menor que o comprimento de onda $(\lambda)$ (onde $\alpha<0,22)$ a aproximação Rayleigh e a secção de retroespalhamento pode ser descrita como: 


$$
\sigma=\frac{\lambda^{2}}{\pi} \alpha^{6}\left|\frac{m^{2}-1}{m^{2}+2}\right|^{2}=\frac{\pi^{5}}{\lambda^{4}}|K|^{2} D^{6}
$$

Onde $D$ é o diâmetro da partícula e $K$ o índice de refração da partícula. Quando as partículas são gotas de água líquida $|K|^{2}=0,93$, já partículas de gelo $|K|^{2}=0,197$ (Rinehart, 1997). Logo, quanto maior for a frequência (menor é $\lambda$ ), menor é a partícula para atingir o regime de espalhamento Mie (Tabela 3.1). Portanto, para monitorar a chuva utilizase comprimentos de onda maiores para evitar o efeito da atenuação da chuva, ou seja, radares banda S.

\begin{tabular}{|c|c|c|}
\hline Banda & Frequência & Comprimento de onda \\
\hline $\mathrm{S}$ & $2-4 \mathrm{GHz}$ & $8-15 \mathrm{~cm}$ \\
\hline $\mathrm{C}$ & $4-8 \mathrm{GHz}$ & $4-8 \mathrm{~cm}$ \\
\hline $\mathrm{X}$ & $8-12 \mathrm{GHz}$ & $2,5-4 \mathrm{~cm}$ \\
\hline $\mathrm{K}$ & $18-27 \mathrm{GHz}$ & $1,2-1,7 \mathrm{~cm}$ \\
\hline $\mathrm{W}$ & $40-300 \mathrm{GHz}$ & $1-7,5 \mathrm{~mm}$ \\
\hline
\end{tabular}

Tabela 3. Frequência e comprimento de onda dos radares meteorológicos

Logo, pode-se relacionar a secção transversal de retro-espalhamento com a refletividade do radar para ambos os regimes de espalhamento, ou seja:

Espalhamento Rayleigh: Fator Refletividade do Radar - Z

$$
Z \approx \sum_{i=0}^{n} D_{i}^{6}
$$

Espalhamento Mie: Refletividade do Radar - $\eta$

$$
\eta \approx \sum_{i=0}^{n} \sigma_{i}
$$

Portanto, para um regime de espalhamento Rayleigh a energia espalhada é proporcional à partícula a sexta-potência, já para o regime Mie é proporcional à secção de retro-espalhamento. 
Portanto para monitorar a chuva, os radares meteorológicos são configurados para operar no regime de espalhamento Rayleigh. Basicamente, a refletividade do radar Z é proporcional ao diâmetro de cada tipo de gota a sexta potência presente no volume amostrado, a relação entre $\mathrm{Z}$ e a distribuição de tamanho de gotas (DSD) pode ser expressa como:

$$
Z\left[m m^{6} m^{-3}\right]=\int_{0}^{\infty} N(D) D^{6} d D
$$

Onde, D é o diâmetro da gota de chuva e N(D) número de gotas de diâmetro D. Já a taxa de precipitação (R) é expressa como:

$$
R\left[m m h^{-1}\right]=\frac{\pi}{6} \int_{0}^{\infty} N(D) D^{3}\left(V_{T}(D)-W\right) d D
$$

Onde $\mathrm{W}$ é velocidade vertical e $\mathrm{V}_{\mathrm{T}}(\mathrm{D})$ é a velocidade terminal da gota de diâmetro D.

Assim, a partir das equações (3.6) e (3.7) é possível derivar uma relação Z-R que viabilize a estimativa de precipitação a partir do radar meteorológico.

$$
Z=A R^{B}
$$

Onde os coeficientes A e B vão variar por fatores como o tipo de precipitação e localidade. Na verdade, se $N(D)$ é conhecida, é possível determinar os coeficientes A e B. Por exemplo, Marshall e Palmer (1948) encontraram a partir de medidas de tamanho de gotas em Otawa, Canadá, que a concentração de gotas podia ser expressa por uma distribuição exponencial $N(D)=N_{0} e^{-\lambda D}\left(\right.$ Onde $\mathrm{N}_{0}$ é $\left.0,08 \mathrm{~cm}^{-4}, \mathrm{e} \lambda\left[\mathrm{mm}^{-1}\right]=4,1 \mathrm{R}[\mathrm{mm} / \mathrm{h}]^{-0,21}\right)$. Utilizando estas informações, temos que A é igual a 200 e B igual a 1,6.

Entretanto, para diminuir as incertezas nas estimativas de precipitação utilizando somente Z, Seliga e Bringi (2018) propuseram a utilização de medidas polarimétricas para estimar a chuva. Basicamente, a polarização define o plano da secção transversal de espalhamento, logo se as polarizações verticais (V) e horizontais (H) são observadas é possível caracterizar a forma da gota de chuva (Zrnic \& Ryzhkov, 1999). Além disso, os radares polarimétricos medem a diferença de fase das polarizações verticais e horizontais 
$\left(\phi_{D P}\right)$ que representa o atraso da onda em uma polarização, ou seja, a quantidade de água ao longo do feixe (Krajewski \& Smith, 2002). Já o gradiente de $\phi_{D P}$, fase diferencial especifica $\left(K_{D P}\right)$ é usado para quantificar o conteúdo de água liquida (Yuter, 2003) e por isso é usado para estimar a chuva.

\subsubsection{Radar meteorológico banda $\mathrm{S}$ de dupla polarização}

O radar Doppler banda S da SELEX, modelo METEOR 600S, está instalado na barragem de Ponte Nova na cabeceira do rio Tietê, município de Salesópolis em São Paulo (Figura 3.5). Este radar que funciona desde o 2014 e substituiu ao radar da McGill, é operado pelo DAEE e FCTH e tem um alcance de $240 \mathrm{~km}$ cobrindo totalmente a cidade de São Paulo. Além das características técnicas resumidas na tabela 3.2, o radar tem uma resolução de 250m realiza varreduras volumétricas a cada 5 minutos.

\begin{tabular}{|l|l|}
\hline Características técnicas do Radar meteorológico banda S \\
\hline Latitude & 233603 ' S \\
\hline Longitude & $455822^{\prime \prime} \mathrm{W}$ \\
\hline Altitude & $928 \mathrm{~m}$ \\
\hline Diâmetro da Antena & $11.2 \mathrm{~m}$ \\
\hline Potência máxima & $850 \mathrm{~kW}$ \\
\hline Comprimento de onda & $10.6 \mathrm{~cm}$ \\
\hline Frequência & $2.83 \mathrm{GHz}$ \\
\hline Número de elevações & 8 \\
\hline Largura do feixe & 0.97 \\
\hline Polarização & Dupla (H e V) \\
\hline Largura do pulso & $250 \mathrm{~m}$ \\
\hline Número de bins & 960 \\
\hline Intervalo de tempo entre varreduras & 5 minutos \\
\hline Nível de ruído & $-31.5 \mathrm{dBZ}$ \\
\hline
\end{tabular}

Tabela 3. Características técnicas do radar banda S de dupla polarização da SELEX, modelo METEOR 600S. Fonte SAISP 


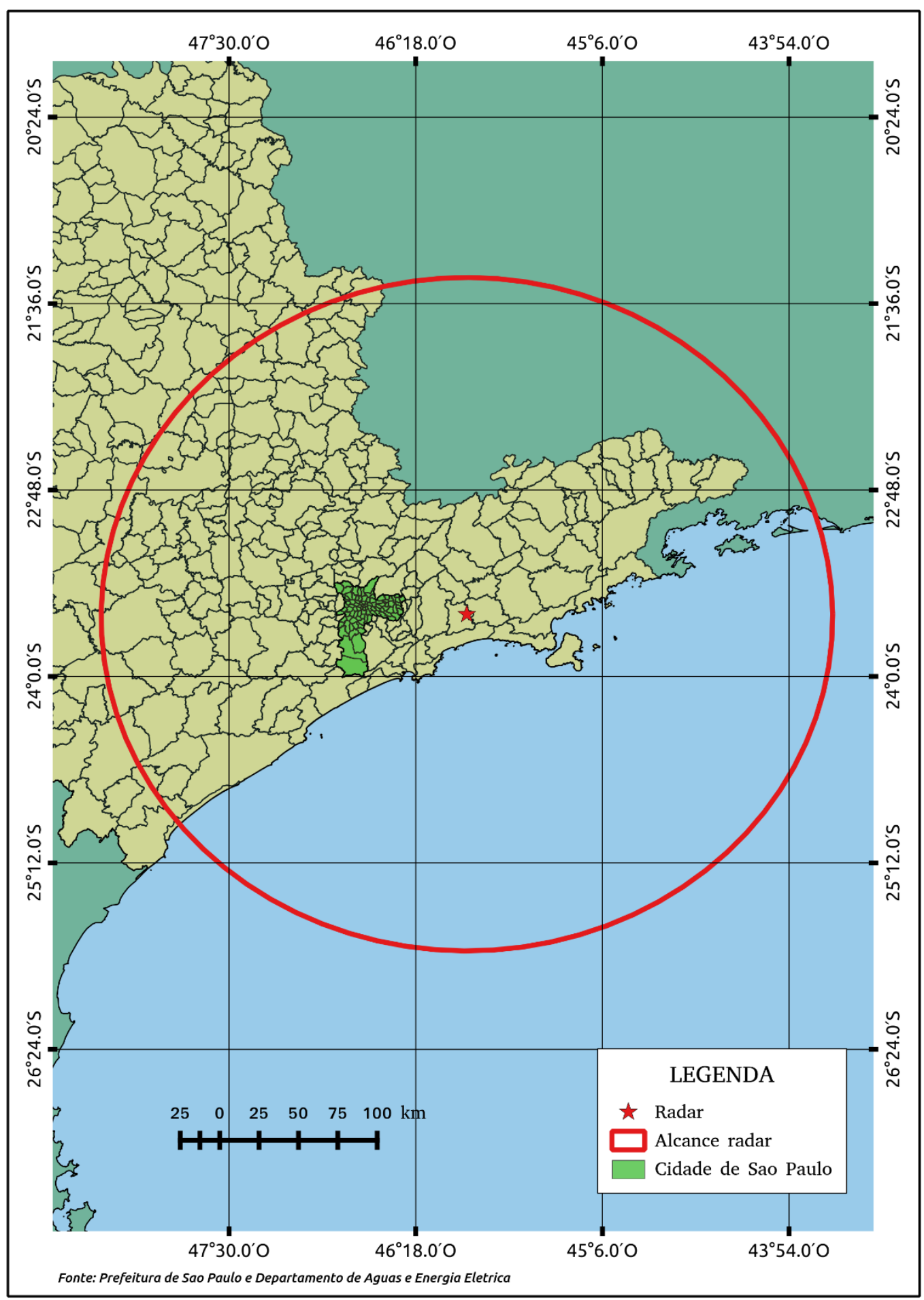

Figura 3. Mapa de localização e alcance do radar Banda S de Dupla Polarização da SELEX. Fonte: Andrea Viteri 


\subsubsection{Algoritmo de estimativa de Precipitação do SPOL}

O radar meteorológico SPOL utiliza o algoritmo de estimativa de precipitação denominado de DPSRI (Dual Polarization Surface Rainfall Intensity) (SELEX System Integration, 2010).

O algoritmo DPSRI utiliza o fator de refletividade de radar $(\mathrm{Z})$, a refletividade diferencial $\left(Z_{D R}\right)$ e a fase diferencial especifica $\left(K_{D P}\right)$. Cada medida é geo-referenciada em modo Pseudo-SRI, ou seja, sobre uma camada que segue a topografia a uma altura constante sobre o solo (SELEX System Integration, 2010).

Para calcular a taxa de precipitação (R) o algoritmo DPSRI calcula inicialmente a $R(Z)$ a partir da relação Z-R definida pela equação (3.9) (Ryzhkov, Giangrande, \& Schuur, 2005):

$$
R=\left[\frac{Z}{300}\right]^{1 / 1,4}
$$

Posteriormente para cada intervalo de $\mathrm{R}(\mathrm{Z})$, calcula-se a taxa de precipitação em função de $Z_{D R}$ e $K_{D P}$, conforme segue:

$$
\begin{array}{lr}
R=\frac{R(Z)}{0.4+5.0 \mid Z_{\left.d r^{-1}\right|^{1.3}}} ; & R(Z)<6 \mathrm{~mm} / \mathrm{h} \\
R=\frac{R\left(K_{d p}\right)}{0.4+3.5 \mid Z_{\left.d r^{-1}\right|^{1.7}}} ; & 6<R(Z)<50 \mathrm{~mm} / \mathrm{h} \\
R=R\left(K_{d p}\right) ; & R(Z)>50 \mathrm{~mm} / \mathrm{h}
\end{array}
$$

Onde, $\mathrm{R}\left(\mathrm{K}_{\mathrm{dp}}\right)$ é dado por:

$$
R\left(K_{d p}\right)=44.0\left|K_{d p}\right|^{0.822} ; \quad K_{d p}>0
$$




\subsubsection{Estatísticas de validação das estimativas de precipitação}

Uma vez estimada a precipitação pelo radar e com o objetivo de quantificar o erro entre as estimativas do radar e as medidas dos pluviômetros, foram adotadas as seguintes estatísticas de verificação: o erro médio (bias), desvio padrão, coeficiente de correlação e o erro médio quadrático (RMSE). Além de serem construídas as tabelas de contingencia para o analise das estatísticas categóricas como a probabilidade de detecção (POD), a taxa de falso alarme (FAR), a taxa de sucesso (TS), a taxa de sucesso critico (TSC) e o viés (BIAS).

Neste caso, o analise da tabela de contingencia foi adotado de Oliveira (2017) para as três escalas temporais (10 min, $1 \mathrm{~h}$ e 1 dia), como se mostra na tabela 3.3. Onde consideraram-se as medições de precipitação para o radar $\left(R_{\text {radar }}\right)$ e o pluviômetro $\left(R_{\text {pluviômetro }}\right)$ adotando um limite $\left(\mathrm{R}_{\mathrm{min}}\right)$ de $0.2 \mathrm{~mm} / \mathrm{h}$. As equações das métricas estatísticas estão listadas na tabela 3.4 junto com o valor ideal a obter em cada uma delas.

\begin{tabular}{|l|c|c|}
\cline { 2 - 3 } \multicolumn{1}{c|}{} & $\mathbf{R}_{\text {radar }}>\mathbf{0}$ & $\mathbf{R}_{\text {radar }} \leq \mathbf{0}$ \\
\hline $\mathbf{R}_{\text {pluviômetro }} \geq \mathbf{R}_{\min }$ & $\mathrm{H}$ & $\mathrm{F}$ \\
\hline $\mathbf{R}_{\text {pluviômetro }}<\mathbf{R}_{\min }$ & $\mathrm{M}$ & $\mathrm{Z}$ \\
\hline
\end{tabular}

Tabela 3. Tabela de contingencia para o radar $\left(R_{\text {radar }}\right)$ e o pluviômetro $\left(R_{\text {pluviômetro }}\right)$. Fonte: Adaptado de Oliveira (2017)

\begin{tabular}{|l|c|c|}
\hline \multicolumn{1}{|c|}{ Métricas Estatísticas } & Equação & Valor ideal \\
\hline Estatísticas de verificação Continuas & $r=\frac{\sum_{i=1}^{N}\left(A_{i}-\bar{A}\right)\left(B_{i}-\bar{B}\right)}{\sqrt{\sum_{i=1}^{N}\left(A_{i}-\bar{A}\right)^{2} \sum_{i=1}^{N}\left(B_{i}-\bar{B}\right)^{2}}}$ & 1 \\
\hline Coeficiente de correlação (r) & bias $=\frac{1}{N} \sum_{i=1}^{N}\left(A_{i}-B_{i}\right)$ & 0 \\
\hline Erro médio (BIAS) & $R M S E=\frac{1}{N-1} \sum_{i=1}^{N}\left(A_{i}-B_{i}\right)^{2}$ & 0 \\
\hline Erro médio quadrático (RMSE) & $s=\sqrt{\frac{1}{N-1} \sum_{i=1}^{N}\left(A_{i}-B_{i}\right)^{2}}$ & 0 \\
\hline Desvio padrão & $\sqrt{ }$ & 1 \\
\hline Estatísticas de verificação Categórica & $P O D=\frac{H}{H+M}$ & 0 \\
\hline Probabilidade de Detecção (POD) & $F A R=\frac{F}{H+F}$ & 1 \\
\hline Taxa de Falso Alarme (FAR) & & 0 \\
\hline
\end{tabular}




\begin{tabular}{|l|c|c|}
\hline Taxa de Sucesso (TS) & $T S=1-F A R$ & 1 \\
\hline Taxa de Sucesso Critico (TSC) & $T S C=\frac{H}{H+F+M}$ & 1 \\
\hline Viés & $V i e ́ s=\frac{P O D}{S R}$ & 1 \\
\hline
\end{tabular}

Tabela 34. Lista das métricas estatísticas utilizadas na validação das estimativas de precipitação. Fonte: Adaptado de Oliveira (2017)

\subsubsection{Gestão de alagamentos}

Segundo o (CENAD, 2014), os alagamentos são fenômenos hidrológicos, ocasionados ao exceder a capacidade dos sistemas de escoamento superficiais e de drenagem urbana formando acúmulos de agua em áreas impermeabilizadas ou rebaixadas. Frente ao processo de expansão urbana, a ocorrência de alagamento nas cidades torna-se recorrente pela falta de áreas favoráveis à infiltração e a canalização de escoamento.

Nos meses de verão, a cidade de São Paulo é atingida por frequentes alagamentos cujas consequências causam diversas perdidas materiais na cidade e aumenta a vulnerabilidade nos bairros que não tem uma boa infraestrutura. Por exemplo, só no ano 2015, foram registrados mais de 300 pontos de alagamento na cidade (Figura 3.6) (CGE, 2016).

A cidade de São Paulo possui iniciativas de mapeamento e monitoramento constante sobre pontos de alagados por meio de órgãos públicos e projetos colaborativos (Hirata, Abrantes, Camargo, \& Quintanilha, 2013). O centro de Gerenciamento de Emergências da cidade de São Paulo disponibiliza diariamente as condições meteorológicas e os pontos de alagamento na cidade, em parceria com a Coordenadoria Municipal de Defesa Civil (COMDEC) e a Companhia de Engenharia de Tráfego (CET), órgão municipal responsável pelo monitoramento, avaliação e controle dos índices de congestionamento diário no trânsito.

O CGE classifica as informações dos pontos de alagamento sob três categorias em relação as condições de trafego: Transitável, Intransitável e Inativo. 


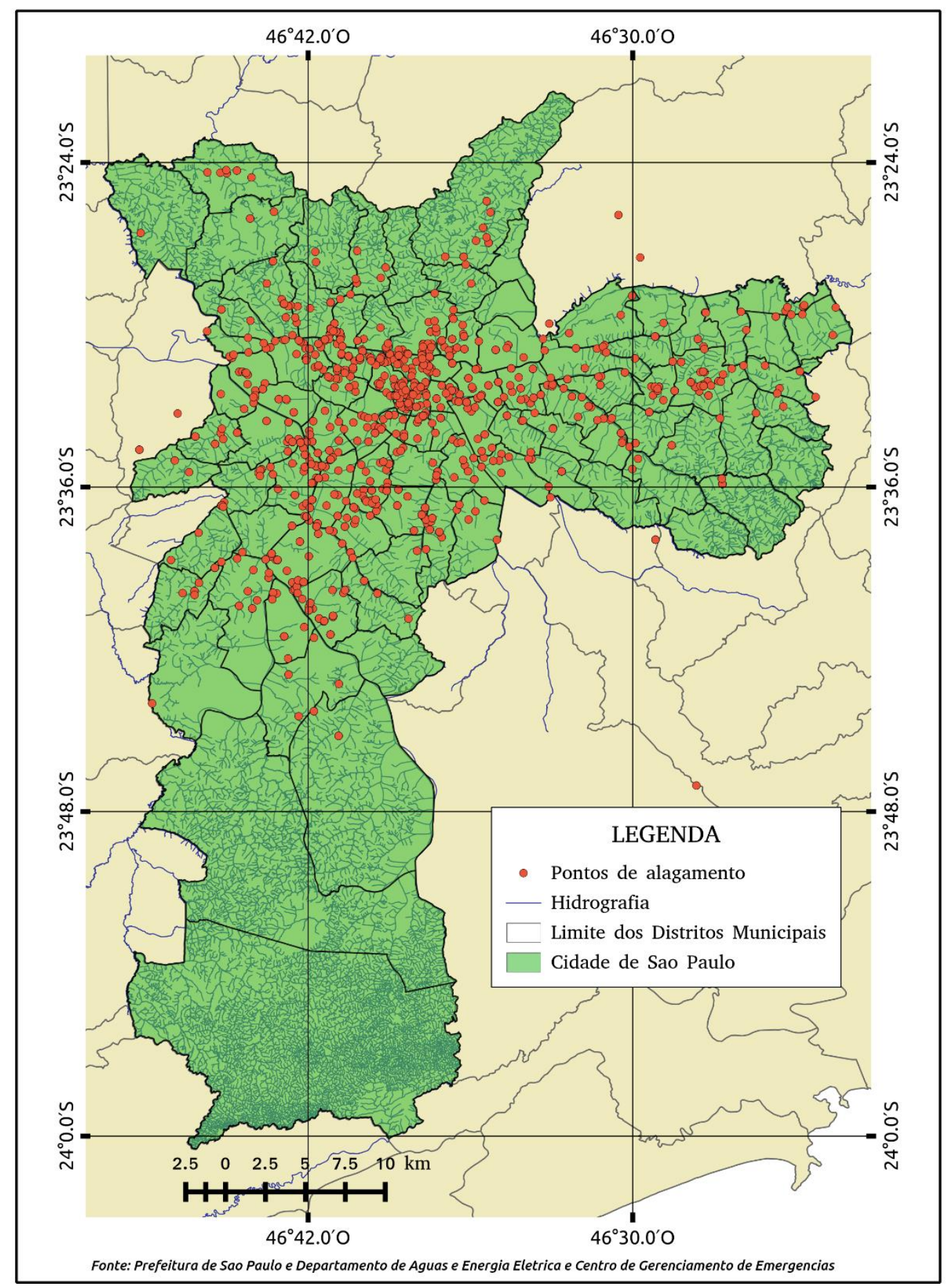

Figura 3. Mapa de localização dos pontos de alagamento registrados em 2015 pelo CGE. Fonte: Andrea Viteri 


\section{Tratamento de dados}

Uma vez que será utilizada a estimativa de precipitação do radar para saber a distribuição de chuva nos bairros da cidade de São Paulo, será necessário analisar períodos com e sem alagamentos ao longo do ano, assim será possível avaliar os diferentes regimes de chuva na cidade. Os dados do radar serão integrados a cada 10 minutos e por dia a fim de caracterizar os diversos padrões da chuva. Basicamente, os padrões de chuva durante eventos de alagamentos ou não na cidade serão analisados a partir:

a) Função Densidade de Probabilidade (PDF)

b) Modelo de Regressão Logística Binaria

\subsection{Função Densidade de Probabilidade - PDF}

Uma análise da precipitação diária se faz relevante não só na área de meteorologia, mas também em hidrologia e agricultura por exemplo. A PDF com um bom ajuste, viabiliza esta análise para três principais pesquisas: (1) modelos de precipitação estocástica, (2) análise da frequência da precipitação e (3) tendência da precipitação em relação a mudança climática global (Hanson \& Vogel, 2008).

Este tipo de análise pode ser conduzido para diferentes durações de precipitação, e neste estudo está restrita a acumulados de 10 min e $24 \mathrm{~h}$.

Consequentemente, a PDF permite o cálculo da probabilidade de um evento e sua distribuição sobre o intervalo de valores que uma variável aleatória pode tomar. Assim, para uma variável aleatória $\mathrm{x}$, a distribuição da probabilidade está definida pela função f(x) (Parzen, 1962).

A distribuição normal é uma função de probabilidade contínua dada pela equação 4.1, que relaciona a média da distribuição $(\mu)$, a variância $(\sigma)$ e a variável independente $(x)$ a ser avaliada: 


$$
f(x, \mu, \sigma)=\frac{1}{\sqrt{2 \pi}} e^{-\frac{(x-\mu)^{2}}{2 \sigma^{2}}}
$$

Assim, a função de densidade de probabilidade é igual a integral da função desde $-\infty$ até $\mathrm{x}$ (Parzen, 1962):

$$
F(x)=\int_{-\infty}^{x} f\left(x^{\prime}\right) d x
$$

E que satisfaz as seguintes condições:
a) $f(x) \geq 0$,
para $\mathrm{a}<\mathrm{x}<\mathrm{b}$
b) $\int_{a}^{b} f(x) d x=1$

Onde a e b podem ser $-\infty$ e $\infty$ respectivamente. Assim esta função determina a distribuição de probabilidades das observações.

\subsection{Modelo de regressão logística binaria}

A regressão logística analisa a associação entre duas variáveis qualitativas, uma dependente e outra independente (exploratória). As variáveis podem ser continuas ou discretas, ou a combinação das duas e não necessariamente tem distribuições normais (Rasyid, Bhandary, \& Yatabe, 2016). Denomina-se binária ao ter como resposta os valores de 0 e 1 , ou seja, sendo $0=$ não alagamento e 1 = alagamento. Logo, a probabilidade $p$ de 1 é o parâmetro de interesse (Johnson \& Wichern, 2007). O que representa a proporção na população que foi identificada como 1.

Uma vantagem é que a regressão logística pode lidar com relações não-lineares entre as duas variáveis (dependente e independente), pois aplica a transformação logarítmica não linear. Porém, requer que as variáveis independentes estejam relacionadas linearmente às probabilidades de um evento. 
Por fim, a regressão logística exige grande quantidade de amostras porque as estimativas da máxima verossimilhança não são como os mínimos quadrados, estimulando os parâmetros desconhecidos em um modelo de regressão linear.

\subsubsection{Regressão Logística Simples}

Considera-se primeiro que a probabilidade de "sucesso" $\mathrm{p}(\mathrm{x})$, sendo x uma variável explicativa qualquer, é definida como:

$$
\log \left\{\frac{p(x)}{1-p(x)}\right\}=\alpha+\beta x
$$

Onde, $\alpha$ e $\beta$ sao parâmetros desconhecidos (Paula, 2013). Logo, este modelo poderia ser aplicado para analisar a ocorrência ou não de um evento. Seriam então amostrados independentemente, $\mathrm{n}_{1}$ dias com presença do evento $(\mathrm{x}=1)$ e $\mathrm{n}_{2}$ dias sem ter sucedido nada $(x=0)$ e $p(x)$ seria a probabilidade de que o evento suceda.

Desta forma, a possibilidade de que aconteça o evento num dia é dada por:

$$
\frac{p(1)}{1-p(1)}=e^{\alpha+\beta}
$$

Caso contrário seria:

$$
\frac{p(0)}{1-p(0)}=e^{\alpha}
$$

Logo, a razão de chances estaria dada por:

$$
\psi=\frac{p(1)\{1-p(0)\}}{p(0)\{1-p(1)\}}=e^{\beta}
$$

Ou seja, depende apenas do parâmetro $\beta$. O que permite interpretar diretamente os coeficientes relacionando as duas variáveis como medidas de associação (Cook et al., 2000). 


\subsubsection{Regressão Logística Múltipla}

Considerando um modelo com várias variáveis de predição:

$$
\log \left\{\frac{p(x)}{1-p(x)}\right\}=\beta_{0}+\beta_{1} x_{1}+\beta_{2} x_{2}+\ldots+\beta_{n} x_{n}
$$

Em que $x=\left(1, x_{1}, \ldots, x_{n}\right)^{T}$ contém as variáveis explicativas. O processo iterativo para obter $\beta$ pode ser expresso como um processo iterativo de mínimos quadrados reponderados (Paula, 2013), e a razão de chances estaria dada por:

$$
\psi=\frac{p\left(Y=1 \mid x=1, x_{1}, \ldots, x_{n}\right) / P\left(Y=0 \mid x=1, x_{1}, \ldots, x_{n}\right)}{p\left(Y=1 \mid x=0, x_{1}, \ldots, x_{n}\right) / P\left(Y=0 \mid x=0, x_{1}, \ldots, x_{n}\right)}=e^{\beta}
$$

A razão pode ser usada para determinar o grau de influência de um resultado e comparar a magnitude de vários fatores dominantes para um resultado em particular.

\subsubsection{Validação do Modelo de Regressão Logística}

A avaliação do modelo dependerá de fatores como:

\section{Critérios de Informação de Akaike - AIC}

O método de Akaike é um procedimento simples para selecionar variáveis explicativas num modelo logístico (Akaike, 1974; Paula, 2013). Supondo que E(M) é a função de verossimilhança no modelo avaliado em $\mathrm{M}$, que é o estimador de máxima verossimilhança e $p(M)$ é o número de parâmetros estimados do modelo, então o AIC é a seguinte (Chaurasia \& Harel, 2012; Paula, 2013):

$$
A I C(M)=-2 \log E(M)+2 p(M)
$$

Sob este critério de seleção, um bom modelo é aquele que tem o valor mínimo AIC entre todos os outros modelos. AIC tem algumas vantagens como estimar a máxima verossimilhança de vários modelos comparados simultaneamente e permite a inferência da média do modelo (Chaurasia \& Harel, 2012). 


\section{Desvio nulo e desvio residual}

O desvio nulo indica a resposta do ajuste prevista pelo modelo logístico com nada além de uma interceptação. Tal modelo prevê um valor constante independentemente do valor da variável exploratória. Assim, ao ser adicionada uma variável explicativa, pode-se determinar se essa variável está ou não aumentando a capacidade preditiva do modelo (Cook et al., 2000). Por outro lado, o desvio residual indica a resposta prevista por um modelo na adição de uma variável explicativa ao modelo logístico. A mudança no desvio na regressão logística, pode ser comparada a uma distribuição de $\mathrm{X}^{2}$ e determinar a significância estatística (Cook et al., 2000).

\section{Matriz de classificação}

A matriz de classificação, ou conhecida também como a tabela de contingência, contém informações sobre classificações reais e previstas realizadas por um sistema de classificação, que ajuda a encontrar a precisão do modelo e evitar a sobreposição. Desta maneira, para um classificador e um instante tem quatro possibilidades. Se o instante é positivo e seu classificador é também, considera-se como "verdadeiro positivo" mas se tem um classificador negativo será um “falso negativo". Por outro lado, se o instante é negativo e seu classificador negativo considera-se como "verdadeiro negativo", ao contrário se tem um classificador positivo será "falso positivo" (Fawcett, 2006). Logo, forma-se a matriz em função dos classificadores e as instâncias (Figura 4.1).

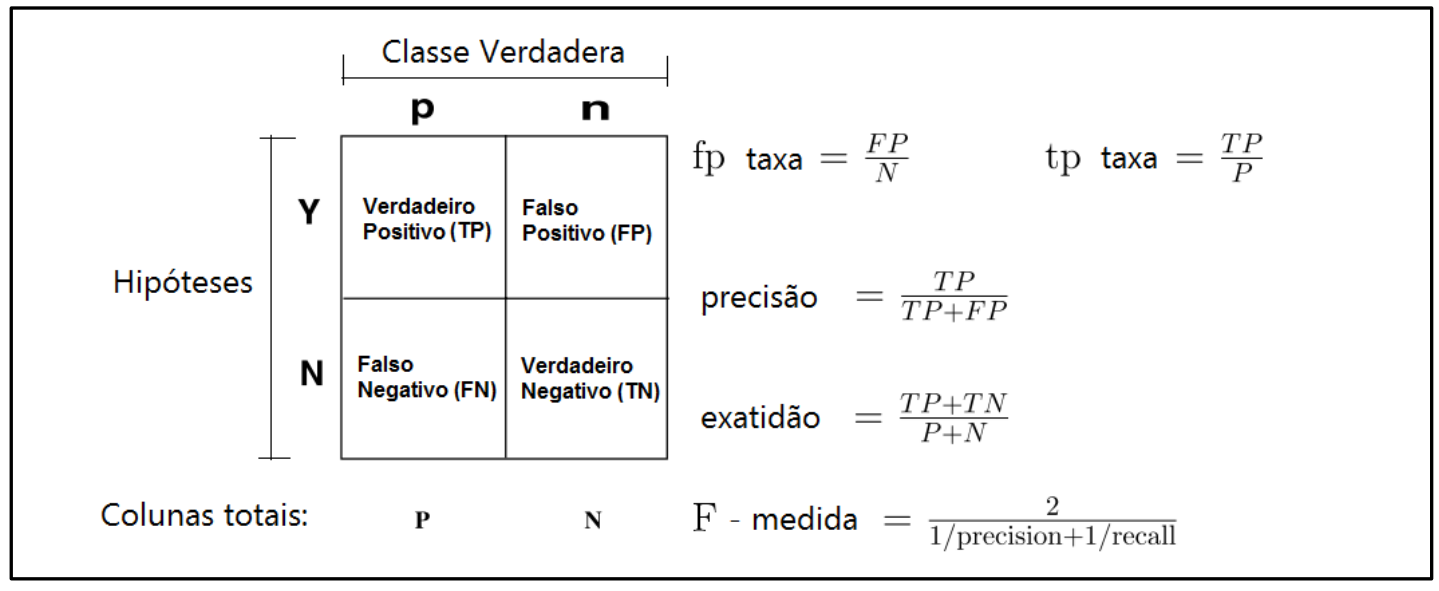

Figura 4.1. Matriz de confusão e medidas usadas comumente para seu cálculo. Adaptado de Fawcett (2006) 
Na figura 4.1, mostra-se também as equações das métricas mais usuais que podem ser calculadas. Os números ao longo da diagonal principal representam as decisões corretas feitas, e os números dessa diagonal representam os erros entre as várias classes.

Uma das vantagens da tabela de contingência é que permite analisar a performance da estimativa sob diferentes aspectos e o propósito de uso dessa informação (Paz \& Collischonn, 2011). Por exemplo, considerando a previsão de ocorrência ou não de alagamentos. Neste estudo foram utilizados os índices denominados como probabilidade de detecção (POD) e taxa de alarme falso (FAR). O POD define-se como o percentual de acertos em estimar a ocorrência do evento, varia entre 0 e 1 e quanto maior o valor é melhor a performance e o índice FAR define-se como o percentual em que o evento não ocorreu, varia entre 0 e 1 e quanto menor o valor é melhor a performance (Paz \& Collischonn, 2011).

\section{Curvas de Características de Operação do Receptor - ROC}

O ROC descreve o desempenho do modelo avaliando a probabilidade prevista para compreender questões de precisão, seleção de critério e interpretação (Rasyid et al., 2016), além de analisar o intercâmbio entre a taxa positiva verdadeira ou TP (sensibilidade) e a taxa do falso positivo ou FP (especificidade). ROC resume o poder preditivo para todos os valores possíveis de $\mathrm{p}>0.5$.

Em um gráfico ROC os eixos estão conformados da seguinte forma, o TP no eixo Y e o FP no eixo X. A linha diagonal $y=x$ representa a estratégia de prever uma classe aleatoriamente (Fawcett, 2006). Assim, um classificador aleatório produzirá um ponto ROC que "desliza" para frente e para trás na diagonal com base na frequência com a qual prevê a classe positiva.

A área sob curva (AUC), referida como índice de precisão ou índice de concordância, é uma medida métrica de desempenho para a curva ROC. Enquanto maior a área sob curva, melhor a potência de previsão do modelo. O ROC de um modelo preditivo perfeito tem TP igual a 1 e FP é igual a 0 . Assim, a área sob a curva ROC é uma maneira conveniente de expressar o grau de discriminação (Liechti, Panziera, Germann, \& Zappa, 2013). 


\section{Caracterização da chuva observada em São Paulo pelo Radar}

Geralmente os alagamentos nas cidades são causados pela falta de um sistema de drenagem eficiente e excesso de chuva acumulada durante um determinado tempo que impede o fluxo de escoamento. Além disso, os alagamentos também podem depender de muitas outras variáveis, como: precipitação prévia (isto é, condições antecedentes), tamanho da bacia, declividade da região, tipo de solo, uso do solo (ou seja, área impermeável) e vegetação (Ahnert, 2011; Bung, Oertel, Schlenkhoff, \& Schlurmann, 2011; Šercl, 2011).

De forma geral, podem dizer que três fatores são os que contribuem na formação e na magnitude dos alagamentos: a) precipitação - volume, intensidade, e a distribuição espacial e temporal; b) propriedades morfológicas - relevo e a cobertura do solo; e c) condições hidrológicas - saturação do solo. Por último, temos que a magnitude do alagamento é determinada pela interação entre estes três fatores (Belachsen, Marra, Peleg, \& Morin, 2017).

O solo pode ser avaliado dependendo de sua umidade, permeabilidade e perfil do solo. A umidade, por exemplo, é um dos fatores importantes no caso dos alagamentos, devido à saturação (Belachsen et al., 2017). Se o solo está saturado ele não permitirá a infiltração de chuva, e a água ficará acumulada na superfície e começará o escoamento superficial direto (Horton, 1940).

A taxa de infiltração, é a velocidade ou intensidade da penetração da água no solo (Horton, 1940). Ela pode ser afetada pela permeabilidade do solo e depende diretamente da textura. Isto é, formação da crosta terrestre, à compactação do solo, contração e expansão do solo e/ou sua condutividade hidráulica (Sampson, 2008). Mas o que influencia na ocorrência de alagamentos são as alterações na superfície como o pavimento, compactação e os incêndios (Tarboton, 2003). Quanto ao perfil do solo sua influência é menor em relação aos outros dois fatores. Este efeito refere-se à organização 
vertical das camadas do solo e à profundidade da coluna do solo. Relaciona também a capacidade que tem o solo para armazenar água e a taxa de infiltração (Tarboton, 2003).

Além dos efeitos do solo mencionados acima, é importante analisar as características físicas da bacia e dos rios que influem na quantidade e no momento em que ocorre o escoamento. Os fatores que podem aumentar a susceptibilidade de alagamento/enchente na bacia são o declive, a forma, o uso do solo e a ordem dos cursos de água e densidade de drenagem (Ahnert, 2011).

O tamanho e a forma da bacia influenciam na velocidade e tempo da vazão. O declive e a rugosidade da superfície afetam diretamente na taxa de infiltração. Ou seja, com o maior declive menor é a taxa de infiltração por causa da gravidade e a velocidade (Tarboton, 2003); e a presença de pedras, vegetação e escombros diminui a velocidade do escoamento e aumenta a infiltração (C. P. M. Oliveira et al., 2014).

A densidade de drenagem dependerá do número de tributários da bacia. Uma bacia com maior densidade de drenagem tem maior eficiência para drenar logo de um evento (Gruntfest \& Handmer, 1999). Porém, a urbanização aumenta artificialmente a densidade de drenagem, sendo as ruas os novos "tributários" o que diminui a infiltração e aumenta a velocidade de escoamento.

\subsection{Controle de qualidade dos pluviômetros}

A tabela 5.1 sumariza os resultados obtidos do controle de qualidade dos pluviômetros do DAEE na cidade de São Paulo. Utilizando os critérios de avaliação nos registros de dados para o ano 2015, observa-se que 41 postos pluviométricos foram desconsiderados na comparação e avaliação da variação da chuva com as estimativas de precipitação do radar. Alguns dos postos pluviométricos que apresentaram valores constantes $>10 \mathrm{~mm} / \mathrm{h}$ por mais de 2 dias (critério do autor) foram utilizados depois de se corroborar que a informação era acorde ao tempo e as chuvas registradas no dia. A informação detalhada dos postos pluviométricos se encontra no Apêndice 1. 


\begin{tabular}{|l|c|}
\hline \multicolumn{1}{|c|}{ Critérios de avaliação } & $\begin{array}{c}\text { Número de postos } \\
\text { pluviométricos }\end{array}$ \\
\hline Registros sem informação & 0 \\
\hline Dados com valores negativos & 41 \\
\hline Valores constantes $>10 \mathrm{~mm} / \mathrm{h}$ por mais de 2 dias & 11 \\
\hline Total postos desconsiderados & 41 \\
\hline
\end{tabular}

Tabela 5.1. Características do controle de qualidade dos postos pluviométricos

\subsection{Variação da chuva estimada pelo Radar}

A rede telemétrica a cargo do DAEE coleta os dados a cada 10 minutos, e para comparar com a chuva estimada pelo radar se faz necessário acumular a chuva neste intervalo, isso é alcançado a partir de duas varreduras sucessivas do radar, sabendo que se realizam as varreduras a cada 5 minutos. Logo, com os dados de chuva obtidos pelos pluviômetros e os dados de chuva estimada pelo radar, se ajustaram para mostrar a variação entre os dois instrumentos em escalas temporais de 10 minutos, 1 hora e 1 dia.

A tabela 5.2 sumariza algumas das características estatísticas obtidas a partir das tabelas de contingencia, além do coeficiente de correlação para as escalas temporais de 10 minutos, 1 hora e 1 dia para os postos pluviométricos que passaram o controle de qualidade. Nela observa-se que há um aumento progressivo do coeficiente de correlação $\left(\mathrm{R}^{2}\right)$, da Probabilidade de Detecção (POD), da Taxa de Falso Alarme (FAR) e do BIAS com o tempo de integração. Logo, tem-se que a correlação média obtida entre todos os pluviômetros passa de 0,53 com $10 \mathrm{~min}$, a 0,72 em $1 \mathrm{~h}$ para em torno de 0,82 na escala diária. Da mesma forma, os índices como a POD, que mostra a porcentagem das estimativas do radar que detectaram corretamente a chuva em relação à chuva registrada pelo pluviômetro, passam de $30 \%$ com 10 min, $43 \%$ com 1 hora a 77\% na escala de acumulação diária. O FAR, que mostra a porcentagem da razão entre a quantidade de vezes que o radar detectou chuva quando os pluviômetros não registraram precipitação, manteve uma média de 5\% na escala temporal de 10 minutos, de $15 \%$ em 1 hora e de $13 \%$ em 1 dia. O BIAS, que representa a razão entre a quantidade total de detecções de precipitação do radar pelo pluviômetro, obtive uma média de $31 \%$ em 10 min, 50\% em 1h e 89\% em 1dia. Já nos casos em que o BIAS supera o 100\% o radar sobredetecta eventos de precipitação e se for menor ao $100 \%$ o radar subdetecta eventos. 


\begin{tabular}{|c|c|c|c|c|c|c|c|c|c|c|c|c|}
\hline \multirow[b]{2}{*}{ Posto } & \multicolumn{4}{|c|}{10 minutos } & \multicolumn{4}{|c|}{1 hora } & \multicolumn{4}{|c|}{1 dia } \\
\hline & $\mathbf{R}^{2}$ & $\begin{array}{c}\text { POD } \\
{[\%]}\end{array}$ & $\begin{array}{c}\text { FAR } \\
{[\%]}\end{array}$ & $\begin{array}{c}\text { BIAS } \\
{[\%]}\end{array}$ & $\mathbf{R}^{2}$ & $\begin{array}{c}\text { POD } \\
{[\%]}\end{array}$ & $\begin{array}{c}\text { FAR } \\
{[\%]}\end{array}$ & $\begin{array}{c}\text { BIAS } \\
{[\%]}\end{array}$ & $\mathbf{R}^{2}$ & $\begin{array}{l}\text { POD } \\
{[\%]}\end{array}$ & $\begin{array}{c}\text { FAR } \\
{[\%]}\end{array}$ & $\begin{array}{c}\text { BIAS } \\
{[\%]}\end{array}$ \\
\hline 1000470 & 0,61 & 33,54 & 4,99 & 35,30 & & 47,20 & 20,21 & 59,16 & 0,85 & 84,86 & 16,04 & 101,8 \\
\hline 1000640 & 0,61 & 33,54 & 4,99 & 35,30 & & 47,20 & 20,21 & 59,16 & 0,85 & 84,86 & 16,04 & 101,8 \\
\hline 1000790 & 0,62 & 35,42 & 3,66 & 36,77 & 0,72 & 46,98 & 16,20 & 56,07 & 0,82 & 84,75 & 12,28 & 96,61 \\
\hline 1000837 & 0,55 & 28,55 & 3,81 & 29,68 & 0,63 & 39,57 & 13,71 & 45,86 & 0,77 & 76,70 & 12,90 & 88,07 \\
\hline 1000838 & 0,49 & 28,03 & 4,08 & 29,22 & 066 & 41,52 & 11,48 & 46,90 & 0,78 & 75,82 & 8,00 & 82,42 \\
\hline 1000839 & 0,55 & 29,70 & 4,79 & 31,19 & 0,73 & 39,83 & 16,27 & 47,57 & 0,83 & 72,63 & 15,58 & 86,03 \\
\hline 1000843 & 0,60 & 30,68 & 6,15 & 32,69 & 0,78 & 42,54 & 15,55 & 50,38 & 0,86 & 70,37 & 12,50 & 80,42 \\
\hline & & 31,10 & 6,25 & 33,17 & 0,66 & 43,92 & 15,77 & 52,15 & & 73,03 & 15,58 & 86,52 \\
\hline & & 24,24 & & 25,36 & & 32,89 & 9,57 & & & 62,78 & 6,61 & 67,22 \\
\hline 1000847 & 0,62 & 32,41 & 4,37 & 33,89 & & 43,60 & 13,90 & 50,64 & 0,75 & 75,69 & 9,87 & 83,98 \\
\hline 1000853 & 0,67 & 35,05 & 6,22 & 37,37 & 0,84 & 46,67 & 18,99 & 57,60 & 0,89 & 79,35 & 13,10 & 91,30 \\
\hline 1000858 & 0,62 & 30,09 & 3,91 & 31,32 & 0,80 & 41,77 & 16,80 & 50,20 & 0,87 & 78,01 & 12,87 & 89,53 \\
\hline 1000868 & & 32,85 & 3,92 & 34,20 & & 43,90 & 14,49 & 51,34 & & 79,78 & 12,88 & 91,57 \\
\hline 11 & & 27,46 & 4,98 & 28,90 & & 39,46 & 13,74 & 45,75 & 86 & 72,77 & 9,15 & 80,10 \\
\hline 149 & & 33,66 & 5,96 & 35,79 & & & 16,76 & 54,41 & 0,85 & 83,89 & 12,72 & 96,11 \\
\hline 157 & & 9,17 & 19,07 & & & & 10,83 & & & 72,77 & 11,46 & 82,20 \\
\hline 346 & 0,52 & 24,73 & 1,72 & 25,17 & 0,71 & 38,30 & 7,09 & 41,23 & 0,80 & 72,83 & 8,84 & 79,89 \\
\hline 413 & 0,37 & 30,09 & 4,34 & 31,45 & & 41,63 & 14,29 & 48,56 & & 75,54 & 13,66 & 87,50 \\
\hline 580 & 0,47 & 32,48 & 6,20 & 34,63 & 0,67 & 47,60 & 23,22 & 62,00 & 0,84 & 86,52 & 27,70 & 119,66 \\
\hline MÉDIA & 0,53 & 29,62 & 5,46 & 31,20 & & 42,64 & 15,21 & 50,55 & 0,82 & 77,00 & 13,04 & 89,02 \\
\hline SD & 0,14 & 5,87 & 3,49 & 5,94 & 0,07 & 3,82 & 3,90 & 6,52 & 0,04 & 6,13 & 4,47 & 11,04 \\
\hline MAX & 0,67 & 35,42 & 19,07 & 37,37 & 0,84 & 47,60 & 23,22 & 62,00 & 0,89 & 86,52 & 27,70 & 119,66 \\
\hline
\end{tabular}

Tabela 5.2. Análise estatístico da validação dos pluviômetros em relação ao radar a escalas temporais de 10 minutos, 1 hora e 1 dia.

A figura 5.1 mostra a dispersão e o ajuste linear dos pluviômetros e das estimativas do radar para escalas temporais de acumulação de precipitação de 10 minutos (Fig. 5.1 a), 1 hora (Fig. 5.1 b) e 1 dia (Fig. 5.1 c). Observamos assim, que o ajuste para 1 dia foi o que mais se aproximou ao ideal com uma correlação de 0,8 , seguido da chuva acumulada em 1 hora que foi de 0,7 e em 10 minutos de 0,4. Nos três casos, conforme ao ajuste linear, houve subestimativa da precipitação em relação ao registrado pelo radar por possuir inclinação inferior a reta 1:1. Esta inclinação ou declive, que é a variação média da precipitação registrada pelo pluviômetro associada a um aumento de uma unidade na precipitação obtida pelo radar, é menor na escala temporal de 1 dia comparada com escalas de 1 hora e 10 minutos. Observamos também, que conforme o tempo de acumulação de chuva aumenta até 1 dia, a dispersão dos pontos diminui consideravelmente. 
a) Chuva acumulada a 10 minutos

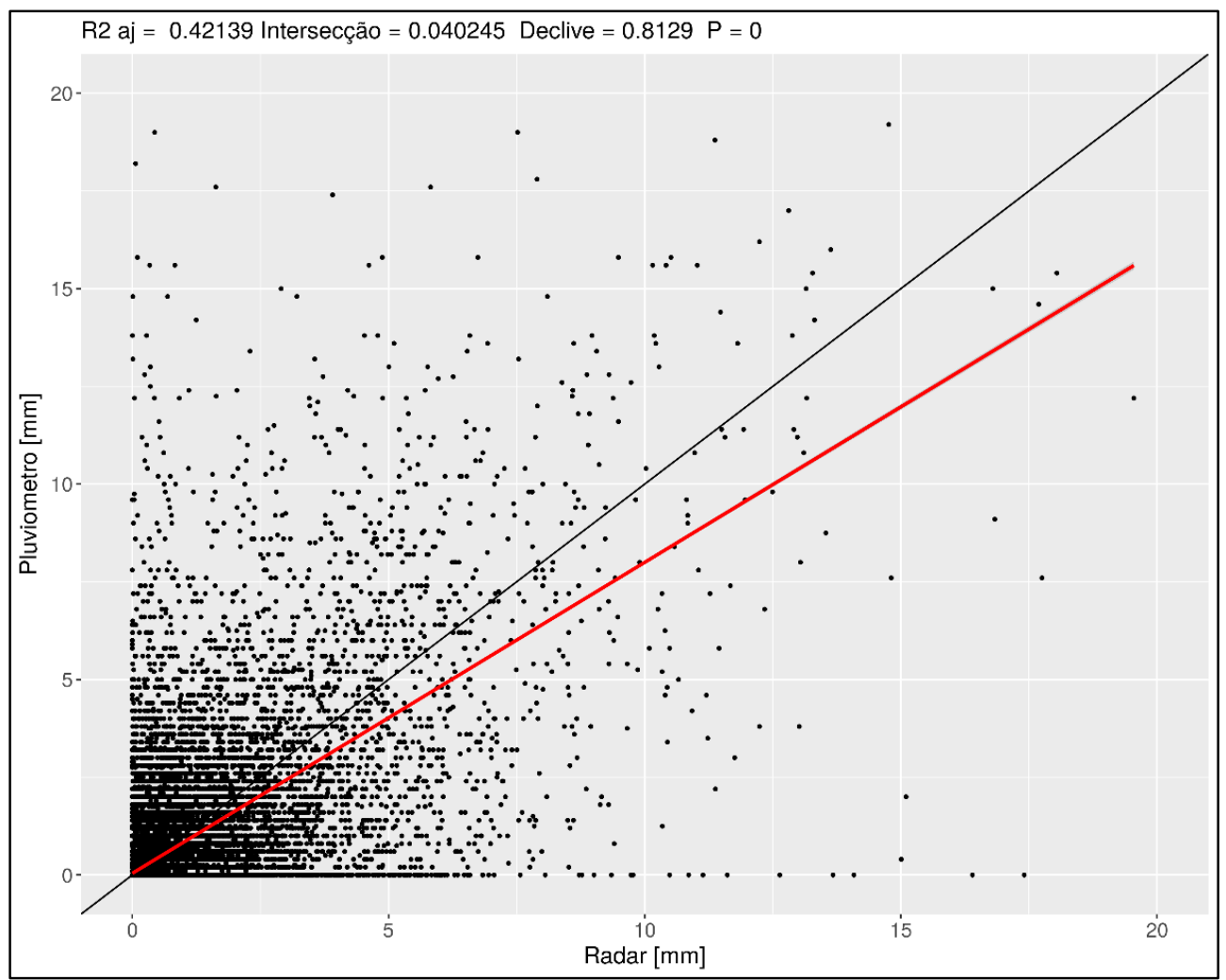

b) Chuva acumulada a 1 hora

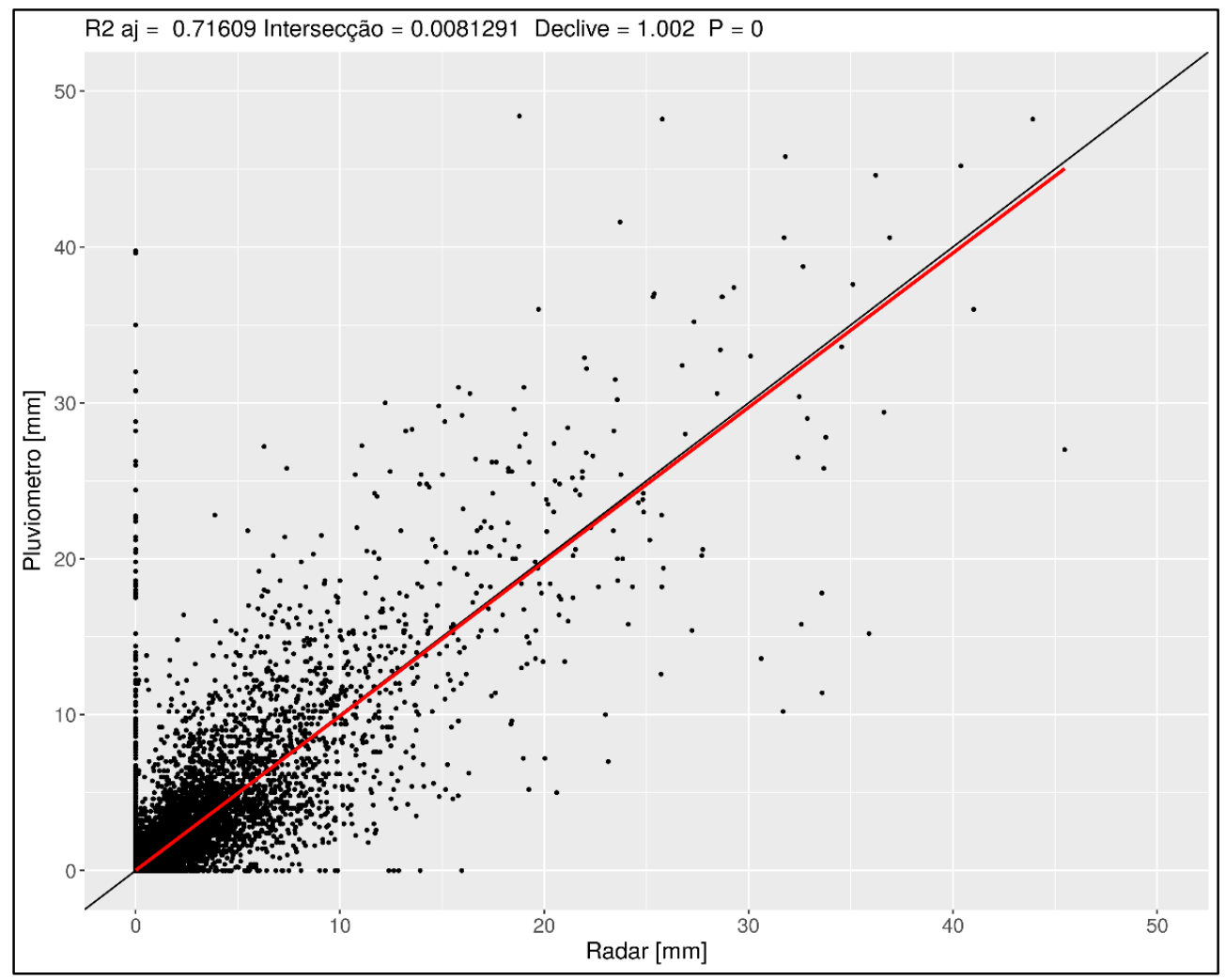


c) Chuva acumulada em 1 dia

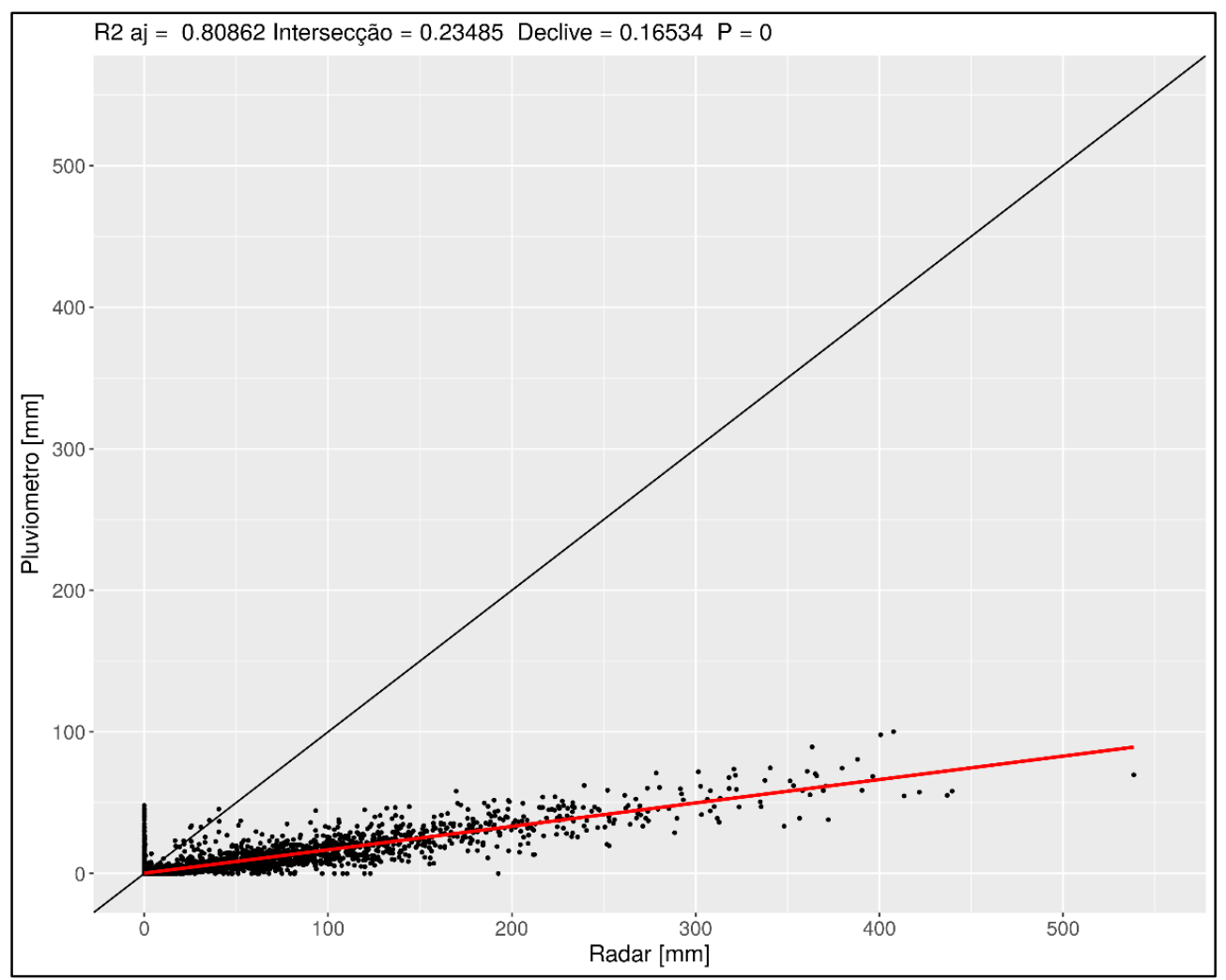

Figura 5.1. Ajustes lineares entre precipitação acumulada pelo pluviômetro e o radar para as escalas temporais de (a) 10 minutos, (b) 1 hora e (c) 1 dia na cidade de São Paulo

\subsection{Análises dos bairros da cidade de São Paulo}

Para identificar os padrões de alagamento para cada um dos bairros da cidade serão feitas as análises seguintes:

a) Análise da PDF para chuva acumulada, taxa de precipitação

b) Análise comparativo entre a duração da chuva e a chuva acumulada

c) Análise comparativo entre a taxa de precipitação e chuva acumulada

d) Fracção da área de chuva no bairro.

Antes de tudo, tem-se na figura 5.2, a distribuição dos bairros da cidade de São Paulo com a indicação do número de ocorrências de alagamento no ano 2015. Os bairros de Santana e Vila Guilherme do nordeste, Freguesia do Ó do noroeste, Morumbi, Itaim Bibi, 
Butantã, Perdizes e Barra Funda da zona oeste, Bom Retiro, República e Santa Cecília (centro), Santo Amaro e Campo Grande da zona centro sul e Belém e Mooca do sudeste registraram mais de 20 eventos de alagamento (representados em cor vermelha). Porém, estes bairros não foram os que tiveram maior volumes de chuva acumulada no ano. Parelheiros e Marsilac foram os bairros que registraram mais de $2000 \mathrm{~mm}$ de chuva no ano inteiro (Figura 5.3) embora Marsilac não tenha apresentado nenhum alagamento.

Nas análises a seguir serão apresentados de forma aleatória somente 3 bairros diferentes, depois é apresentado um resumo das caraterísticas calculadas por dia para todos bairros. 


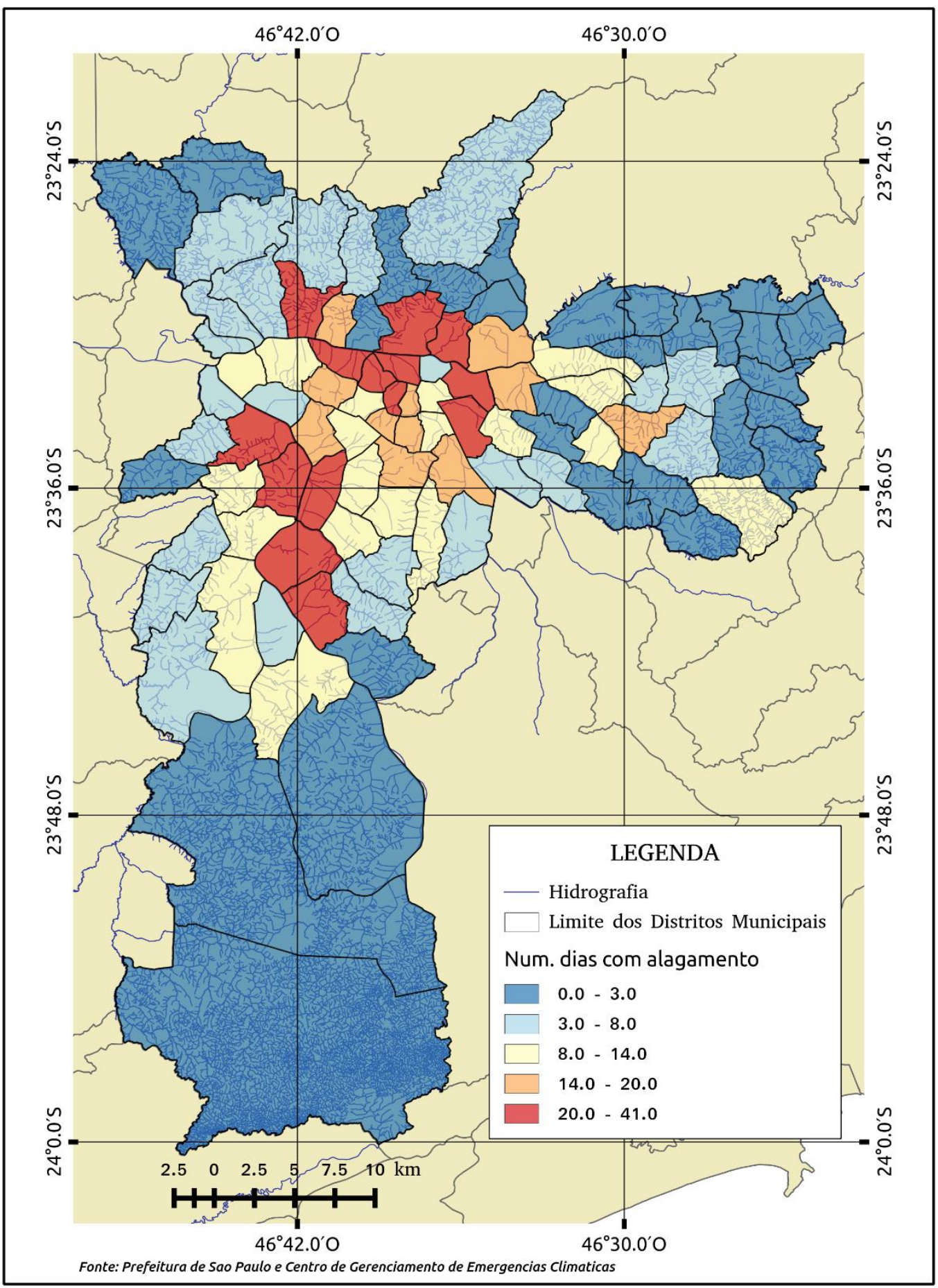

Figura 5.2. Mapa do número total de ocorrências de alagamento no ano 2015 para os bairros da cidade de São Paulo. Fonte: Andrea Viteri 


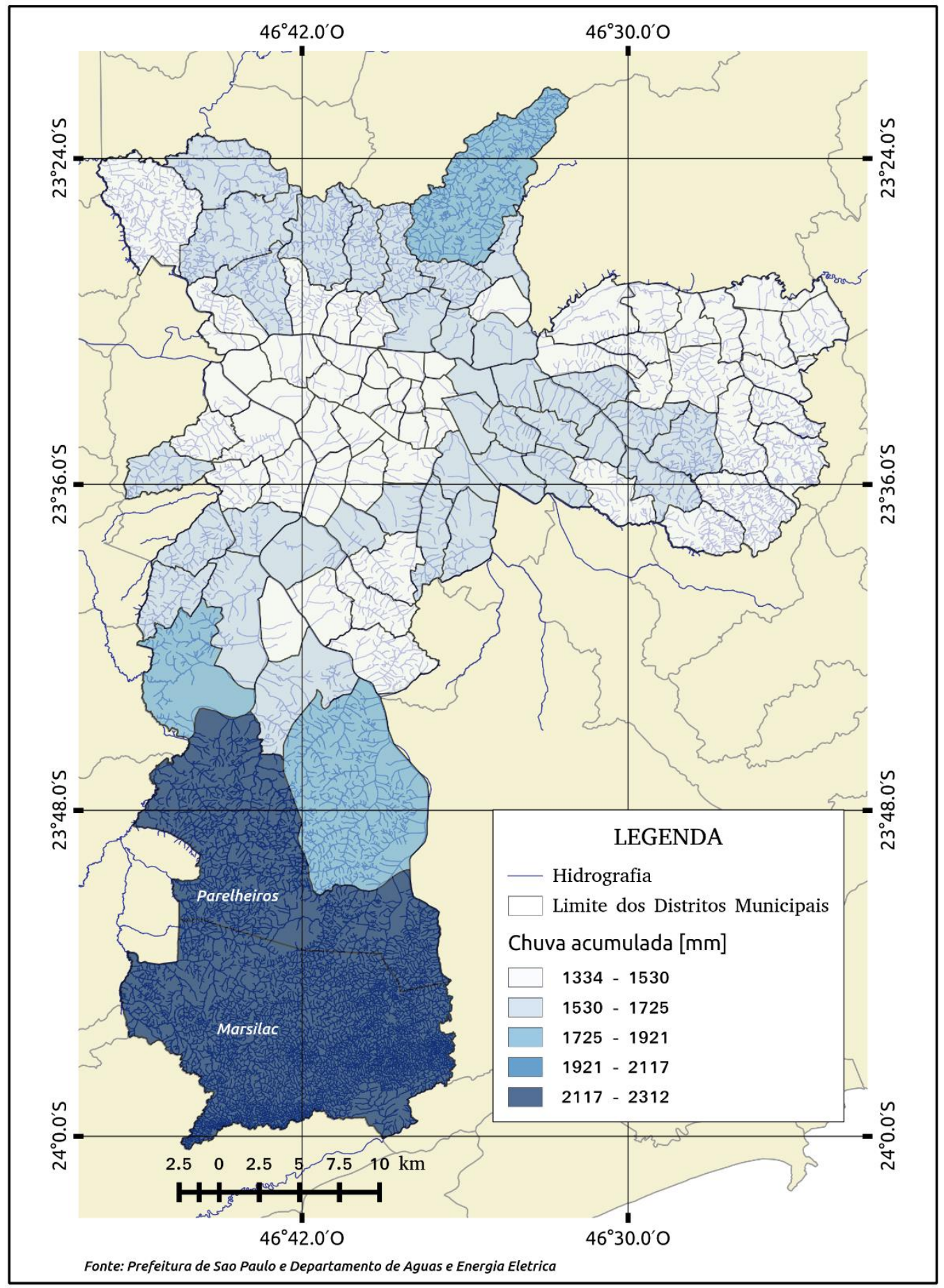

Figura 5.3. Mapa de chuva acumulada estimada no ano 2015 pelo radar para a cidade de São Paulo em relação à chuva acumulada. Fonte: Andrea Viteri 


\subsubsection{Função Densidade de Probabilidade - PDF}

Nesta secção, as diferenças entre os dias que apresentaram eventos com alagamento e sem alagamento são analisadas a partir das características espaço temporais da chuva. O resumo das propriedades e as características dos eventos para os bairros de Sacomã, Campo Limpo e República (escolhidos aleatoriamente) são resumidos na tabela 5.3.

Podemos notar que a duração média da chuva nos três bairros é de 9 horas com uma média de chuva acumulada de 1549 mm no ano. Dos bairros aqui mostrados, República, localizado no centro da cidade, apresentou no ano 2015 mais dias com alagamento (26 dias) que Campo Limpo da região sul (8 dias) e Sacomã da região sudeste (5 dias). Não obstante, registrou uma taxa máxima de precipitação no ano de $60 \mathrm{~mm} / \mathrm{h}$ menor ao bairro de Campo Limpo, assim como também um menor volume de chuva total acumulada em comparação com os dois bairros.

Observamos também, que Campo Limpo registrou uma maior intensidade máxima de chuva durante o ano de $76 \mathrm{~mm} / \mathrm{h}$. Logo, ao analisar os dias com eventos de alagamento, a taxa de precipitação máxima média foi de $44 \mathrm{~mm} / \mathrm{h}$ e o volume médio de chuva antes do registro do evento foi de $14,3 \mathrm{~mm}$, maior em comparação com Republica e Sacomã. Além disso, nota-se que as intensidades máximas registradas nos dias com alagamento superam em duas vezes aos dias sem alagamento aproximadamente. Nos três bairros analisados, Campo Limpo, Republica e Sacomã, a intensidade da precipitação é primordial na hora de determinar o padrão de alagamento pelo baixo volume de chuva obtido antes de se registrar os eventos de alagamento. 


\begin{tabular}{|c|c|c|c|c|c|c|c|c|}
\hline Bairro & $\begin{array}{c}\text { Vol. de } \\
\text { chuva } \\
\text { total } \\
\text { no ano } \\
\text { [mm] }\end{array}$ & $\begin{array}{c}\text { Intensidade } \\
\text { máx. }\left(\mathbf{R}_{\text {máx }}\right) \\
{[\mathbf{m m} / \mathbf{h}]}\end{array}$ & $\begin{array}{l}\text { Número de } \\
\text { dias com } \\
\text { alagamento }\end{array}$ & $\begin{array}{l}\text { Duração } \\
\text { média de } \\
\text { chuva [h] }\end{array}$ & $\begin{array}{c}\text { Média } \\
\mathbf{R}_{\text {máx }} \\
{[\mathbf{m m} / \mathbf{h}]}\end{array}$ & $\begin{array}{c}\text { Média da } \\
\mathbf{R}_{\text {máx} \cdot \text { Dias }} \\
\text { com } \\
\text { alagamento } \\
{[\mathrm{mm} / \mathrm{h}]}\end{array}$ & 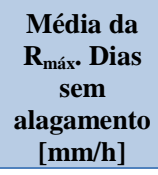 & $\begin{array}{c}\text { Média vol. } \\
\text { de chuva } \\
\text { antes do } \\
\text { alagamento } \\
\text { [mm] }\end{array}$ \\
\hline $\begin{array}{l}\text { Campo } \\
\text { Limpo }\end{array}$ & 1660 & 76 & 8 & 9 & $\begin{array}{l}19,4 \\
(15)\end{array}$ & $\begin{array}{c}44 \\
(19)\end{array}$ & $\begin{array}{c}17,2 \\
(12,5)\end{array}$ & $\begin{array}{c}14,3 \\
(14,7)\end{array}$ \\
\hline República & 1382 & 60 & 26 & 8,2 & $\begin{array}{c}19 \\
(13,6) \\
\end{array}$ & $\begin{array}{c}25,7 \\
(13,4) \\
\end{array}$ & $\begin{array}{c}15,8 \\
(12,7)\end{array}$ & $\begin{array}{c}8,3 \\
(7,4)\end{array}$ \\
\hline Sacomã & 1605 & 57 & 5 & 9,5 & $\begin{array}{c}20 \\
(13)\end{array}$ & $\begin{array}{l}31,8 \\
(13)\end{array}$ & $\begin{array}{c}18,8 \\
(12,6)\end{array}$ & $\begin{array}{c}8,6 \\
(7,2)\end{array}$ \\
\hline
\end{tabular}

Tabela 5.3. Média e desvio padrão (em parênteses) das propriedades espaciais e temporais das chuvas e dos eventos de alagamento no ano 2015 para os bairros de Campo Limpo, Republica e Sacomã

Na figura 5.4 - esquerda, são mostradas as funções densidade de probabilidade da taxa de precipitação máxima $[\mathrm{mm} / \mathrm{h}]$ registrada para todos os dias (1) com eventos de alagamento, representada pela cor azul e (2) sem eventos de alagamento representada pela cor preta, para os bairros de (a) Campo Limpo, (b) Republica e (c) Sacomã. A forma da PDF é mesma de uma distribuição normal e a linha ponteada representa a média dos dados. Além disso, se pode comparar com algumas das propriedades especificadas na tabela 5.3 dos dias com e sem eventos de alagamento e pelo "boxplot" ou diagrama de caixa representada na figura 5.4 - direita, onde o ponto vermelho representa a média dos dados, a linha que atravessa a caixa marca a mediana, as bordas da caixa inferior e superior representam os quartis ao 25 e $75 \%$ e os pontos pretos fora das caixas representam os valores extremos.

Observamos que para o bairro de Campo Limpo (Figura 5.4 a), a intensidade média de chuva foi de $44 \mathrm{~mm} / \mathrm{h}$ para os dias que registraram eventos de alagamento e 17 $\mathrm{mm} / \mathrm{h}$ para os dias sem registro de alagamento, o que influi na grande diferença ao comparar a chuva acumulada em cada caso (Figura 5.4 a - direita). Do mesmo modo, a probabilidade de ocorrência de alagamento no bairro foi de $21 \%$ ao atingir uma intensidade de precipitação entre 40 e $50 \mathrm{~mm} / \mathrm{h}$. 


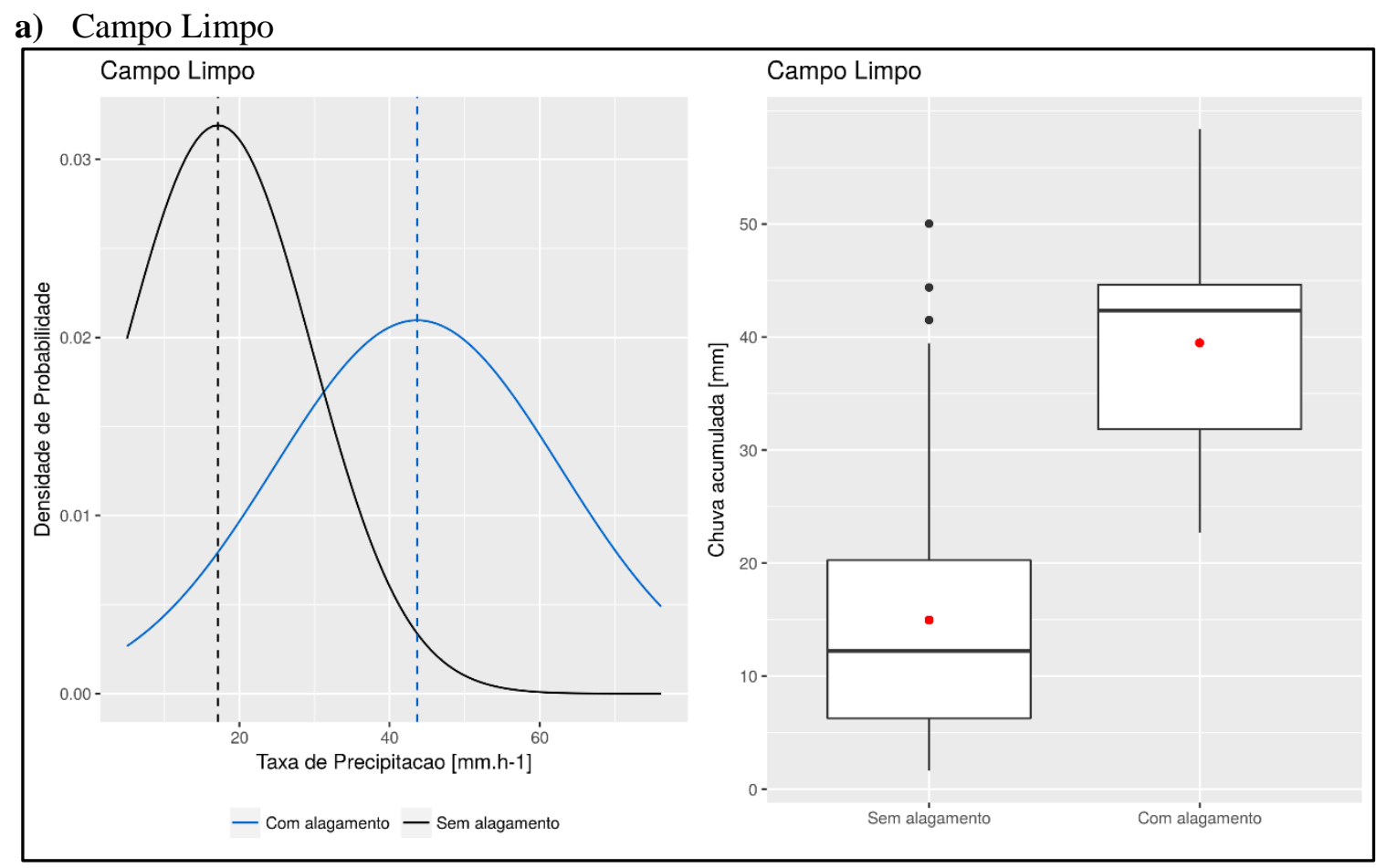

\section{b) República}

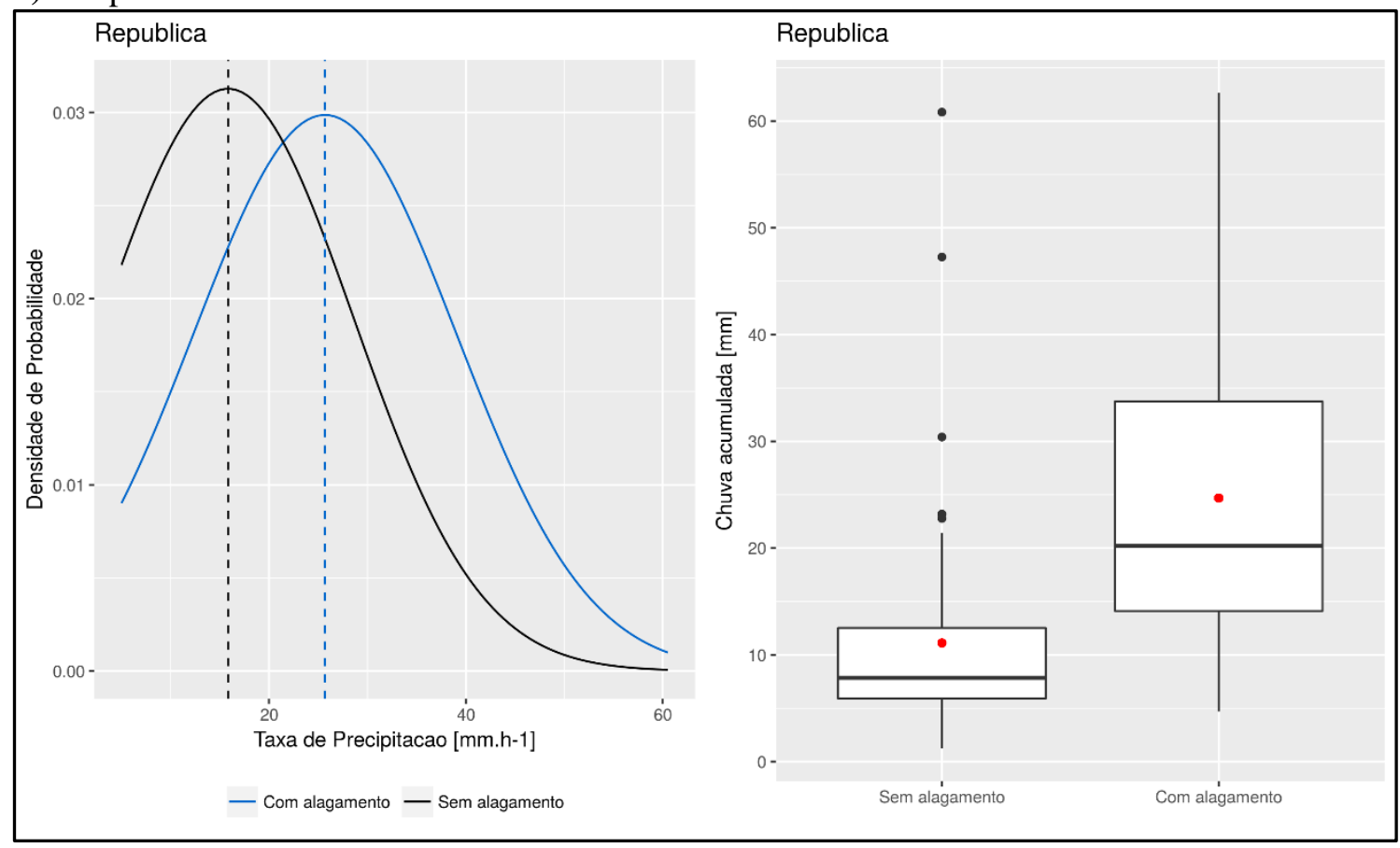


c) Sacoma

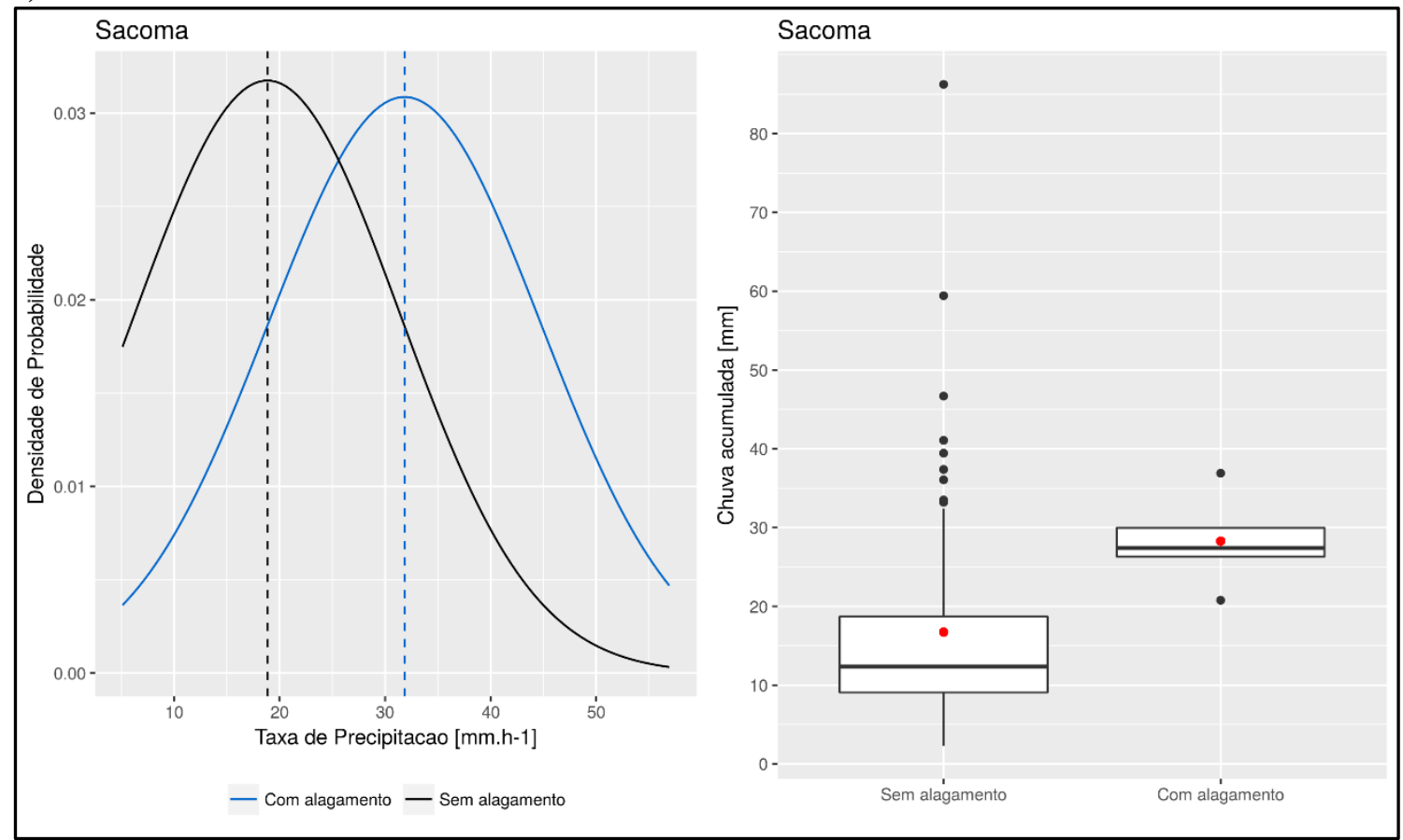

Figura 5.4. Comparação dos dias com e sem alagamento nos bairros de a) Campo Limpo, b) República e c) Sacomã: (ESQUERDA) Função Densidade de Probabilidade para os dias com alagamento (linha azul) e sem alagamento (linha preta), as linhas ponteadas representam as intensidades médias. (DIREITA) Comparação das propriedades da chuva acumulada no ano dos dias com e sem alagamento, o ponto vermelho representa o valor médio, a linha preta em cada caixa marca a mediana, as bordas da caixa baixa e superior representam os quartis ao 25 e $75 \%$, respectivamente, e os pontos pretos fora das caixas representam os valores extremos.

O bairro da Republica registrou uma intensidade média de chuva de $26 \mathrm{~mm} / \mathrm{h}$ para os dias com eventos de alagamento e apresentou uma probabilidade de ocorrência de alagamento de $29 \%$ se tiver intensidades maiores a $20 \mathrm{~mm} / \mathrm{h}$ (Fig. $5.4 \mathrm{~b}$ - esquerda). Vemos também uma alta variabilidade nos acumulados de chuva observados nos dias com alagamento (Fig. 5.4b - direita), sendo o volume máximo registrado de $60 \mathrm{~mm}$ e um acumulado de chuva médio de $25 \mathrm{~mm}$.

Os dias com alagamento no bairro de Sacomã registram uma intensidade média de chuva aproximada de $32 \mathrm{~mm} / \mathrm{h}$ (Figura 5.4 c - esquerda) e uma probabilidade de ocorrência de alagamento de $30 \%$ se se tiver dias com intensidades de chuva entre 25 e 35 $\mathrm{mm} / \mathrm{h}$. Ao comparar o volume de chuva acumulada em cada tipo de evento, os dias com alagamento superam com uma média superior a $30 \mathrm{~mm}$ de chuva em relação aos dias sem registro de alagamento (Figura 5.4 - direita). 


\subsubsection{Duração da chuva vs Chuva acumulada}

Comparou-se a chuva acumulada total obtida por dia em relação à duração da chuva para todos os bairros. Neste caso, foram escolhidos como exemplo os bairros de Belém, Cursino e Morumbi localizados nas zonas centro, sudeste e oeste, respectivamente. Como apresentado na tabela 5.4, o volume de chuva acumulada média entre os três bairros é de 1577 mm com duração média de 9 horas de período de chuva. Além disso, observamos que durante o ano 2015, o bairro que registrou mais dias com eventos de alagamento foi Morumbi (40 dias) seguido de Belém (32 dias) e Cursino (13 dias), com intensidades de chuva máxima registrados no ano de $90 \mathrm{~mm} / \mathrm{h}, 182 \mathrm{~mm} / \mathrm{h}$ e $71 \mathrm{~mm} / \mathrm{h}$, respectivamente. Notase também, que o bairro de Morumbi registrou menor volume de chuva nos dias com alagamento $(20 \mathrm{~mm})$, porém mais dias com eventos de alagamento, sendo o bairro mais vulnerável em comparação com os bairros de Cursino e Belém.

\begin{tabular}{|c|c|c|c|c|c|}
\hline Bairro & $\begin{array}{c}\text { Volume de chuva } \\
\text { total no ano } \\
{[\mathrm{mm}]}\end{array}$ & $\begin{array}{c}\text { Intensidade } \\
\text { máx. }\left(\mathbf{R}_{\text {máx }}\right) \\
{[\mathbf{m m} / \mathbf{h}]}\end{array}$ & $\begin{array}{l}\text { Número de dias } \\
\text { com alagamento }\end{array}$ & $\begin{array}{c}\text { Duração média } \\
\text { de chuva [h] }\end{array}$ & $\begin{array}{c}\text { Média da chuva } \\
\text { acumulada em Dias com } \\
\text { alagamento }[\mathrm{mm}]\end{array}$ \\
\hline Belém & 1614 & 182 & 32 & 8,6 & $\begin{array}{c}25 \\
(18,4)\end{array}$ \\
\hline Cursino & 1609 & 71 & 13 & 9,6 & $\begin{array}{r}33,4 \\
(14,7) \\
\end{array}$ \\
\hline Morumbi & 1507 & 90 & 40 & 9 & $\begin{array}{c}19,5 \\
(15,5)\end{array}$ \\
\hline
\end{tabular}

Tabela 5.4. Média e desvio padrão (em parênteses) das propriedades espaciais e temporais das chuvas e dos eventos de alagamento no ano 2015 para os bairros de Belém, Cursino e Morumbi

Nas figuras seguintes, representa-se a comparação das duas variáveis para os bairros, esta comparação foi feita por intervalos, para $10 \mathrm{~mm}$ de chuva acumulada em 1 hora e cada diferença de cores mostra o número de dias com alagamento nesse intervalo.

O bairro de Belém por exemplo, registrou maior parte dos alagamentos acima dos $20 \mathrm{~mm}$ de chuva acumulada acima das 6 horas de chuva, parte destes eventos estão concentrados entre os 20 e $50 \mathrm{~mm}$ de chuva acumulada num intervalo de 12 a 18 horas. Temse eventos registrados em menor tempo, que acumularam um volume de chuva entre 10 e 20 mm de chuva em 3 a 6 horas (Figura 5.5 a). Observamos de igual maneira, que a tendência dos alagamentos é para uma maior duração de chuva com volumes que atingem os 50mm. 
Há dois eventos que acumularam maior chuva num tempo menor, que pode ser característica de precipitações convectivas.

No bairro de Cursino foram registrados a maior parte dos alagamentos com volumes de chuva entre 20 e $40 \mathrm{~mm}$ num intervalo de 5 a 17 horas (Figura 5.5 b), concentrados alguns deles com $30 \mathrm{~mm}$ de chuva acumulada entre 8 a 10 horas. Além disso, pode-se observar que dois eventos de alagamento registraram um volume maior a $60 \mathrm{~mm}$ de chuva em mais de 12 horas. A tendência dos alagamentos é em relação à chuva acumulada no dia, ou seja, maior acumulação de chuva num tempo menor.

Por outro lado, no bairro de Morumbi os eventos de alagamento começaram a ser mais recorrentes a partir de um volume de chuva de $10 \mathrm{~mm}$ em ao redor de 7 horas e conforme aumenta o tempo de chuva maior é o acumulado de chuva e maior a probabilidade de ocorrência de alagamento. Assim, observamos que os eventos de alagamento chegam a se concentrar a mais de 10 horas de precipitação com uma quantidade superior aos $20 \mathrm{~mm}$ de chuva (Figura $5.5 \mathrm{c}$ ).

a) Belém

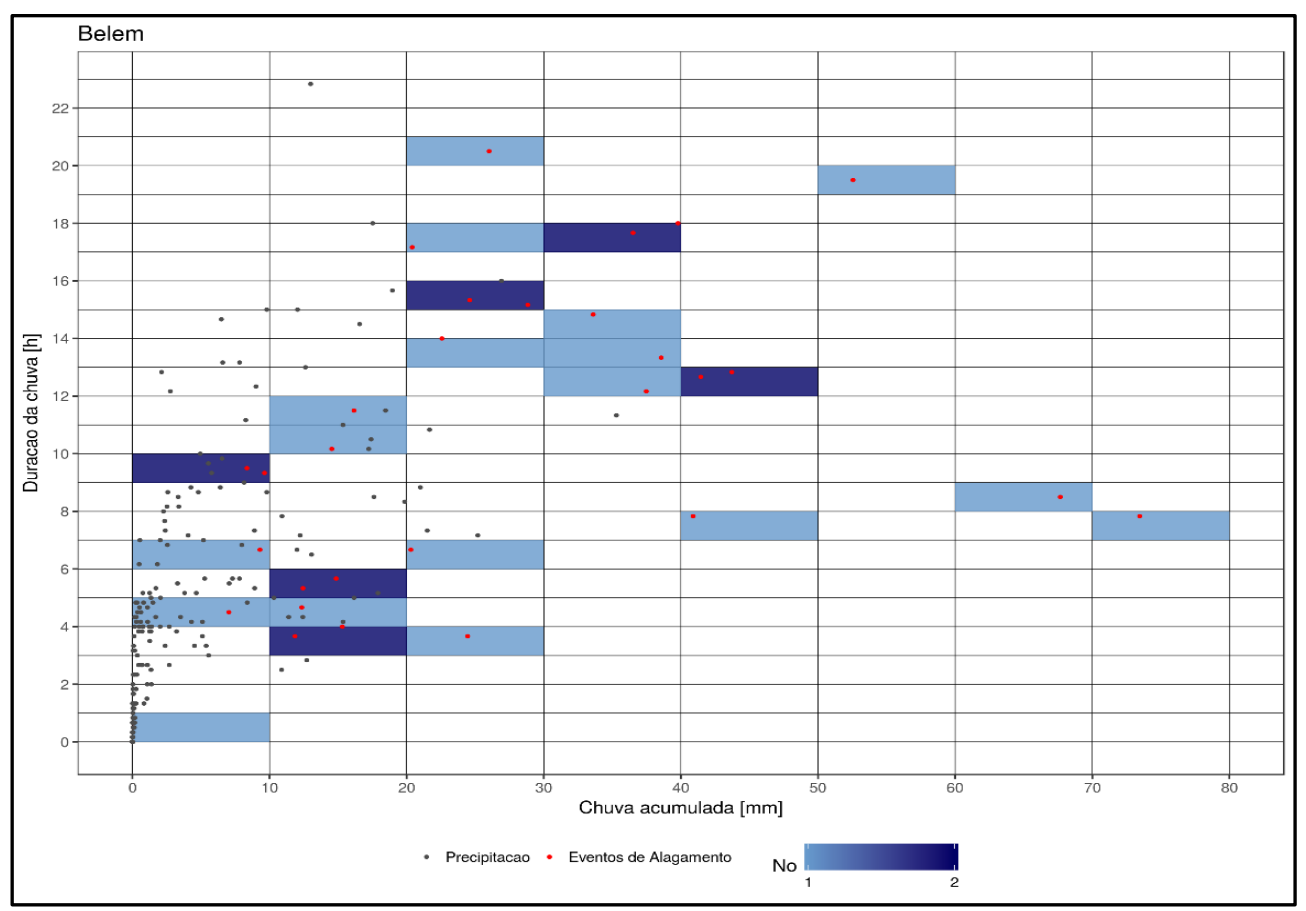


b) Cursino

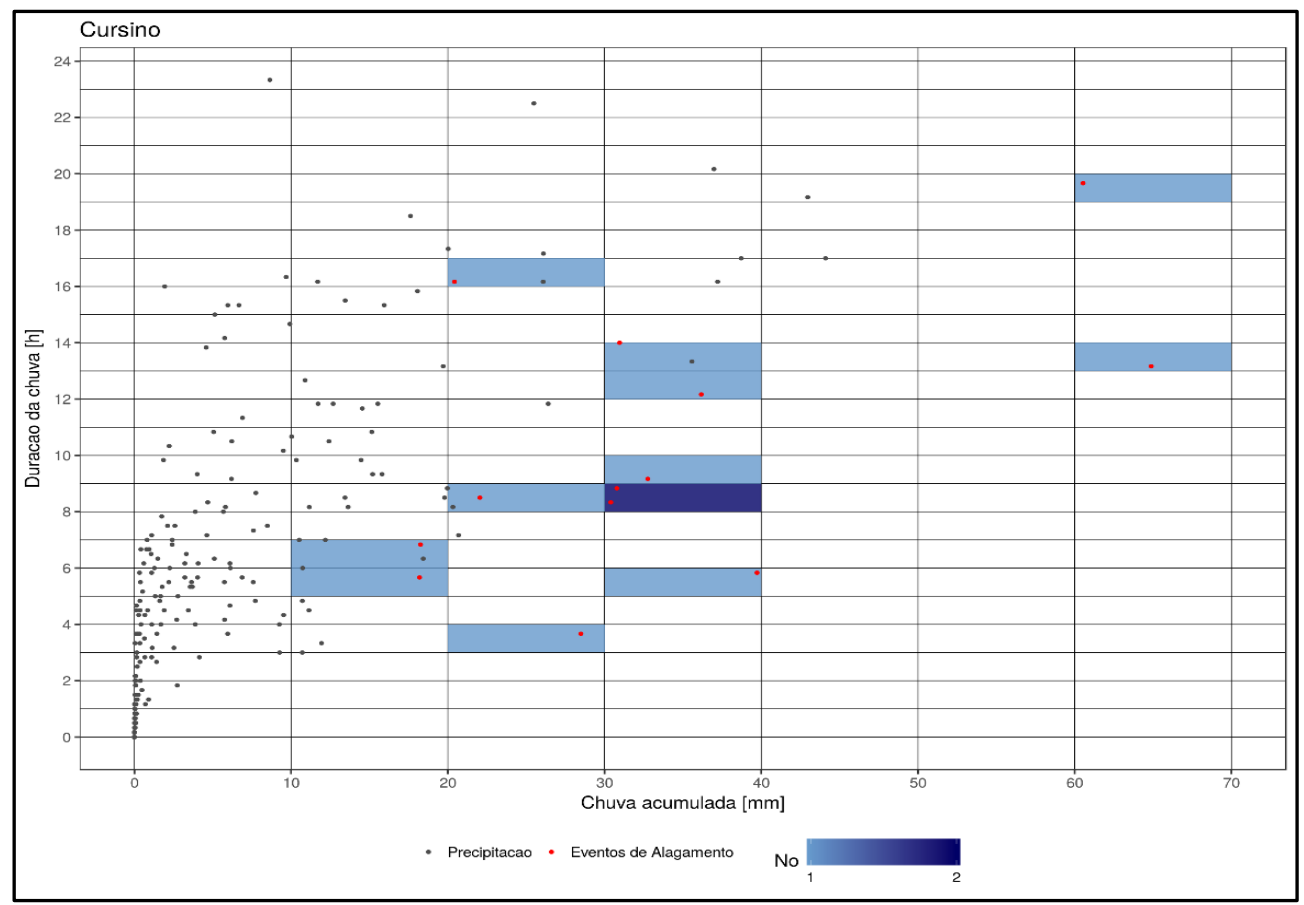

c) Morumbi

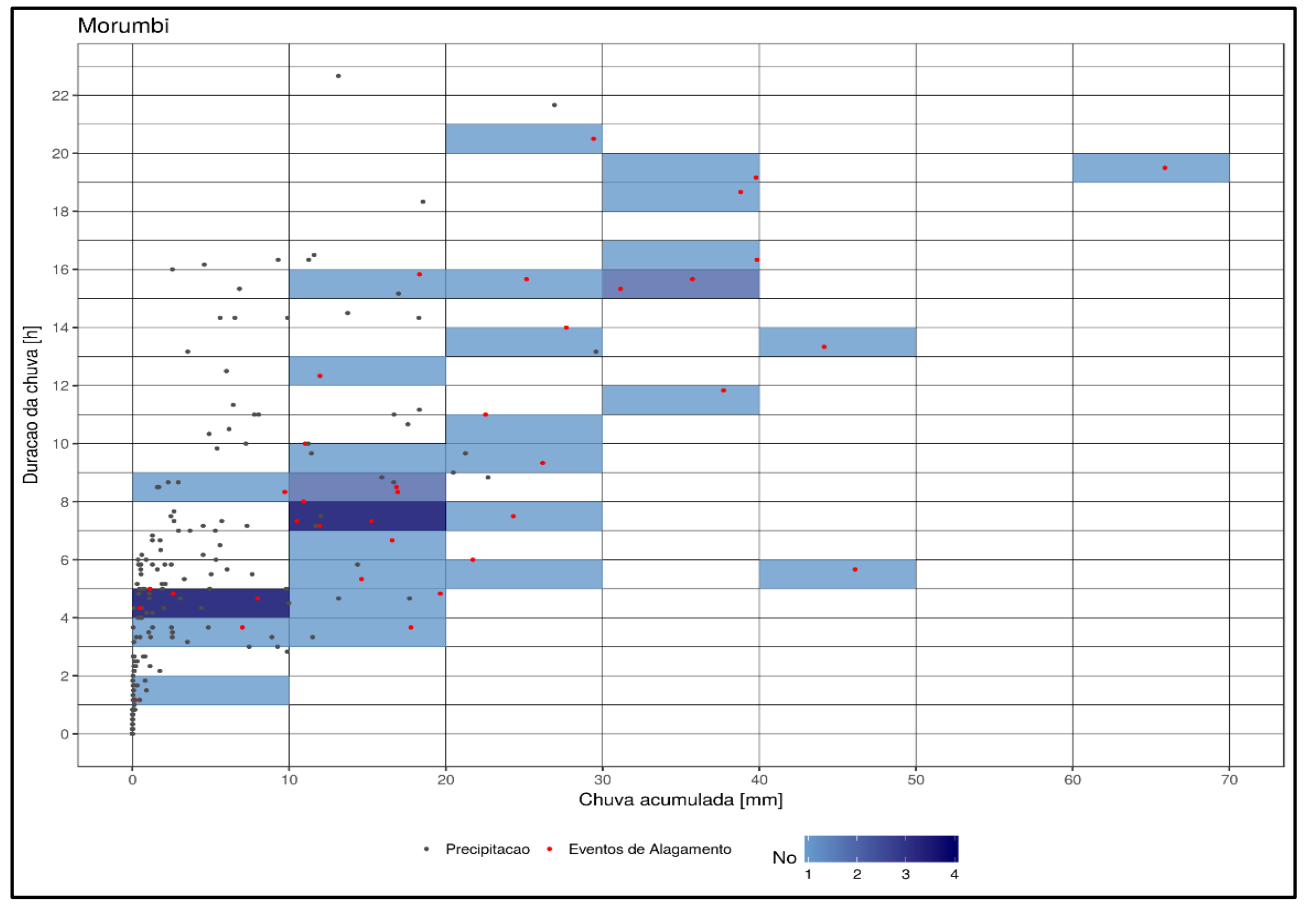

Figura 5.5. Gráfico de frequência e dispersão entre a chuva acumulada e a duração da chuva por dia ano 2015 para os bairros de Belém, Cursino e Morumbi 


\subsubsection{Taxa de precipitação vs Chuva acumulada}

Nesta análise, comparou-se a chuva acumulada total obtida por dia em relação à taxa de precipitação máxima registrada para todos os bairros. Foram escolhidos os bairros de Barra Funda, localizado na margem do rio Tietê, Butantã e Itaim Bibi na margem do rio Pinheiros. Durante o ano 2015, foram registrados ao redor de 30 dias com alagamento sendo Itaim Bibi o bairro com maior registro (39 dias). Na tabela 5.5 se resumem as características temporais das chuvas e dos eventos de alagamento nos três bairros.

Observamos que a duração média da chuva é de 9 horas com um acumulado médio de chuva total no ano de 1451,4 mm. Considerando só os dias com alagamento, Barra Funda obteve maior volume de chuva com uma média acumulada de chuva de $22 \mathrm{~mm}$ e Butantã a maior intensidade de precipitação com $84 \mathrm{~mm} / \mathrm{h}$.

\begin{tabular}{|c|c|c|c|c|c|}
\hline Bairro & $\begin{array}{c}\text { Volume de } \\
\text { chuva total no } \\
\text { ano [mm] }\end{array}$ & $\begin{array}{c}\text { Intensidade } \\
\text { máx. }\left(\mathbf{R}_{\mathbf{m a ́ x}}\right) \\
{[\mathbf{m m} / \mathbf{h}]}\end{array}$ & $\begin{array}{c}\text { Número de dias } \\
\text { com alagamento }\end{array}$ & $\begin{array}{c}\text { Duração } \\
\text { média de } \\
\text { chuva [h] }\end{array}$ & $\begin{array}{c}\text { Média da chuva } \\
\text { acumulada em Dias } \\
\text { com alagamento [mm] }\end{array}$ \\
\hline $\begin{array}{c}\text { Barra } \\
\text { Funda }\end{array}$ & 1397,4 & 49 & 27 & 8,8 & 22,1 \\
\hline Butantã & 1478,2 & 84 & 28 & 9,4 & $(18)$ \\
\hline & & 78 & 39 & 8,5 & $(15,5)$ \\
\hline Itaim Bibi & 1478,5 & & & & 19,1 \\
\hline
\end{tabular}

Tabela 5.5. Média e desvio padrão (em parênteses) das propriedades espaciais e temporais das chuvas e dos eventos de alagamento no ano 2015 para os bairros de Barra Funda, Butantã e Itaim Bibi

Nas figuras seguintes, representa-se a comparação das duas variáveis para os bairros, esta comparação foi feita por intervalos, para $10 \mathrm{~mm}$ de chuva acumulada em 10 $\mathrm{mm} / \mathrm{h}$, e cada diferença de cores mostra o número de dias com alagamento nesse intervalo.

Barra Funda foi um dos bairros que registrou as menores intensidades de precipitação em comparação com Butantã e Itaim Bibi, com uma taxa de precipitação máxima de $49 \mathrm{~mm} / \mathrm{h}$ no mês de outubro. Neste bairro a maior parte dos alagamentos foi acima de $20 \mathrm{~mm}$ de chuva acumulada no dia e com taxa de precipitação maior a $20 \mathrm{~mm} / \mathrm{h}$ (Figura 5.6 a), havendo maior concentração nos intervalos de 10 a $30 \mathrm{~mm}$ de chuva acumulada e 10 a $30 \mathrm{~mm} / \mathrm{h}$ de taxa de precipitação e 40 a $50 \mathrm{~mm}$ de chuva acumulada e maior que $40 \mathrm{~mm} / \mathrm{h}$. 
No caso de Butantã, a taxa de precipitação máxima registrada foi de $84 \mathrm{~mm} / \mathrm{h}$ no dia 14 de janeiro o representando como um dos bairros com maior intensidade de chuva registrado no ano. Além disso, a maioria dos alagamentos ocorrem acima de $30 \mathrm{~mm}$ de chuva acumulada no dia e com taxa de precipitação maior a $10 \mathrm{~mm} / \mathrm{h}$ (Figura 5.6 b). Porém, se teve maior frequência com chuva acumulada maior que $10 \mathrm{~mm}$ e precipitação maior que $10 \mathrm{~mm} / \mathrm{h}$. Itaim Bibi teve uma taxa de precipitação máxima de $78 \mathrm{~mm} / \mathrm{h}$ no dia 14 de janeiro de 2015 nas horas da tarde. $\mathrm{O}$ bairro registrou a maioria dos alagamentos acima de $20 \mathrm{~mm}$ de chuva acumulada no dia com taxa de precipitação maior $20 \mathrm{~mm} / \mathrm{h}$ (Figura $5.6 \mathrm{c}$ ). Observamos também, que os alagamentos são mais recorrentes nos intervalos de 10 a $40 \mathrm{~mm}$ de chuva e de 10 a $60 \mathrm{~mm} / \mathrm{h}$ de intensidade de precipitação.

a) Barra Funda

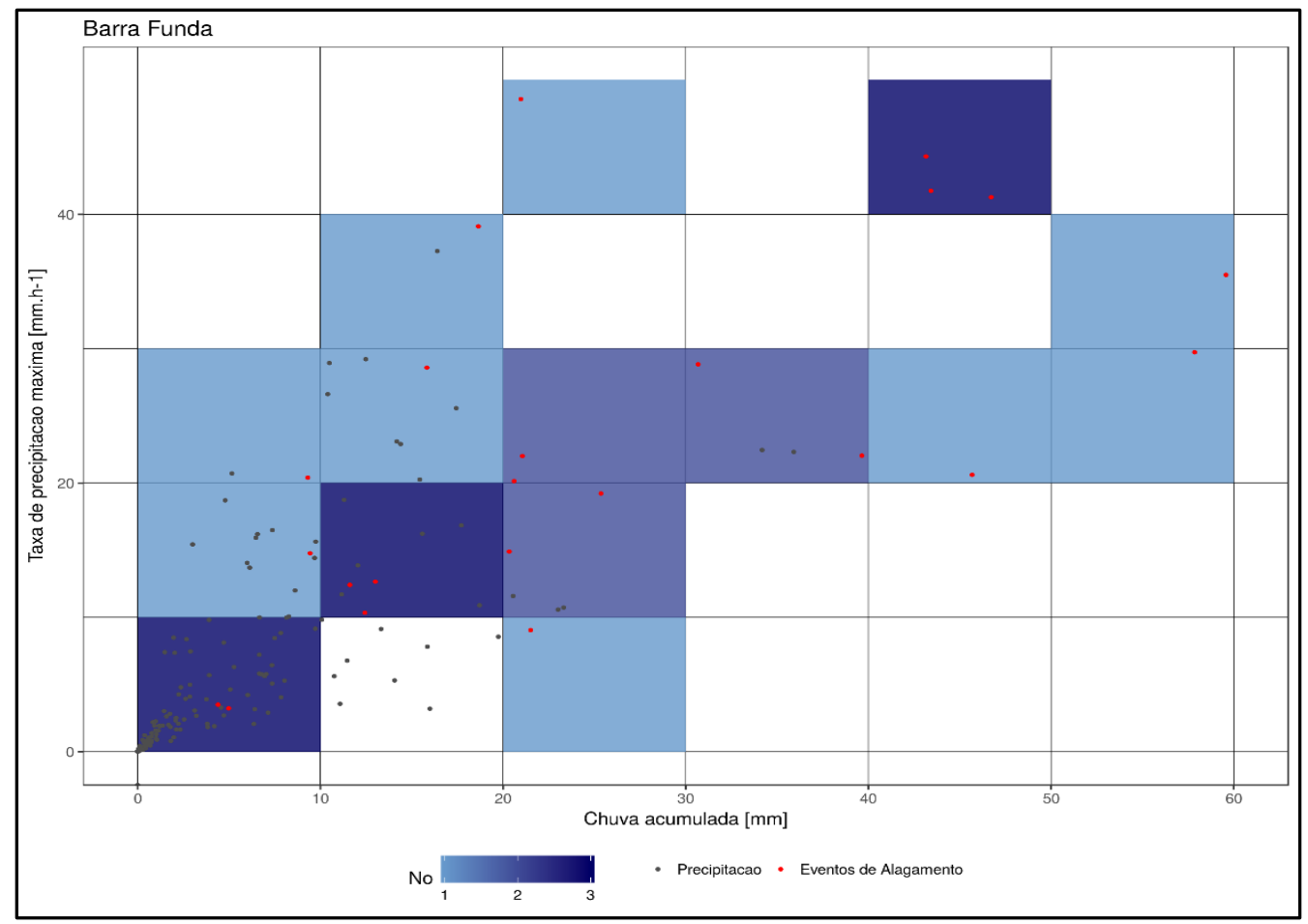




\section{b) Butantã}

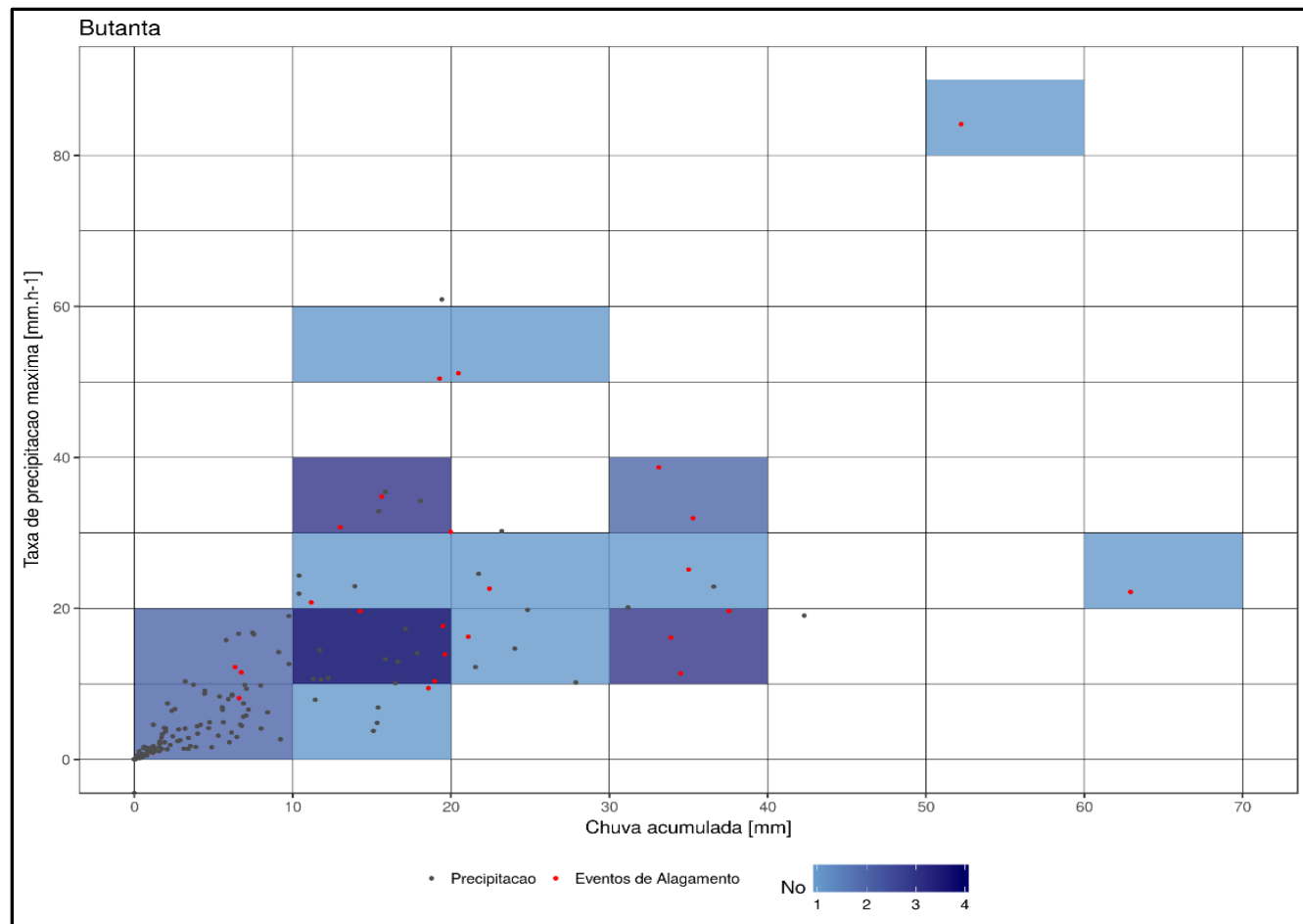

c) Itaim Bibi

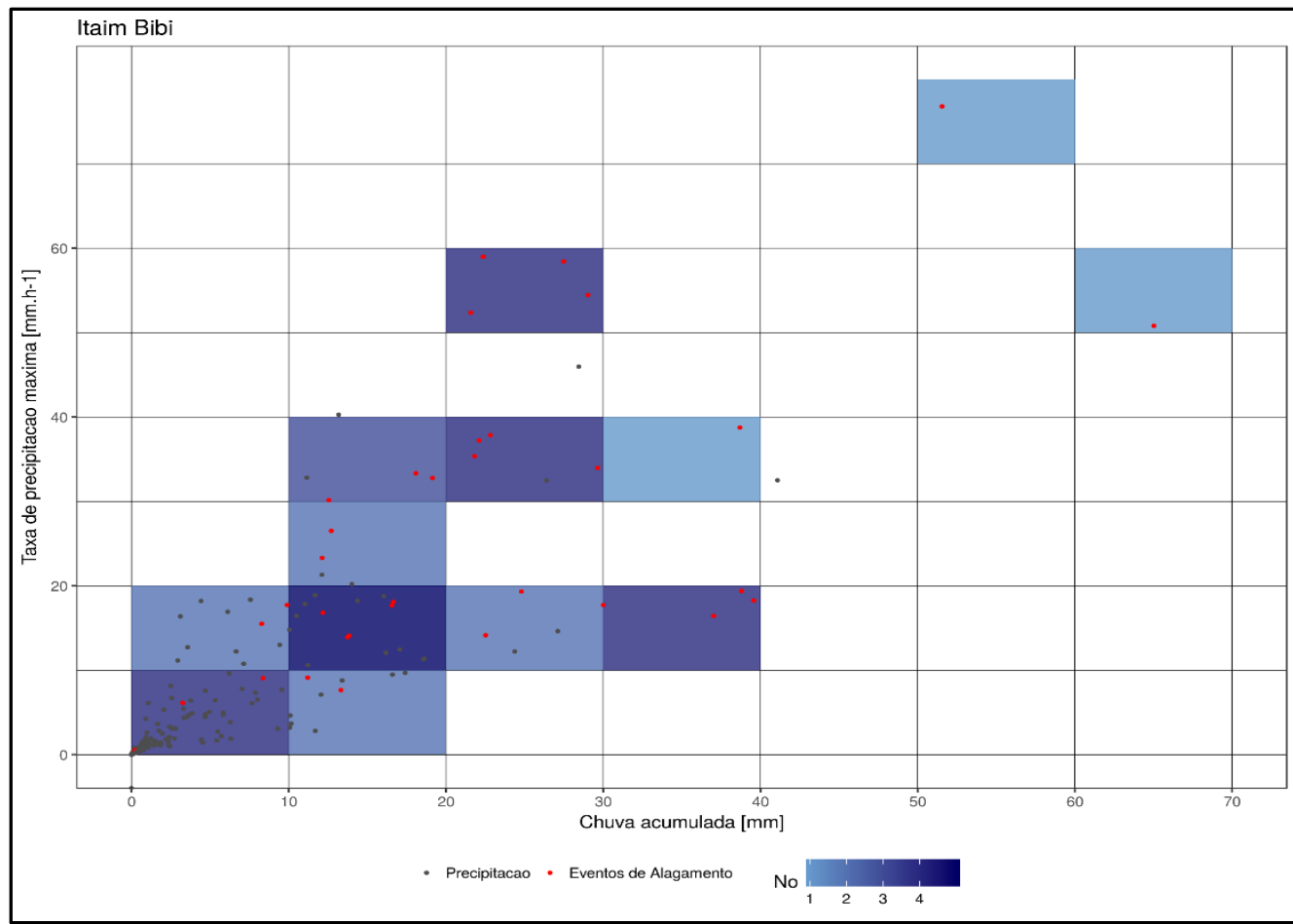

Figura 5.6. Gráfico de frequência e dispersão entre a chuva acumulada e a taxa de precipitação máxima por dia - ano 2015 nos bairros de Barra Funda, Butantã e Itaim Bibi 


\subsubsection{Fração da área de chuva vs Chuva acumulada}

A fração da área de chuva foi calculada para as escalas espaciais (n) com precipitações acima de 30, 40 e $50 \mathrm{~mm} / \mathrm{h}$, em relação à área de cada bairro, assim como se mostra na equação:

$$
\text { Fraçao }=\frac{\text { número de pixels com taxa de precipitaçao }>n}{\text { número total de pixels no bairro }}
$$

Logo para a análise, a precipitação média de cada fração foi acumulada em 10 minutos separando os instantes que tiveram alagamento, desde seu tempo inicial até a água ter se filtrado. Para este caso, foram escolhidos os bairros de Agua Rasa, Ipiranga e Santana e na tabela 5.6 se resumem as características dos bairros.

Observamos na tabela 5.6, que para os três bairros a duração média dos eventos foi de 9 horas e a área media é $16,7 \mathrm{~km}^{2}$. O bairro de Santana, localizado na região norte e na proximidade do rio Tietê, registrou 46 dias com alagamentos durante o ano, maior em comparação com os bairros de Agua Rasa e Ipiranga que registraram 12 e 16 dias, respectivamente. No entanto, a intensidade da chuva máxima registrada no ano para o bairro de Santana (46 mm/h) foi menor comparado com os bairros de Ipiranga e Agua Rasa, que estão localizados mais para o sul da cidade.

\begin{tabular}{|c|c|c|c|c|c|}
\hline Bairro & $\begin{array}{c}\text { Volume de chuva } \\
\text { total no ano [mm] }\end{array}$ & $\begin{array}{c}\text { Intensidade } \\
\text { máx. (Rmáx) } \\
{[\mathbf{m m} / \mathbf{h}]}\end{array}$ & $\begin{array}{c}\text { Número de } \\
\text { dias com } \\
\text { alagamento }\end{array}$ & $\begin{array}{c}\text { Duração média } \\
\text { de chuva [h] }\end{array}$ & $\begin{array}{c}\text { Área do } \\
\text { bairro [km2] }\end{array}$ \\
\hline Agua Rasa & 1605 & 99 & 12 & 9 & 12,33 \\
\hline Ipiranga & 1668 & 110 & 16 & 9,6 & 19,45 \\
\hline Santana & 1570 & 46 & 41 & 9 & 18,37 \\
\hline
\end{tabular}

Tabela 5.6. Propriedades espaciais e temporais das chuvas e dos eventos de alagamento para os bairros de Agua Rasa, Ipiranga e Santana no ano 2015 para os bairros de Agua Rasa, Ipiranga e Santana

Na figura 5.7 é apresentado a distribuição da fração da área de chuva no bairro (em porcentagem) em relação à chuva acumulada média aos 10 minutos para precipitações maiores a $30 \mathrm{~mm} / \mathrm{h}$, onde os pontos vermelhos representam os eventos de alagamento. Já na 
figura 5.8 estão as funções de densidade de probabilidade da fração de chuva caso a precipitação seja maior a $30 \mathrm{~mm} / \mathrm{h}$ e maior a $50 \mathrm{~mm} / \mathrm{h}$ para os bairros de (a) Agua Rasa, (b) Ipiranga e (c) Santana. A figura também diferença os eventos (1) com alagamento, representada pela cor azul e (2) sem alagamento, representado pela cor preta. A forma da PDF é mesma de uma distribuição normal e a linha ponteada representa a média dos dados

Por tanto, vemos que a maior parte dos alagamentos registrados no bairro de Agua Rasa (Figura 5.7 a) cobrem o 50\% da área do bairro, com um volume de chuva de 10mm aproximadamente nos 10 minutos. Além disso, tem-se casos que o bairro é coberto em sua totalidade com um volume de chuva maior aos $10 \mathrm{~mm}$ sem registrar alagamento. Na figura 5.8a, considerando só os instantes com alagamento, mostra uma média de $20 \%$ da área do bairro de Agua Rasa coberto por precipitações maiores a $30 \mathrm{~mm} / \mathrm{h}$ e $12 \%$ da área por precipitações maiores a $50 \mathrm{~mm} / \mathrm{h}$ (Figura 5.8 b) com uma probabilidade de ocorrência de $22 \%$ e $52 \%$, respectivamente.

No caso do bairro de Ipiranga, figura 5.7b, a distribuição da precipitação é mais dispersa, abrangendo maior parte do bairro com acumulados de chuva que atingem os $16 \mathrm{~mm}$ aproximadamente. Observa-se que em dos eventos de alagamento, o bairro ocupou o $50 \%$ da área do bairro com um volume médio de chuva em torno dos $10 \mathrm{~mm}$, no entanto a maioria deles alcançou apenas o $25 \%$ da área do bairro. Constatamos nas figuras $5.8 \mathrm{c}-5.8 \mathrm{~d}$ que a média da fração da área de chuva para precipitações maiores a $30 \mathrm{~mm} / \mathrm{h}$ foi de $15 \%$ da área do bairro e para as precipitações maiores a $50 \mathrm{~mm} / \mathrm{h}$ foi de $35 \%$ com probabilidade de ocorrência de $20 \%$ e $64 \%$, nessa ordem.

Observamos que o bairro de Santana, um dos bairros com maior número de dias com alagamento, apresenta na figura 5.7c precipitações que abrangem quase a totalidade da área do bairro com volumes de chuva que vão entre os $6 \mathrm{~mm}$ e $14 \mathrm{~mm}$. Parte dos alagamentos registrados ocupam mais do $50 \%$ da área com volumes maiores aos $9 \mathrm{~mm}$ de chuva. E nas figuras 5.8e - 5.8f se mostram as medias das frações da área do bairro em relação ás precipitações maiores a $30 \mathrm{~mm} / \mathrm{h}$ com $20 \%$ e precipitações maiores a $50 \mathrm{~mm} / \mathrm{h}$ com $15 \%$ e probabilidades de ocorrência de $20 \%$ e $20,5 \%$, respectivamente. 
a) Agua Rasa

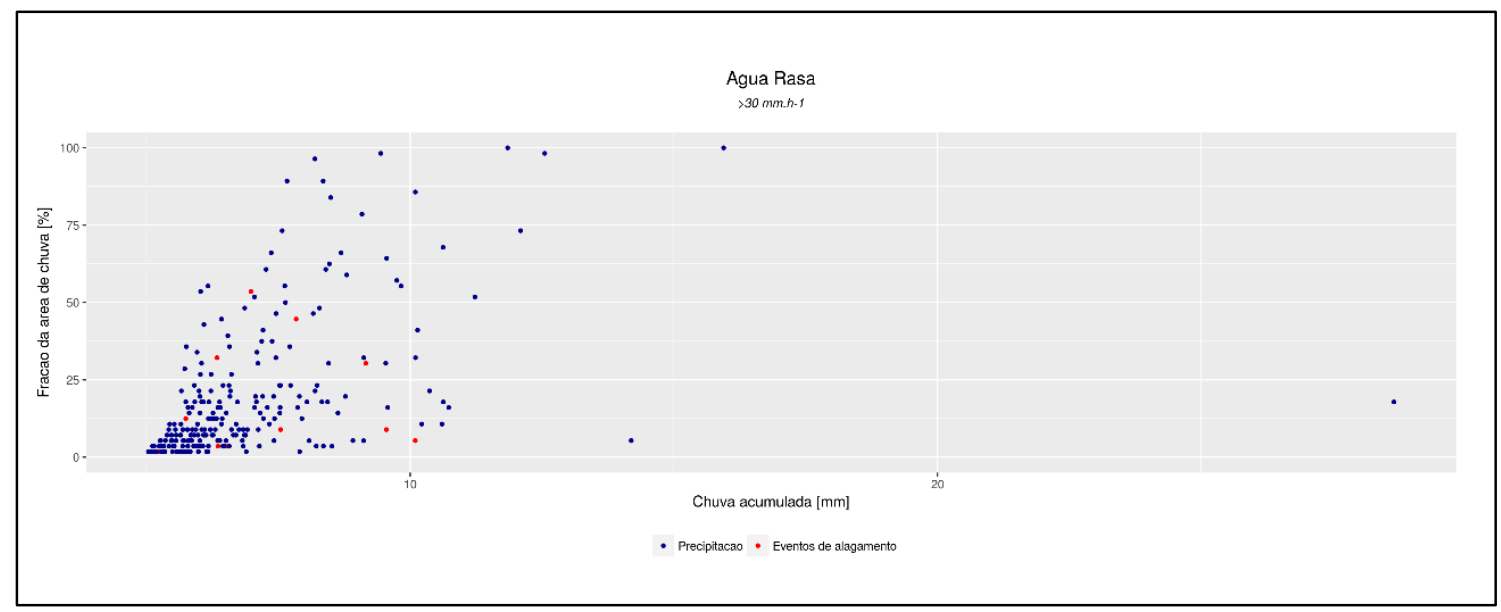

b) Ipiranga

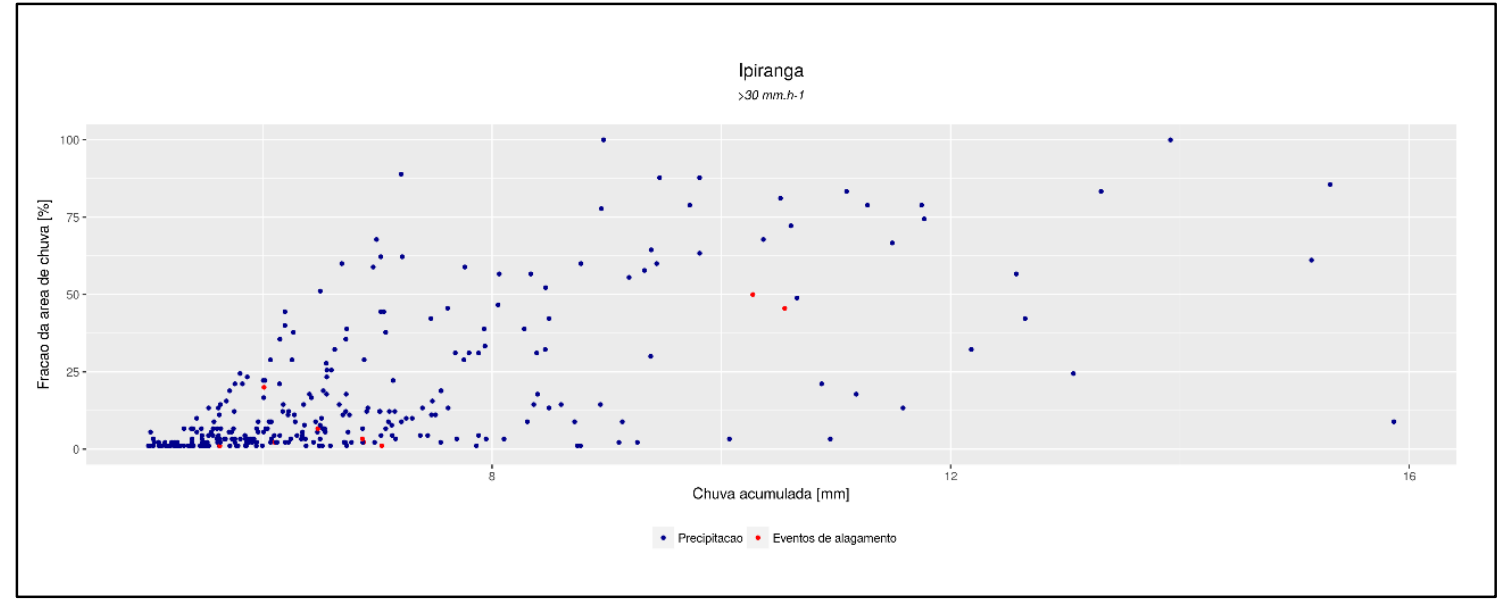

c) Santana

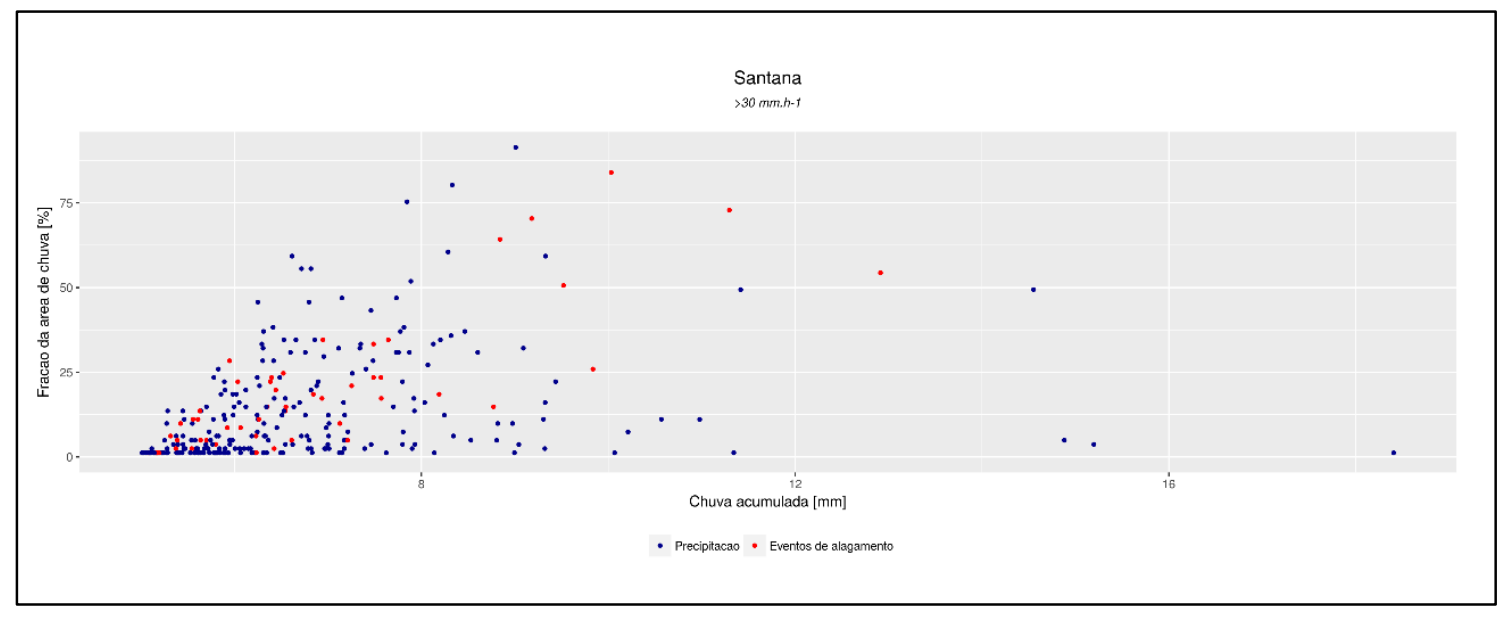

Figura 5.7. Comparação da fração da área de chuva nos bairros de (a) Agua Rasa, (b) Ipiranga $e$ (c) Santana em relação à chuva acumulada média na escala temporal de 10 minutos. 
a) Agua Rasa - 30mm/h

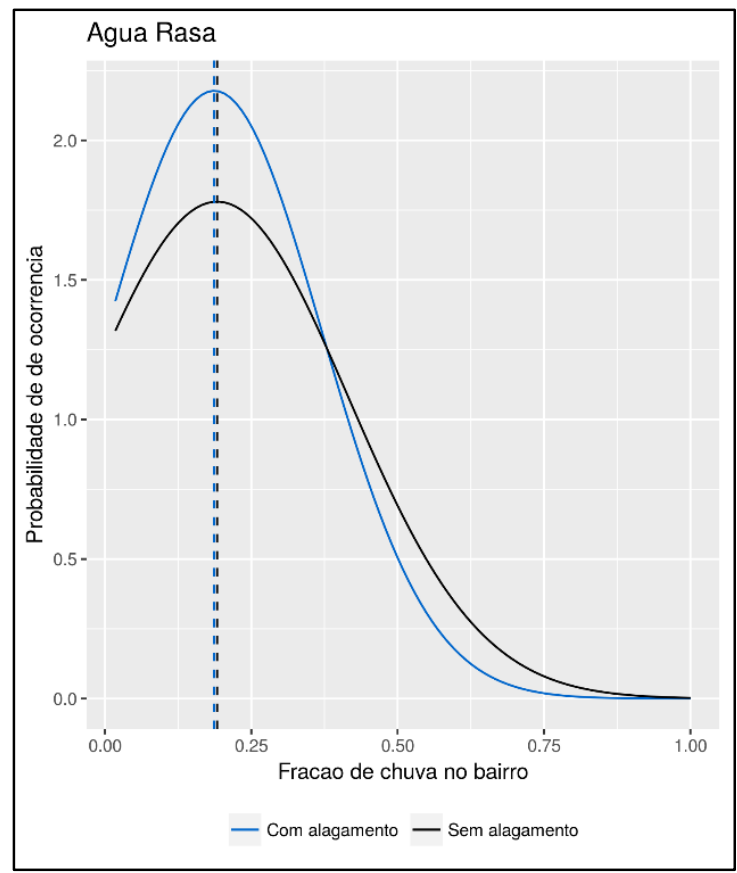

c) Ipiranga - $30 \mathrm{~mm} / \mathrm{h}$

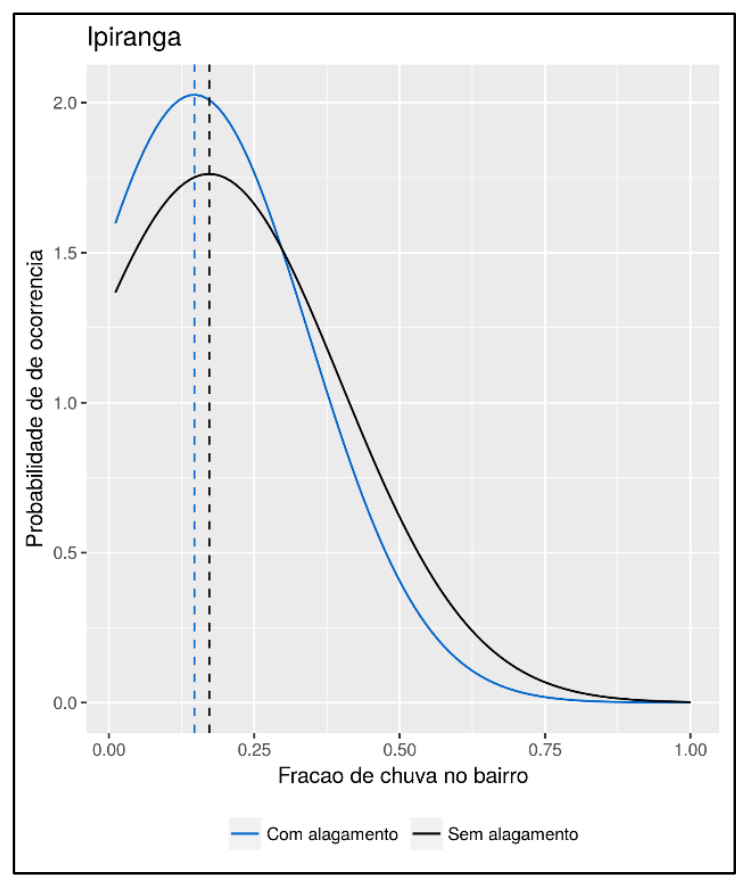

b) Agua Rasa - 50mm/h

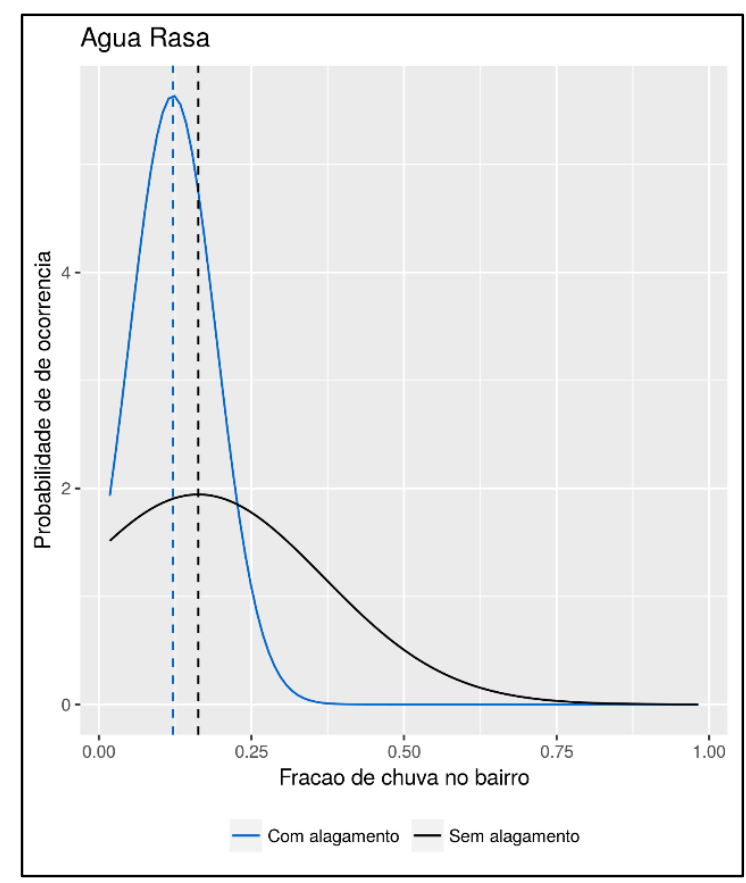

d) Ipiranga - $50 \mathrm{~mm} / \mathrm{h}$

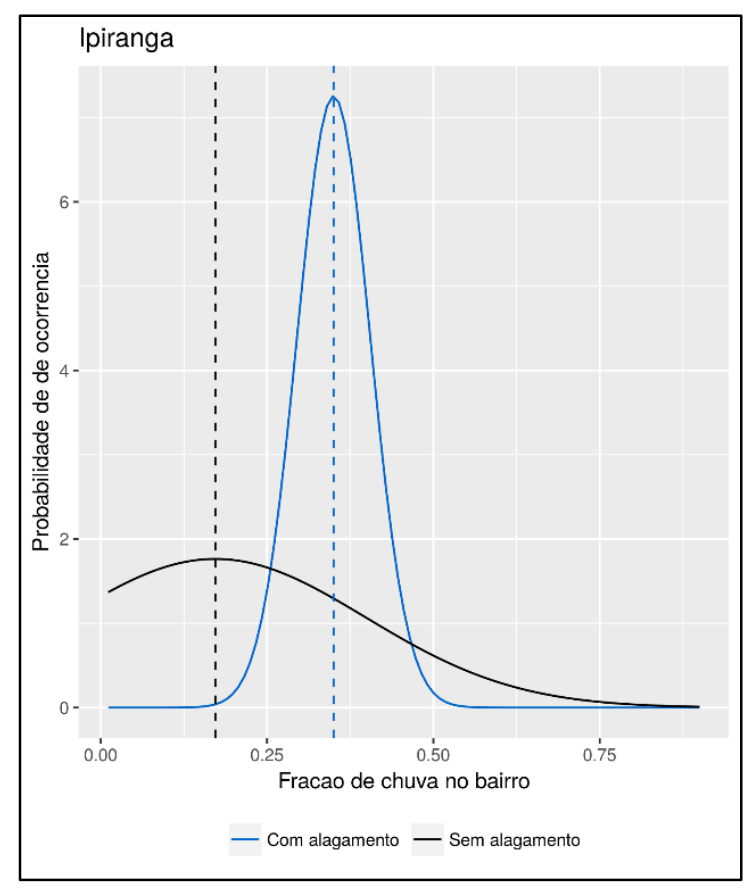


e) Santana $-30 \mathrm{~mm} / \mathrm{h}$

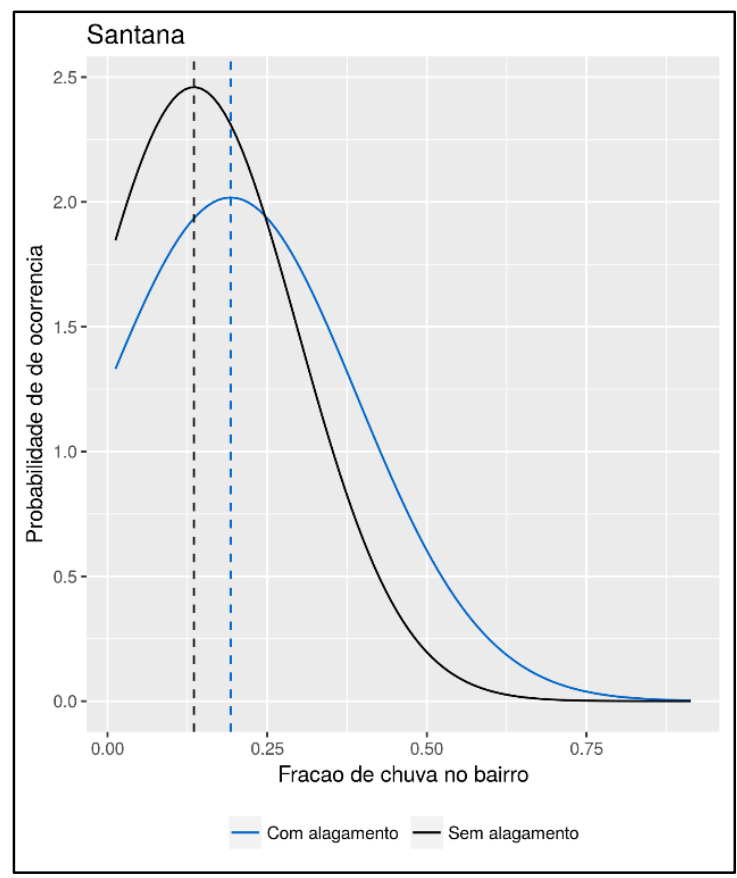

f) Santana $-50 \mathrm{~mm} / \mathrm{h}$

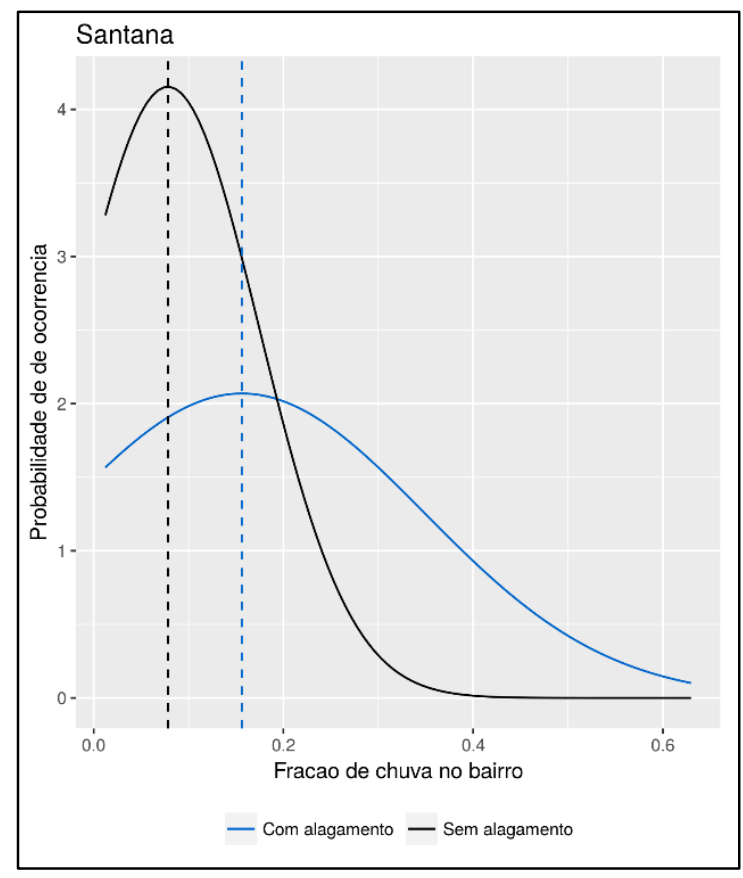

Figura 5.8. Função Densidade de Probabilidade da fração da área de chuva para os bairros de Agua Rasa com precipitações maiores a 30mm/h (a) e 50mm/h (b), Ipiranga (c) e (d) e Santana (e) $e(f)$ para eventos com alagamento (linha azul) e sem alagamento (linha preta); as linhas ponteadas representam o valor médio.

\subsubsection{Resumo}

A partir de cada uma das análises foi determinado um padrão diário de probabilidade de ocorrência de alagamento para os bairros da cidade de São Paulo, que se resume na tabela 5.7. Porém, deve ser enfatizado que não foi factível de se obter um padrão de alagamento em alguns bairros da cidade, devido a (1) não registraram eventos de alagamento no ano 2015 ou (2) registraram só 1 evento de alagamento. Observamos também, que na última coluna se resume o padrão médio de alagamento, obtida para o volume de chuva e a intensidade da precipitação máxima no dia.

A figura 5.9 representa espacialmente o padrão médio de alagamento da intensidade da chuva máxima obtido nos bairros da cidade de São Paulo. A diferença de cores mostra os padrões por intervalos que vão desde os $10 \mathrm{~mm} / \mathrm{h}$ até os $55 \mathrm{~mm} / \mathrm{h}$, sendo que os bairros nos intervalos com menor intensidade são os mais vulneráveis para ocorrência de alagamento. Portanto, os bairros de Jardim Helena, Vila Curuçá, Grajaú, Jaraguá, Bom Retiro 
e Santana são os bairros com maior vulnerabilidade e probabilidade de alagamento entre os 10 e $20 \mathrm{~mm} / \mathrm{h}$.

\begin{tabular}{|c|c|c|c|c|c|c|c|c|c|c|c|}
\hline \multirow[t]{2}{*}{$\begin{array}{l}\mathbf{N} \\
\mathbf{0}\end{array}$} & \multirow[t]{2}{*}{ Bairro } & \multirow{2}{*}{$\begin{array}{l}\text { PDF - } \\
\text { R máx. } \\
\text { [mm/h] }\end{array}$} & \multirow{2}{*}{$\begin{array}{r}\text { Prob } \\
{[\%]} \\
\end{array}$} & \multirow{2}{*}{$\begin{array}{c}\begin{array}{c}\text { PDF - } \\
\text { Volume } \\
\text { de chuva } \\
\text { total no } \\
\text { ano }\end{array} \\
\text { [mm }]\end{array}$} & \multirow{2}{*}{\begin{tabular}{|c|} 
Prob \\
{$[\%]$} \\
\end{tabular}} & \multicolumn{2}{|c|}{$\begin{array}{c}\text { Chuva } \\
\text { acumulada vs } \\
\text { Duração }\end{array}$} & \multicolumn{2}{|c|}{$\begin{array}{c}\text { Chuva } \\
\text { acumulada vs } \\
\text { R máx. }\end{array}$} & \multirow{2}{*}{$\begin{array}{c}\text { Padrão } \\
\text { Médio da } \\
\text { Intensidad } \\
\text { e máx. de } \\
\text { chuva }\end{array}$} & \multirow{2}{*}{$\begin{array}{c}\begin{array}{c}\text { Padrão } \\
\text { Médio da } \\
\text { chuva } \\
\text { acumulada }\end{array} \\
\text { [mm] }\end{array}$} \\
\hline & & & & & & [mm] & {$[\mathbf{h}]$} & {$[\mathrm{mm}]$} & {$[\mathrm{mm} / \mathrm{h}]$} & & \\
\hline 1 & Agua Rasa & 25 & 19 & 30 & 25 & 30 & 8 a 18 & 35 & 20 & 22,50 & 31,67 \\
\hline 2 & \begin{tabular}{|l|} 
Alto de \\
Pinheiros \\
\end{tabular} & 40 & 14 & 30 & 53 & 35 & 5 a 14 & & & 40,00 & 32,50 \\
\hline 3 & Anhanguera & & & & & & & & & & \\
\hline 4 & Aricanduva & 35 & 24 & 25 & 26 & & & & & 35,00 & 25,00 \\
\hline 5 & Artur Alvim & 40 & 28 & 30 & 22 & 40 & 6 a 19 & 40 & 40 & 40,00 & 36,67 \\
\hline 6 & Barra Funda & 20 & 32 & 25 & 25 & 20 & 4 a 20 & 25 & 20 & 20,00 & 23,33 \\
\hline 7 & Bela Vista & 25 & 20 & 20 & 23 & & & & & 25,00 & 20,00 \\
\hline 8 & Belém & 30 & 12 & 25 & 23 & 25 & 4 a 21 & 25 & 20 & 25,00 & 25,00 \\
\hline 9 & Bom Retiro & 15 & 27 & 20 & 26 & 20 & 7 a 21 & 20 & 10 & 12,50 & 20,00 \\
\hline 10 & Brás & 20 & 24 & 25 & 19 & 40 & 8 a 13 & & & 20,00 & 32,50 \\
\hline 11 & Brasilândia & 30 & 19 & 30 & 21 & & & & & 30,00 & 30,00 \\
\hline 12 & Butantã & 20 & 23 & 20 & 28 & 20 & 6 a 20 & 30 & 20 & 20,00 & 23,33 \\
\hline 13 & Cachoeirinha & 25 & 20 & 25 & 24 & & & & & 25,00 & 25,00 \\
\hline 14 & Cambuci & 35 & 17 & 20 & 29 & & & & & 35,00 & 20,00 \\
\hline 15 & Campo Belo & 40 & 16 & 25 & 25 & 35 & 3 a 20 & 35 & 60 & 50,00 & 31,67 \\
\hline 16 & $\begin{array}{l}\text { Campo } \\
\text { Grande }\end{array}$ & 20 & 17 & 20 & 22 & 35 & 3 a 21 & 40 & 20 & 20,00 & 31,67 \\
\hline 17 & \begin{tabular}{|l|} 
Campo \\
Limpo
\end{tabular} & 40 & 21 & 35 & 33 & & & & & 40,00 & 35,00 \\
\hline 18 & Cangaiba & 25 & 91 & 30 & 17 & & & & & 25,00 & 30,00 \\
\hline 19 & \begin{tabular}{|l|} 
Capão \\
Redondo
\end{tabular} & 40 & 14 & 30 & 20 & & & & & 40,00 & 30,00 \\
\hline 20 & Carrão & 45 & 15 & 25 & 32 & & & & & 45,00 & 25,00 \\
\hline 21 & Casa Verde & 30 & 13 & 25 & 12 & & & & & 30,00 & 25,00 \\
\hline 22 & $\begin{array}{l}\text { Cidade } \\
\text { Ademar }\end{array}$ & & & & & & & & & & \\
\hline 23 & Cidade Dutra & 20 & 19 & 25 & 16 & 50 & 4 a 21 & 50 & 20 & 20,00 & 41,67 \\
\hline 24 & Cidade Líder & 30 & 23 & 25 & 32 & & & & & 30,00 & 25,00 \\
\hline 25 & \begin{tabular}{|l|} 
Cidade \\
Tiradentes
\end{tabular} & & & & & & & & & & \\
\hline 26 & Consolação & 20 & 30 & 35 & 18 & 40 & 12 a 19 & 40 & 20 & 20,00 & 38,33 \\
\hline 27 & Cursino & 35 & 24 & 30 & 27 & 30 & 6 a 20 & 30 & 35 & 35,00 & 30,00 \\
\hline 28 & $\begin{array}{l}\text { Ermelino } \\
\text { Matarazzo } \\
\end{array}$ & & & & & & & & & 20,00 & 5,00 \\
\hline 29 & $\begin{array}{l}\text { Freguesia do } \\
\text { O }\end{array}$ & 20 & 28 & 20 & 24 & & & & & 20,00 & 20,00 \\
\hline
\end{tabular}




\begin{tabular}{|c|c|c|c|c|c|c|c|c|c|c|c|}
\hline \multirow[t]{2}{*}{ No } & \multirow[t]{2}{*}{ Bairro } & \multirow{2}{*}{$\begin{array}{c}\text { PDF - R } \\
\text { máx. } \\
{[\mathrm{mm} / \mathbf{h}]}\end{array}$} & \multirow{2}{*}{$\begin{array}{l}\text { Prob } \\
{[\%]}\end{array}$} & \multirow{2}{*}{$\begin{array}{c}\text { PDF - } \\
\text { Vol. de } \\
\text { chuva } \\
\text { total n } \\
\text { ano } \\
{[\mathrm{mm}]}\end{array}$} & \multirow{2}{*}{$\begin{array}{c}\text { Prob } \\
{[\%]}\end{array}$} & \multicolumn{2}{|c|}{$\begin{array}{c}\text { Chuva } \\
\text { acumulada vs } \\
\text { Duração }\end{array}$} & \multicolumn{2}{|c|}{$\begin{array}{c}\text { Chuva } \\
\text { acumulada vs } R \\
\text { máx. }\end{array}$} & \multirow{2}{*}{$\begin{array}{r}\text { Padrão } \\
\text { Médio da } \\
\text { Intensidade } \\
\text { máx. de } \\
\text { chuva } \\
{[\mathrm{mm} / \mathrm{h}]}\end{array}$} & \multirow{2}{*}{$\begin{array}{r}\text { Padrão } \\
\text { Médio da } \\
\text { chuva } \\
\text { acumulada } \\
{[\mathrm{mm}]}\end{array}$} \\
\hline & & & & & & [mm] & [h] & {$[\mathrm{mm}]$} & {$[\mathrm{mm} / \mathrm{h}]$} & & \\
\hline 30 & Grajau & 10 & 76 & 25 & 23 & & & & & 10,00 & 25,00 \\
\hline 31 & Guaianases & 50 & 84 & 25 & 26 & & & & & 50,00 & 25,00 \\
\hline 32 & Iguatemi & 20 & 24 & 20 & 41 & & & & & 20,00 & 20,00 \\
\hline 33 & Ipiranga & 40 & 14 & 30 & 14 & 40 & 6 a 20 & 30 & 45 & 42,50 & 33,33 \\
\hline 34 & Itaim Bibi & 25 & 22 & 20 & 29 & 20 & 3 a 21 & 20 & 20 & 22,50 & 20,00 \\
\hline 35 & $\begin{array}{l}\text { Itaim } \\
\text { Paulista }\end{array}$ & 45 & 71 & 45 & 78 & & & & & 45,00 & 45,00 \\
\hline 36 & Itaquera & 40 & 17 & 30 & 21 & 40 & 6 a 20 & 35 & 60 & 50,00 & 35,00 \\
\hline 37 & Jabaquara & 25 & 28 & 20 & 51 & & & & & 25,00 & 20,00 \\
\hline 38 & Jacana & 30 & 59 & 30 & 46 & & & & & 30,00 & 30,00 \\
\hline 39 & Jaguará & 40 & 14 & 30 & 20 & & & & & 40,00 & 30,00 \\
\hline 40 & Jaguaré & 40 & 13 & 25 & 26 & & & & & 40,00 & 25,00 \\
\hline 41 & Jaraguá & 10 & 45 & 20 & 31 & & & & & 10,00 & 20,00 \\
\hline 42 & $\begin{array}{l}\text { Jardim } \\
\text { Ângela }\end{array}$ & 35 & 16 & 30 & 25 & & & & & 35,00 & 30,00 \\
\hline 43 & $\begin{array}{l}\text { Jardim } \\
\text { Helena }\end{array}$ & 35 & 10 & & & & & & & 35,00 & \\
\hline 44 & \begin{tabular}{|l|} 
Jardim \\
Paulista
\end{tabular} & 25 & 25 & 20 & 23 & & & & & 25,00 & 20,00 \\
\hline 45 & $\begin{array}{l}\text { Jardim São } \\
\text { Luís }\end{array}$ & 25 & 18 & 30 & 22 & & & & & 25,00 & 30,00 \\
\hline 46 & $\begin{array}{l}\text { Jose } \\
\text { Bonifácio } \\
\end{array}$ & 50 & 48 & 25 & 48 & & & & & 50,00 & 25,00 \\
\hline 47 & Lajeado & & & & & & & & & & \\
\hline 48 & Lapa & 25 & 22 & 25 & 19 & & & & & 25,00 & 25,00 \\
\hline 49 & Liberdade & 35 & 20 & 30 & 21 & 30 & 2 a 16 & 35 & 20 & 27,50 & 31,67 \\
\hline 50 & Limão & 20 & 32 & 25 & 25 & 45 & 7 a 16 & & & 20,00 & 35,00 \\
\hline 51 & Mandaqui & & & & & & & & & & \\
\hline 52 & Marsilac & & & & & & & & & & \\
\hline 53 & Moema & 35 & 15 & 25 & 23 & & & 30 & 60 & 47,50 & 27,50 \\
\hline 54 & Mooca & 35 & 10 & 30 & 16 & 35 & 8 a 14 & 35 & 40 & 37,50 & 33,33 \\
\hline 55 & Morumbi & 25 & 20 & 20 & 28 & 20 & 5 a 21 & 20 & 20 & 22,50 & 20,00 \\
\hline 56 & Parelheiros & & & 25 & 22 & & & & & 5,00 & 25,00 \\
\hline 57 & Pari & 30 & 18 & 30 & 21 & & & & & 30,00 & 30,00 \\
\hline 58 & $\begin{array}{l}\text { Parque do } \\
\text { Carmo }\end{array}$ & 45 & 26 & 25 & 28 & & & & & 45,00 & 25,00 \\
\hline 59 & Pedreira & & & & & & & & & & \\
\hline 60 & Penha & 30 & 18 & 25 & 35 & 35 & 6 a 19 & 35 & 25 & 27,50 & 31,67 \\
\hline 61 & Perdizes & 20 & 28 & 25 & 21 & 35 & 11 a 16 & & & 20,00 & 30,00 \\
\hline 62 & Perus & & & & & & & & & & \\
\hline 63 & Pinheiros & 25 & 21 & 20 & 26 & 30 & 4 a 20 & & & 25,00 & 25,00 \\
\hline
\end{tabular}




\begin{tabular}{|c|c|c|c|c|c|c|c|c|c|c|c|}
\hline \multirow[t]{2}{*}{ No } & \multirow[t]{2}{*}{ Bairro } & \multirow{2}{*}{$\begin{array}{c}\text { PDF - R } \\
\text { máx. } \\
{[\mathrm{mm} / \mathbf{h}]}\end{array}$} & \multirow{2}{*}{$\begin{array}{l}\text { Prob } \\
{[\%]}\end{array}$} & \multirow{2}{*}{ 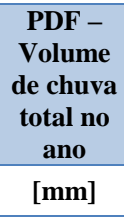 } & \multirow{2}{*}{$\begin{array}{l}\text { Prob } \\
\text { [\%] }\end{array}$} & \multicolumn{2}{|c|}{$\begin{array}{c}\text { Chuva } \\
\text { acumulada vs } \\
\text { Duração }\end{array}$} & \multicolumn{2}{|c|}{$\begin{array}{c}\text { Chuva } \\
\text { acumulada vs } R \\
\text { máx. }\end{array}$} & \multirow{2}{*}{$\begin{array}{r}\text { Padrão } \\
\text { Médio da } \\
\text { Intensidade } \\
\text { máx. de } \\
\text { chuva } \\
{[\mathrm{mm} / \mathrm{h}]}\end{array}$} & \multirow{2}{*}{$\begin{array}{r}\text { Padrão } \\
\text { Médio da } \\
\text { chuva } \\
\text { acumulada } \\
\text { [mm] }\end{array}$} \\
\hline & & & & & & [mm] & {$[\mathbf{h}]$} & {$[\mathrm{mm}]$} & {$[\mathrm{mm} / \mathrm{h}]$} & & \\
\hline 64 & Pirituba & 25 & 27 & 35 & 22 & & & & & 25,00 & 35,00 \\
\hline 65 & Ponte Rasa & 45 & 57 & 30 & 23 & & & & & 45,00 & 30,00 \\
\hline 66 & $\begin{array}{l}\text { Raposo } \\
\text { Tavares }\end{array}$ & 25 & 24 & 40 & 25 & & & & & 25,00 & 40,00 \\
\hline 67 & Republica & 20 & 29 & 20 & 27 & 20 & 6 a 19 & 25 & 20 & 20,00 & 21,67 \\
\hline 68 & Rio Pequeno & 25 & 14 & 40 & 16 & 60 & 6 a 19 & 60 & 20 & 22,50 & 53,33 \\
\hline 69 & Sacomã & 25 & 30 & 25 & 61 & & & & & 25,00 & 25,00 \\
\hline 70 & Santa Cecilia & 15 & 32 & 20 & 27 & 20 & 7 a 21 & 20 & 20 & 17,50 & 20,00 \\
\hline 71 & Santana & 15 & 34 & 20 & 29 & 20 & 4 a 21 & 20 & 10 & 12,50 & 20,00 \\
\hline 72 & Santo Amaro & 25 & 18 & 25 & 26 & 35 & 4 a 21 & 35 & 20 & 22,50 & 31,67 \\
\hline 73 & $\begin{array}{l}\text { São } \\
\text { Domingos }\end{array}$ & 20 & 25 & 35 & 22 & & & & & 20,00 & 35,00 \\
\hline 74 & São Lucas & 25 & 23 & 25 & 16 & 50 & 13 a 19 & & & 25,00 & 37,50 \\
\hline 75 & São Mateus & & & & & & & & & & \\
\hline 76 & São Miguel & & & & & & & & & & \\
\hline 77 & São Rafael & & & & & & & & & & \\
\hline 78 & Sapopemba & & & & & & & & & & \\
\hline 79 & Saúde & 40 & 18 & 25 & 27 & & & 30 & 60 & 50,00 & 27,50 \\
\hline 80 & Se & 20 & 24 & 20 & 25 & 30 & 8 a 15 & 30 & 20 & 20,00 & 26,67 \\
\hline 81 & Socorro & 30 & 12 & 30 & 15 & 50 & 4 a 21 & 50 & 20 & 25,00 & 43,33 \\
\hline 82 & Tatuapé & 30 & 16 & 25 & 23 & 35 & 6 a 20 & 35 & 20 & 25,00 & 31,67 \\
\hline 83 & Tremembé & 20 & 33 & 30 & 100 & & & & & 20,00 & 30,00 \\
\hline 84 & Tucuruvi & 25 & 93 & 45 & 41 & & & & & 25,00 & 45,00 \\
\hline 85 & Vila Andrade & 30 & 20 & 35 & 33 & & & & & 30,00 & 35,00 \\
\hline 86 & Vila Curuçá & 40 & 10 & & & & & & & 40,00 & \\
\hline 87 & Vila Formosa & 50 & 14 & 35 & 58 & & & & & 50,00 & 35,00 \\
\hline 88 & V Guilherme & 20 & 30 & 20 & 26 & 30 & 4 a 19 & 30 & 30 & 25,00 & 26,67 \\
\hline 89 & Vila Jacuí & & & & & & & & & & \\
\hline 90 & V Leopoldina & 35 & 16 & 25 & 26 & & & & & 35,00 & 25,00 \\
\hline 91 & Vila Maria & 25 & 20 & 20 & 25 & 30 & 6 a 19 & 30 & 30 & 27,50 & 26,67 \\
\hline 92 & Vila Mariana & 40 & 16 & 25 & 26 & 35 & 3 a 19 & 40 & 40 & 40,00 & 33,33 \\
\hline 93 & Vila Matilde & 40 & 17 & 25 & 47 & 30 & 6 a 16 & 35 & 50 & 45,00 & 30,00 \\
\hline 94 & V Medeiros & & & & & & & & & & \\
\hline 95 & \begin{tabular}{|l|} 
Vila \\
Prudente \\
\end{tabular} & 40 & 16 & 35 & 10 & & & & & 40,00 & 35,00 \\
\hline 96 & Vila Sonia & 45 & 12 & 30 & 21 & 35 & 3 a 19 & 40 & 20 & 32,50 & 35,00 \\
\hline & MÉDIA & 29,9 & 26 & 26,8 & 28 & 33 & & 33 & 28,9 & 29,97 & 29,31 \\
\hline & $\sigma$ & 9,7 & 17,5 & 5,8 & 14 & $\mathbf{9 , 9}$ & & 9,2 & 14,9 & 10,55 & 29,31 \\
\hline
\end{tabular}

Tabela 5.7. Resumo dos padrões diários de cada analise para os bairros da cidade de São Paulo por dia 


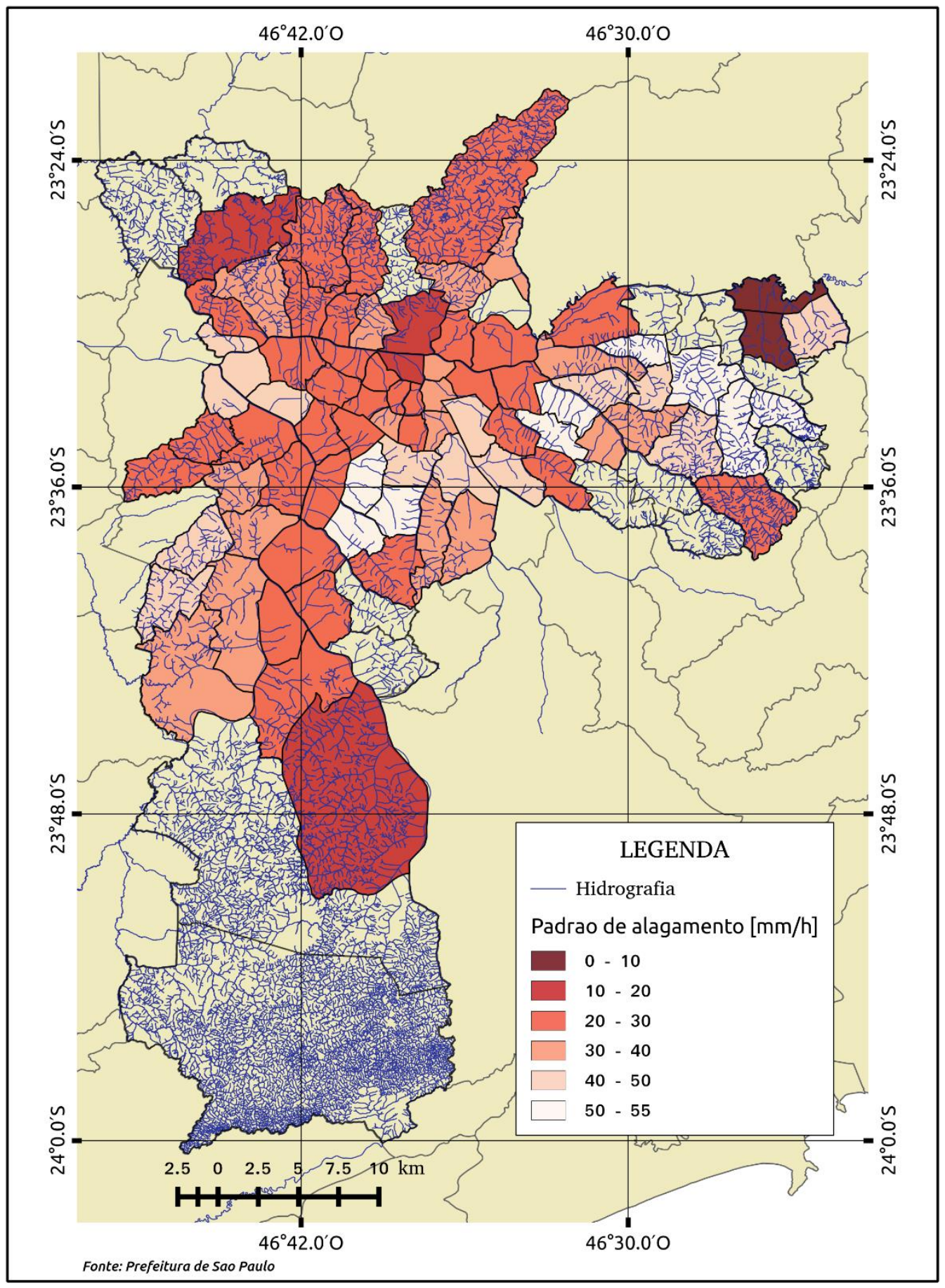

Figura 5.9. Mapa do padrão médio da probabilidade de ocorrência de alagamento de acordo com a taxa de precipitação máxima para o ano 2015 nos bairros da cidade de São Paulo. Fonte: Andrea Viteri 


\subsection{Análises dos pontos alagados nos bairros da cidade de São Paulo}

Durante o ano 2015, o CGE registrou mais de 354 pontos alagados pelo CGE em toda a cidade de São Paulo, os quais se concentraram nas regiões oeste, centro sul e centro como mostradas na figura 5.10. Alguns destes pontos tem a característica de ser recorrentes no mesmo dia, ou seja podendo apresentar num mesmo dia diversos eventos de alagamento. Neste caso, tem pontos que são distinguidos (as bolinhas maiores vermelhas e laranjas obscuras) e que representam maior recorrência, como o localizado em Bom Retiro, no centro da cidade com uma frequência de alagamento no ano de 37 vezes e no bairro de Santana com 28. Suma com eles os bairros de Republica com 27, Itaim Bibi com 26, Mooca com 23, Butantã com 21 e Saúde com 20 ocorrências de alagamento no mesmo lugar registrados no ano 2015.

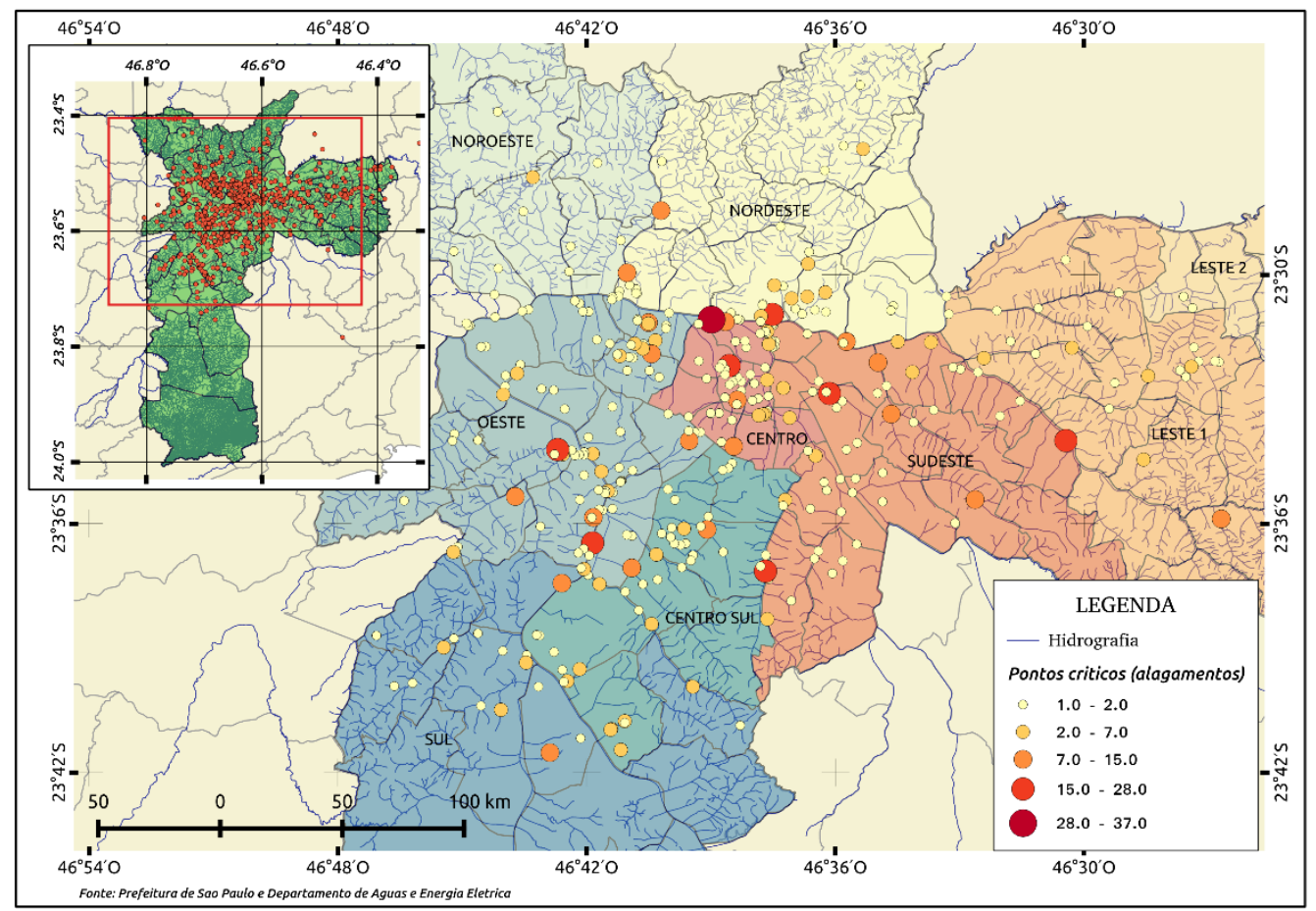

Figura 5.10. Mapa de localização dos pontos alagados e a frequência de ocorrência de alagamento durante o ano 2015 na cidade de São Paulo. Fonte: Andrea Viteri 
Além disso, observamos na figura 5.10 que maior parte dos alagamentos se concentram nas margens dos rios principias da cidade, o rio Pinheiros e Tietê e nas zonas baixas como os bairros da zona centro.

Para a análise foram escolhidos os bairros de Itaim Bibi, Bom Retiro e Santana, e no final está resumido os pontos com frequência de alagamento maior a 5, a média obtida da taxa de precipitação e média da chuva acumulada antes de se iniciar o alagamento.

O ponto crítico do bairro de Itaim Bibi se encontra nas redondezas do Rio Pinheiros e a avenida das Nações Unidas. Na figura 5.11, se expõem dois casos de precipitação ocorridos no ano, para o mês de janeiro e fevereiro que foram os meses que apresentaram maior número de alagamentos. Nos dias com alagamento, 26 e 27 de janeiro, foi registrado um acumulado de $13 \mathrm{~mm}$ de chuva em 11 horas e $10 \mathrm{~mm}$ em 6 horas, respectivamente. Os alagamentos ocorreram por volta das 4 horas da manhã no dia 26 e às 22:00 HL no dia 27 e com taxa de precipitação de $8 \mathrm{~mm} / \mathrm{h}$ e $6 \mathrm{~mm} / \mathrm{h}$ nesse mesmo ordem. O 16 de fevereiro (dia 47 contando desde o primeiro dia do ano) se registrou o alagamento às 19:00 HL com uma intensidade da precipitação maior a $10 \mathrm{~mm} / \mathrm{h}$ e atingindo os $17 \mathrm{~mm} / \mathrm{h}$. Em ambos casos, os alagamentos sucederam ao atingir precipitações de $10 \mathrm{~mm} / \mathrm{h}$, caracterizando-lhes como alagamento por chuva instantânea. 


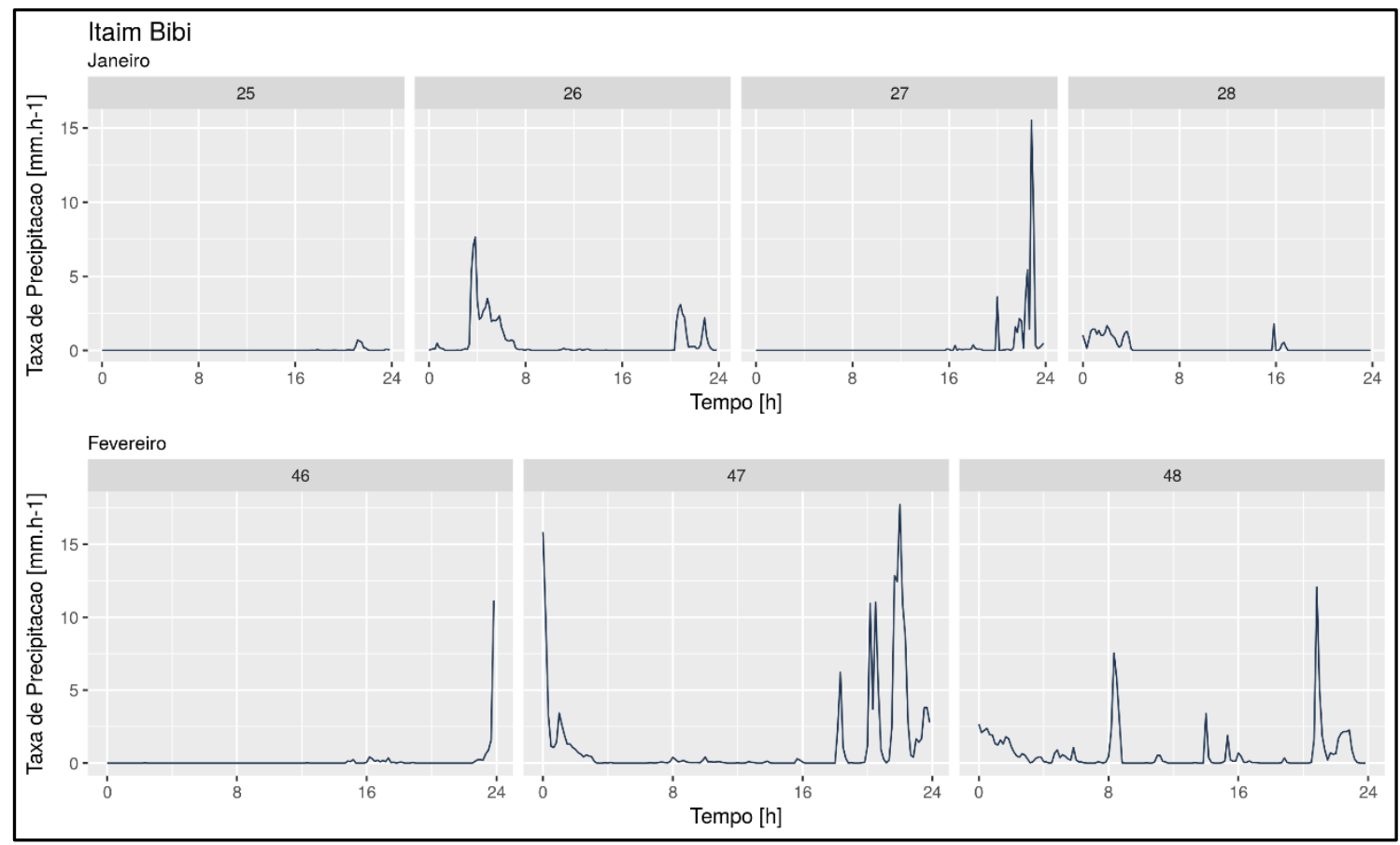

Figura 5.11. Distribuição da precipitação para os dias 25, 26,27 e 28 de janeiro e 46, 47 e 48 de fevereiro do ano 2015

Observamos na figura 5.12 dois casos de precipitação no bairro de Bom Retiro para os meses de novembro e dezembro. O ponto crítico localiza-se perto do Rio Tietê e próximo da avenida Casa Verde. Para exemplificar, escolheram-se os dias 1 e 2 de novembro e 20 e 21 de dezembro de 2015 (Figura 5.12). No primeiro dia de novembro, o alagamento foi registrado às 08:30 HL com precipitações maiores que $10 \mathrm{~mm} / \mathrm{h}$ e um volume de chuva de $24 \mathrm{~mm}$. No dia seguinte, o alagamento foi registrado às 06:00 HL e um acumulado de 21 $\mathrm{mm}$ de chuva com intensidade de precipitação maior que $10 \mathrm{~mm} / \mathrm{h}$. Os dois dias apresentaram o evento de alagamento depois de acumular mais de $20 \mathrm{~mm}$ de chuva aproximadamente.

No mês de dezembro, o dia 20 (dia 354 contando desde o primeiro dia do ano) registrou o alagamento às 17:00 HL, atingindo uma precipitação maior que $30 \mathrm{~mm} / \mathrm{h}$ com um acumulado de $23 \mathrm{~mm}$ e no dia 21 (355) o alagamento ocorreu às 18:00 HL ao tiver uma intensidade maior que $20 \mathrm{~mm} / \mathrm{h}$, acumulando no dia $44 \mathrm{~mm}$ de chuva. Estes dois eventos, indicam que os alagamentos ocorreram quando a precipitação é maior que $20 \mathrm{~mm} / \mathrm{h}$. 


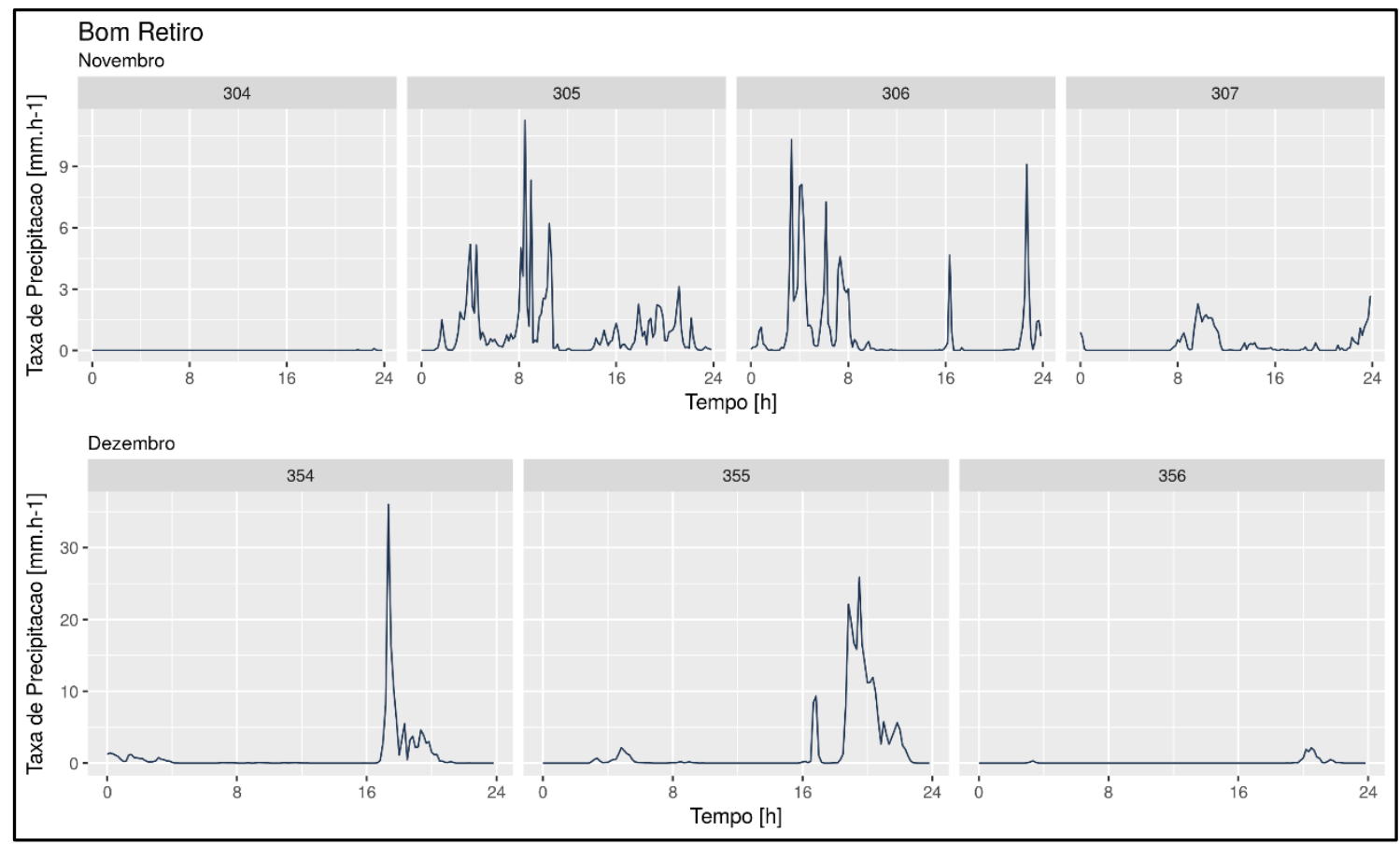

Figura 5.12. Distribuição da precipitação do bairro de Bom Retiro para o mês de novembro nos dias 304, 305, 306, 307 e dezembro os dias 353, 354, 355, 356 do ano 2015

Em Santana, o ponto localiza-se nas redondezas do rio Tietê e o Córrego Carandiru e da Av. Cruzeiro do Sul. Maior parte dos alagamentos foram registrados nos meses de outubro e novembro como se mostra na figura 5.13. No mês de outubro por exemplo, temos o dia 22 (dia 295 contando a partir do dia 1, ano 2015) que registrou o evento às 06:30 $\mathrm{HL}$ após acumular $15 \mathrm{~mm}$ de chuva aproximadamente, e com uma taxa de precipitação maior que $20 \mathrm{~mm} / \mathrm{h}$, sendo um alagamento por chuva instantânea. Porém, o acumulado total no dia foi de quase $25 \mathrm{~mm}$ de chuva. Para os dias 1 e 2 de novembro (correspondentes aos dias 305 e 306) os eventos foram registrados na manhã, às 10:50 HL e às 06:50 HL, respectivamente. No primeiro dia (305), o alagamento ocorreu logo de atingir uma precipitação de $8 \mathrm{~mm} / \mathrm{h}$ e $12 \mathrm{~mm}$ de chuva acumulada. No dia 306, ao ter acumulado 15 $\mathrm{mm}$ de chuva e com intensidade maior que $10 \mathrm{~mm} / \mathrm{h}$. Consequentemente, os alagamentos registrados nestes dois dias, ocorreram após a chuva acumulada maior aos $12 \mathrm{~mm}$ de chuva e com precipitações não tão fortes. 


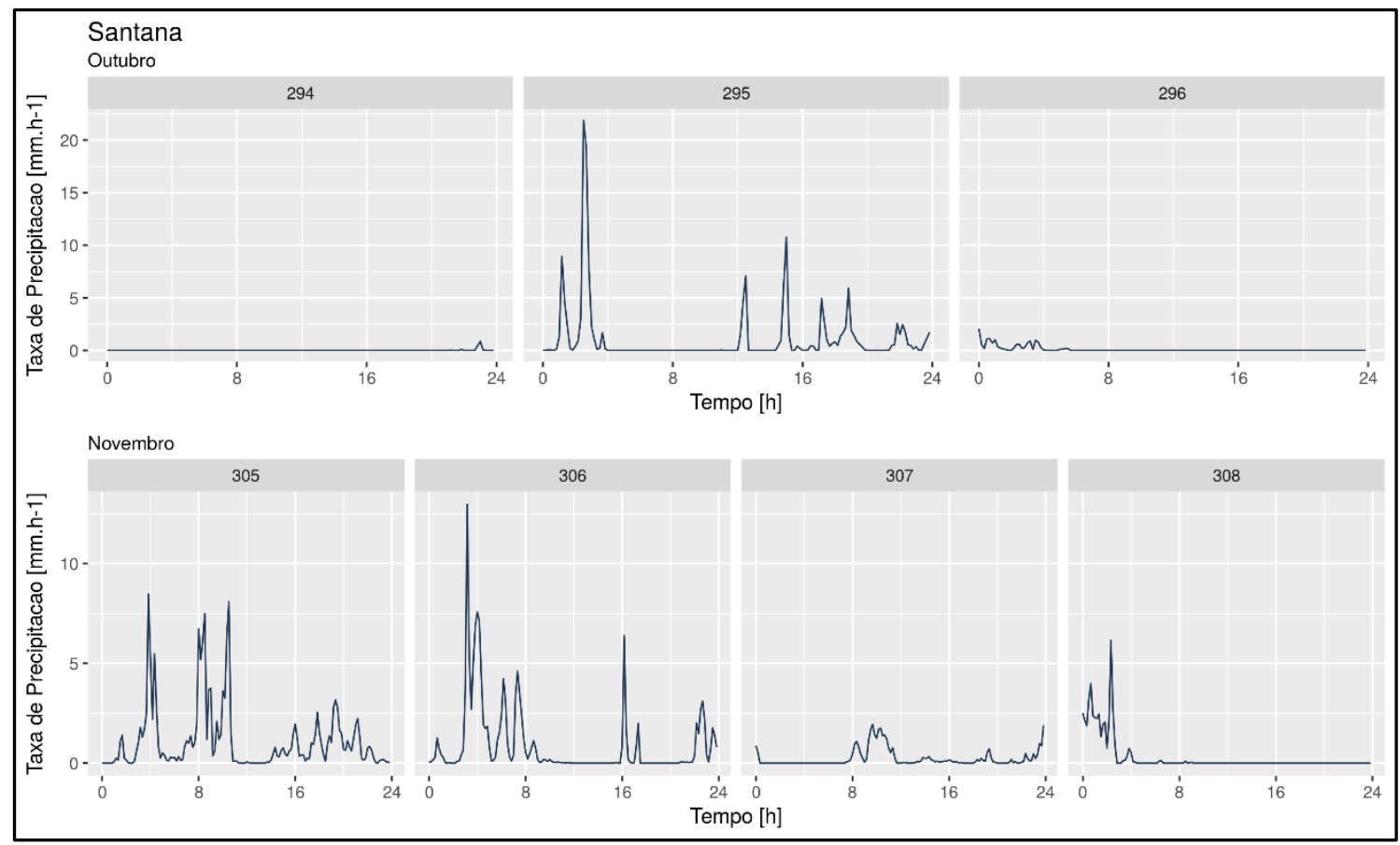

Figura 5.13. Distribuição da precipitação do bairro de Santana para o mês de outubro nos dias 294, 295 e 296, e o mês de novembro nos dias 305, 306, 307 e 308 do ano 2015

Na tabela 5.8 se resume a frequência de ocorrência de alagamento no ano 2015, o valor médio da taxa de precipitação $(\mathrm{mm} / \mathrm{h})$ na escala de 10 minutos e a média da chuva acumulada antes de ser registrado o alagamento no ponto $(\mathrm{mm})$. A figura 5.14 apresenta graficamente os valores resumidos na tabela 5.8, onde os pontos com maior frequência estão localizados nos bairros de Bom Retiro, Santana, Republica, Itaim Bibi, Mooca e Butantã.

Observa-se na tabela que a taxa de precipitação mínima registrada foi de $10 \mathrm{~mm} / \mathrm{h}$ e máxima de $60 \mathrm{~mm} / \mathrm{h}$, sendo a média de todos os pontos de $27 \mathrm{~mm} / \mathrm{h}$. Por outro lado, o mínimo acumulado de chuva antes de se registrar o alagamento foi de $6 \mathrm{~mm}$, máximo de $19 \mathrm{~mm}$ de chuva e com uma média de $9,5 \mathrm{~mm}$ de chuva.

\begin{tabular}{|l|c|c|c|}
\hline \multicolumn{1}{|c|}{ Bairro } & Frequência & $\begin{array}{c}\text { R médio } \\
{[\mathbf{m m} / \mathbf{h}]}\end{array}$ & $\begin{array}{c}\text { Média da chuva } \\
\text { acumulada antes do } \\
\text { alagamento [mm] }\end{array}$ \\
\hline Bom Retiro & 37 & 20 & 10,209 \\
\hline Santana & 28 & 10 & 9,367 \\
\hline Republica & 27 & 20 & 8,251 \\
\hline Itaim Bibi & 26 & 10 & 7,831 \\
\hline Mooca & 23 & 40 & 9,789 \\
\hline Butantã & 21 & 20 & 9,762 \\
\hline Saúde & 20 & 60 & 6,730 \\
\hline
\end{tabular}




\begin{tabular}{|c|c|c|c|}
\hline Bairro & Frequência & $\begin{array}{c}\text { R médio } \\
{[\mathrm{mm} / \mathrm{h}]}\end{array}$ & $\begin{array}{l}\text { Média da chuva } \\
\text { acumulada antes do } \\
\text { alagamento }[\mathrm{mm}]\end{array}$ \\
\hline Aricanduva & 19 & & 6,584 \\
\hline Bela Vista & 15 & & 6,039 \\
\hline Belém & 13 & 20 & 10,363 \\
\hline Iguatemi & 13 & & 8,260 \\
\hline São Lucas & 13 & & 14,928 \\
\hline Morumbi & 12 & 20 & 9,358 \\
\hline Agua Rasa & 11 & 20 & 13,748 \\
\hline Barra Funda & 11 & 20 & 9,369 \\
\hline Bom Retiro & 11 & 10 & 10,209 \\
\hline Vila Maria & 11 & 30 & 7,243 \\
\hline Itaim Bibi & 10 & 20 & 7,831 \\
\hline Jardim Paulista & 10 & & 7,275 \\
\hline Limão & 10 & & 8,457 \\
\hline Freguesia do $\mathrm{O}$ & 9 & & 8,121 \\
\hline Perdizes & 9 & & 10,392 \\
\hline Republica & 9 & 20 & 8,251 \\
\hline Vila Andrade & 9 & & 11,265 \\
\hline Vila Sonia & 9 & 20 & 11,446 \\
\hline Moema & 8 & 60 & 8,115 \\
\hline Socorro & 8 & 20 & 7,800 \\
\hline Cambuci & 7 & & 9,953 \\
\hline Moema & 7 & 60 & 8,115 \\
\hline Se & 7 & 20 & 8,613 \\
\hline Vila Matilde & 7 & 50 & 9,797 \\
\hline Brás & 6 & & 10,880 \\
\hline Campo Grande & 6 & 20 & 7,672 \\
\hline Perdizes & 6 & & 10,392 \\
\hline Perdizes & 6 & & 10,392 \\
\hline Santana & 6 & 10 & 9,367 \\
\hline Santo Amaro & 6 & 20 & 9,425 \\
\hline Santo Amaro & 6 & 20 & 9,425 \\
\hline Vila Guilherme & 6 & 30 & 9,902 \\
\hline Vila Guilherme & 6 & 30 & 9,902 \\
\hline Vila Mariana & 6 & 40 & 10,486 \\
\hline Barra Funda & 5 & 20 & 9,369 \\
\hline Campo Belo & 5 & 60 & 7,854 \\
\hline Campo Grande & 5 & 20 & 7,672 \\
\hline Campo Grande & 5 & 20 & 7,672 \\
\hline Capão Redondo & 5 & & 19,316 \\
\hline Santo Amaro & 5 & 20 & 9,425 \\
\hline Se & 5 & 20 & 8,613 \\
\hline MÉDIA & 2,7 & 26,5 & 9,5 \\
\hline$\sigma$ & 4,2 & 14,4 & 2,15 \\
\hline
\end{tabular}

Tabela 5.8. Resumo das características dos pontos de alagamento mais recorrentes no ano 2015 


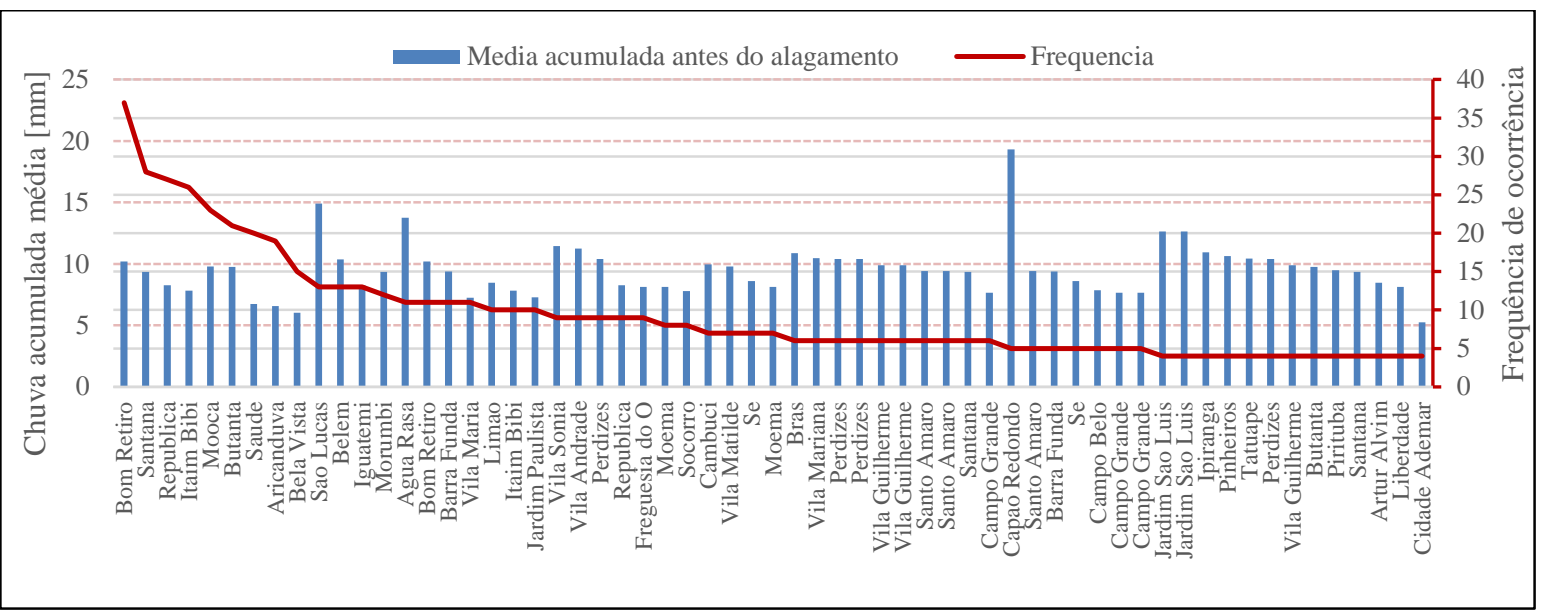

Figura 5.14. Diagrama de frequências de ocorrência de eventos de alagamento e da chuva acumulada média antes do alagamento

\subsection{Análises do modelo de regressão logística binária}

Com o propósito de prever os alagamentos em cada um dos bairros se estabeleceu um modelo de regressão logística binária, e que segundo Chau \& Chan (2005) o define como a probabilidade de ocorrência de alagamento dividida pela probabilidade de ausência de ocorrência de alagamento.

Portanto, com base em valores de um conjunto de variáveis de condicionamento foi possível analisar a possibilidade de prever a presença de evento de alagamento ou não nos bairros da cidade de São Paulo.

No modelo foram analisados os parâmetros seguintes: acumulado da chuva no dia (24 horas), taxa de precipitação máxima $(\mathrm{mm} / \mathrm{h})$ e duração da chuva total (min) a partir dos dados estimados pelo radar durante o ano 2015 (Figura 5.15). Usaram-se 73 bairros da cidade de São Paulo que registraram eventos de alagamento por mais de dois dias. 


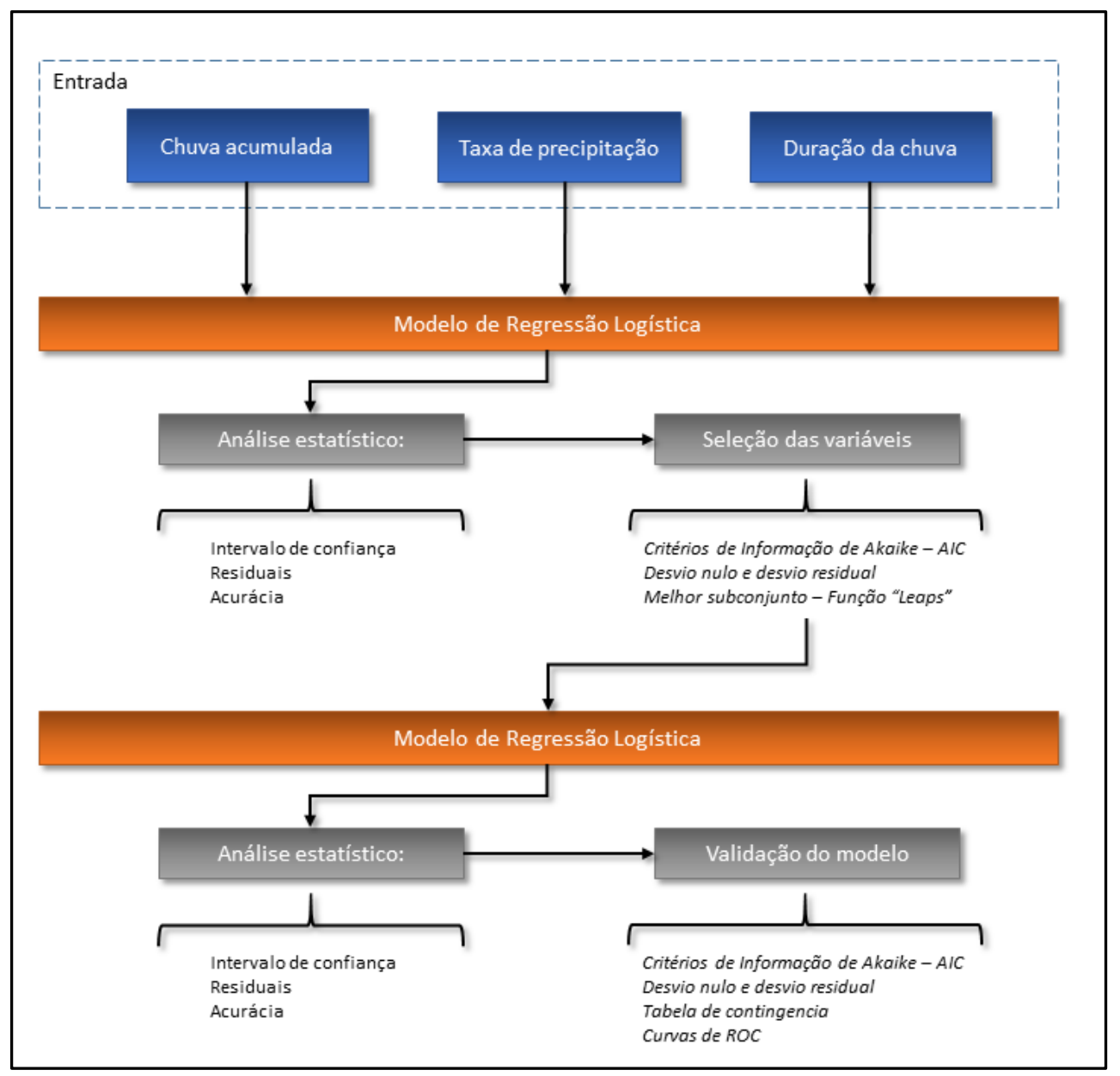

Figura 5.15. Esquema do modelo de investigação para o prognóstico de alagamentos nos bairros da cidade de São Paulo

Portanto, seguindo o esquema da figura 5.15, na construção do modelo foi utilizado de forma aleatória $75 \%$ dos dados de precipitação e os $25 \%$ remanescentes foram utilizados para validação. Cada bairro foi analisado dependendo da validação e critérios especificados na secção 4.2.3. Por exemplo, na escolha dos parâmetros se aplicou o critério de $\mathrm{R}^{2}$ ajustado, que de forma gráfica mostra as medidas do ajuste ao longo do eixo Y para vários modelos criados por combinações de variáveis que estão especificadas no eixo X. Especificamente, o critério de $\mathrm{R}^{2}$ ajustado, calculou-se dividindo o erro quadrado da média residual pela variância.

Observamos na figura 5.16 que para o bairro de Santana, as variáveis que obtiveram melhor ajuste foram: a chuva acumulada e a taxa de precipitação máxima, com um $\mathrm{R}^{2}$ ajustado de 0,41 , sendo 1 o valor ideal. 


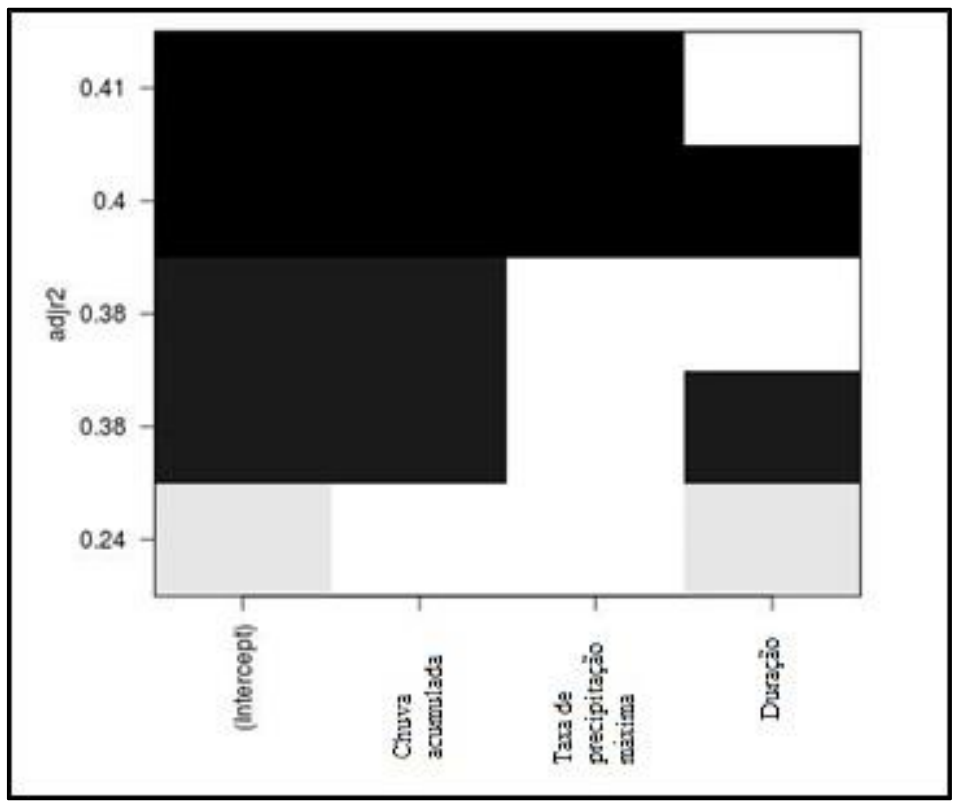

Figura 5.16. Tabela gráfica de seleção de subconjuntos para o bairro de Santana

Logo, o modelo de regressão logística binária foi gerado novamente a partir das variáveis escolhidas. Na tabela 5.9, se mostram os coeficientes $\left(\beta_{\mathrm{i}}\right)$ calculados para cada um dos bairros conforme as variáveis que se ajustaram ao modelo (equação 5.1). Sendo 0: constante, 1: chuva acumulada, 2: Taxa da precipitação máxima (R) e 3: duração da chuva.

$$
\log \left\{\frac{p(x)}{1-p(x)}\right\}=\beta_{0}+\beta_{1} x_{1}+\beta_{2} x_{2}+\beta_{3} x_{3}
$$

A figura 5.17 apresenta os bairros em função das variáveis ajustadas no modelo de regressão logística binária. Observa-se que há bairros que consideram as 3 variáveis: a chuva acumulada, a taxa de precipitação máxima e a duração da chuva, assim como também há bairros que foram ajustadas com duas variáveis ou só com uma variável.

\begin{tabular}{|r|l|r|r|r|r|}
\hline No & \multicolumn{1}{|c|}{ Bairro } & Constante & $\begin{array}{c}\text { Chuva } \\
\text { acumulada } \\
{[\mathbf{m m}]}\end{array}$ & $\begin{array}{c}\text { Taxa de } \\
\text { precipitação } \\
{[\mathbf{m m} / \mathbf{h}]}\end{array}$ & \multicolumn{1}{c|}{ Duração } \\
\hline $\mathbf{1}$ & Agua Rasa & $-6,1247$ & 0,1357 & $-0,0093$ & 0,001736 \\
\hline $\mathbf{2}$ & Alto de Pinheiros & $-7,5632$ & 0,0404 & 0,0897 & 0,001574 \\
\hline $\mathbf{3}$ & Aricanduva & $-3,6185$ & & 0,0573 & $-0,001018$ \\
\hline $\mathbf{4}$ & Artur Alvim & $-5,8238$ & 0,0456 & 0,0875 & $-0,000412$ \\
\hline $\mathbf{5}$ & Barra Funda & $-3,3360$ & 0,0292 & 0,1947 & $-0,002916$ \\
\hline $\mathbf{6}$ & Bela Vista & $-4,1418$ & 0,0546 & 0,0333 & \\
\hline
\end{tabular}




\begin{tabular}{|c|c|c|c|c|c|}
\hline No & Bairro & Constante & $\begin{array}{r}\text { Chuva } \\
\text { acumulada } \\
{[\mathrm{mm}]}\end{array}$ & $\begin{array}{r}\text { Taxa de } \\
\text { precipitação } \\
{[\mathrm{mm} / \mathrm{h}]}\end{array}$ & Duração \\
\hline 7 & Belém & $-3,9537$ & 0,1838 & & $-0,000004$ \\
\hline 8 & Bom Retiro & $-4,1969$ & 0,2281 & & \\
\hline 9 & Brás & $-5,6182$ & 0,1076 & 0,0195 & 0,000738 \\
\hline 10 & Brasilândia & $-4,7795$ & 0,0809 & & 0,000215 \\
\hline 11 & Butantã & $-3,9739$ & 0,0737 & 0,0707 & 0,000272 \\
\hline 12 & Cachoeirinha & $-5,0431$ & 0,0805 & & 0,000640 \\
\hline 13 & Cambuci & $-4,7524$ & $-0,0375$ & 0,1078 & \\
\hline 14 & Campo Belo & $-6,2365$ & $-0,0098$ & 0,0936 & 0,003204 \\
\hline 15 & Campo Grande & $-3,5578$ & 0,0775 & 0,0424 & \\
\hline 16 & Campo Limpo & $-4,8336$ & 0,1497 & & $-0,002271$ \\
\hline 17 & Capão Redondo & $-6,0883$ & 0,0461 & 0,0753 & \\
\hline 18 & Carrão & $-6,8974$ & $-0,0403$ & 0,1592 & \\
\hline 19 & Cidade Ademar & $-5,1752$ & $-0,1638$ & & 0,004518 \\
\hline 20 & Cidade Dutra & $-4,2636$ & 0,0522 & 0,0342 & 0,000076 \\
\hline 21 & Cidade Líder & $-4,4072$ & 0,0837 & 0,0421 & \\
\hline 22 & Consolação & $-5,4403$ & 0,1479 & $-0,0375$ & 0,001148 \\
\hline 23 & Cursino & $-4,9980$ & 0,1662 & 0,0982 & $-0,004355$ \\
\hline 24 & Freguesia do $\mathrm{O}$ & $-3,5603$ & 0,0910 & & \\
\hline 25 & Grajau & $-5,5378$ & 0,0646 & 0,0046 & \\
\hline 26 & Iguatemi & $-4,6572$ & & 0,0893 & \\
\hline 27 & Ipiranga & $-4,2007$ & & 0,1153 & $-0,000640$ \\
\hline 28 & Itaim Bibi & $-3,6442$ & 0,1642 & 0,0667 & $-0,001102$ \\
\hline 29 & Itaquera & $-7,7778$ & 0,0468 & 0,0816 & 0,002995 \\
\hline 30 & Jabaquara & $-5,1528$ & & & 0,003126 \\
\hline 31 & Jacana & $-6,7926$ & & 0,1335 & \\
\hline 32 & Jaguará & $-4,7244$ & $-0,0454$ & 0,0893 & \\
\hline 33 & Jaguaré & $-5,0123$ & & 0,0768 & \\
\hline 34 & Jaraguá & $-4,4306$ & 0,1017 & $-0,0273$ & \\
\hline 35 & Jardim Ângela & $-5,2671$ & 0,0779 & & $-0,000767$ \\
\hline 36 & Jardim Paulista & $-4,2391$ & & 0,0783 & \\
\hline 37 & Jardim São Luís & $-5,4040$ & 0,0121 & 0,1292 & 0,000194 \\
\hline 38 & Lapa & $-5,9893$ & 0,0410 & 0,0711 & 0,002444 \\
\hline 39 & Liberdade & $-4,7230$ & 0,1180 & 0,0548 & $-0,001969$ \\
\hline 40 & Limão & $-4,3956$ & 0,0605 & 0,0672 & $-0,000173$ \\
\hline 41 & Moema & $-5,2459$ & & 0,0949 & \\
\hline 42 & Mooca & $-4,4225$ & 0,0664 & 0,0695 & 0,000117 \\
\hline 43 & Morumbi & $-3,4009$ & 0,1463 & 0,0446 & $-0,000599$ \\
\hline 44 & Parelheiros & $-5,6584$ & 0,0741 & $-0,0156$ & \\
\hline 45 & Pari & $-4,6091$ & & 0,0720 & $-0,000435$ \\
\hline
\end{tabular}




\begin{tabular}{|c|c|c|c|c|c|}
\hline No & Bairro & Constante & $\begin{array}{r}\text { Chuva } \\
\text { acumulada } \\
{[\mathrm{mm}]}\end{array}$ & $\begin{array}{r}\text { Taxa de } \\
\text { precipitação } \\
{[\mathrm{mm} / \mathrm{h}]}\end{array}$ & Duração \\
\hline 46 & $\begin{array}{l}\text { Parque do } \\
\text { Carmo }\end{array}$ & $-13,2914$ & & 0,1732 & 0,006641 \\
\hline 47 & Penha & $-8,5001$ & 0,0339 & 0,1022 & 0,004110 \\
\hline 48 & Perdizes & $-2,7504$ & 0,1507 & & $-0,003357$ \\
\hline 49 & Pinheiros & $-4,3823$ & 0,0598 & 0,0714 & 0,000182 \\
\hline 50 & Pirituba & $-5,0212$ & 0,1021 & & $-0,000399$ \\
\hline 51 & Ponte Rasa & $-6,3645$ & $-0,2018$ & 0,2216 & $-0,002904$ \\
\hline 52 & Republica & $-3,3266$ & 0,0756 & 0,0457 & \\
\hline 53 & Rio Pequeno & $-5,1123$ & 0,2438 & $-0,1035$ & $-0,004309$ \\
\hline 54 & Sacomã & $-4,9524$ & & 0,0773 & \\
\hline 55 & Santa Cecilia & $-3,7324$ & 0,0623 & & 0,002156 \\
\hline 56 & Santana & $-3,3387$ & 0,2644 & $-0,0823$ & \\
\hline 57 & Santo Amaro & $-4,6511$ & 0,0783 & 0,0630 & 0,000430 \\
\hline 58 & São Domingos & $-10,2312$ & 0,1737 & 0,0270 & 0,000920 \\
\hline 59 & São Lucas & $-4,8372$ & 0,1368 & & $-0,001085$ \\
\hline 60 & Saúde & $-6,6063$ & 0,0338 & 0,1210 & 0,001461 \\
\hline 61 & Se & $-3,4791$ & 0,1006 & & \\
\hline 62 & Socorro & $-4,3713$ & 0,0825 & & $-0,000031$ \\
\hline 63 & Tatuapé & $-4,2789$ & 0,1496 & & $-0,000423$ \\
\hline 64 & Tremembé & $-5,4412$ & 0,0994 & & \\
\hline 65 & Vila Andrade & $-4,5676$ & 0,1263 & & $-0,001365$ \\
\hline 66 & Vila Formosa & $-8,6348$ & 0,0926 & 0,0570 & 0,000241 \\
\hline 67 & Vila Guilherme & $-3,2991$ & 0,0731 & 0,0445 & \\
\hline 68 & Vila Leopoldina & $-4,7342$ & & 0,0829 & 0,000745 \\
\hline 69 & Vila Maria & $-3,3364$ & 0,1049 & & $-0,001171$ \\
\hline 70 & Vila Mariana & $-4,7340$ & $-0,0095$ & 0,1155 & 0,000486 \\
\hline 71 & Vila Matilde & $-6,4481$ & & 0,1370 & 0,001646 \\
\hline 72 & Vila Prudente & $-4,6100$ & $-0,2849$ & 0,2714 & \\
\hline 73 & Vila Sonia & $-3,1686$ & 0,2401 & $-0,0002$ & $-0,008960$ \\
\hline
\end{tabular}

Tabela 5.9. Coeficientes do modelo de Regressão Logística Binária para os bairros de São Paulo 


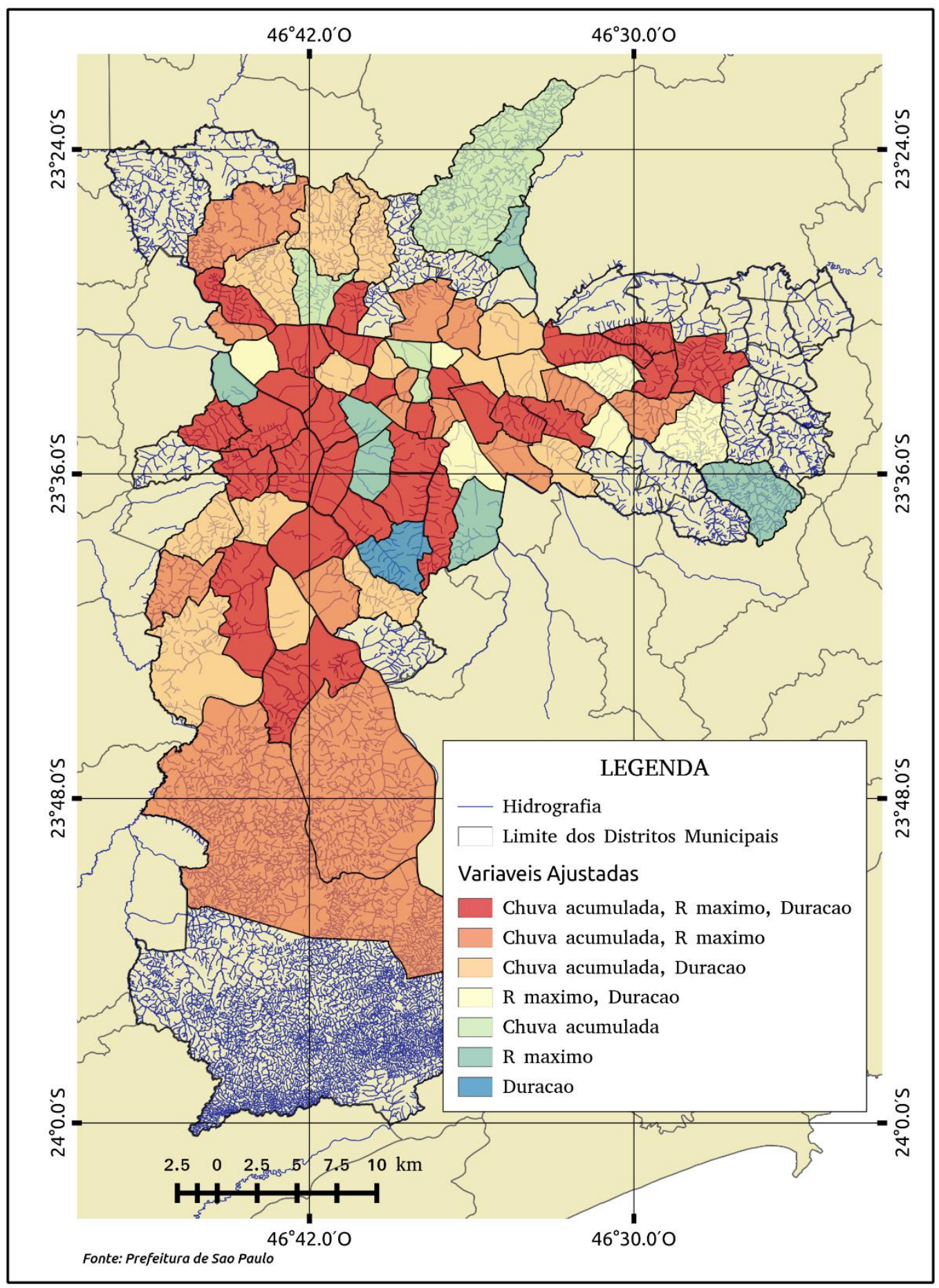

Figura 5.17. Mapa de variáveis ajustadas no modelo de regressão logística binária nos bairros da cidade de São Paulo. Fonte: Andrea Viteri

Usando os coeficientes do modelo de regressão logística, a probabilidade de ocorrência de alagamento foi calculada para cada um dos bairros. Se os valores são maiores 
que 0,5 (o número de 1 é assignado) considera-se como provável para acontecer um alagamento, mas se for menor que 0,5 (o número de 0 é assignado) não teria possibilidade de alagamento.

Logo, a partir do $25 \%$ dos dados para validação, se calcularam as probabilidades de detecção (POD) e a taxa de falso alarme (FAR) para avaliar e comparar a possibilidade de ocorrência de alagamento ou não em cada bairro de São Paulo, em função da tabela de contingência.

Os resultados dos índices calculados para cada bairro estão representados nas figuras 5.18 e 5.19 para eventos com e sem alagamento e se resumem detalhadamente na tabela do apêndice A4.1. Nas figuras, os bairros representados pela cor vermelho são os que obtiveram valores próximos ao ideal nos índices POD e FAR. Sabendo que no caso do índice POD o valor ideal deveria ser próximo a 1 (ou seja 100\%), observamos que a probabilidade para eventos sem alagamento é maior comparado com a POD para eventos com alagamento em todos os bairros analisados. Para o índice FAR o valor ideal é próximo a 0, ou seja o número de eventos que não foram prognosticados. Neste caso, o número de falsos alarmes é maior para eventos sem alagamento comparado com a FAR de eventos com alagamento.

Comparando-se esses índices, a POD média foi de 96\% e FAR médio de 2,5\% para eventos sem alagamento e para eventos com alagamento a POD média foi de $1 \%$ e FAR médio de $0,6 \%$.

Entretanto, os bairros que obtiveram maior porcentagem de eventos com alagamento foram Belém, Morumbi, Santana e Itaim Bibi com um POD de 6\%, ou seja, temse a possibilidade de apresentar entre 8 e 10 dias com alagamento. Por outro lado, os bairros com maior número de casos sem alagamento foram os bairros de Cidade Ademar, Grajau, Parelheiros, Parque do Carmo, Rio Pequeno, Sacomã, Tremembé e Vila Formosa com um POD de $99 \%$ e FAR de $1,1 \%$. 
a) POD: Eventos com alagamento

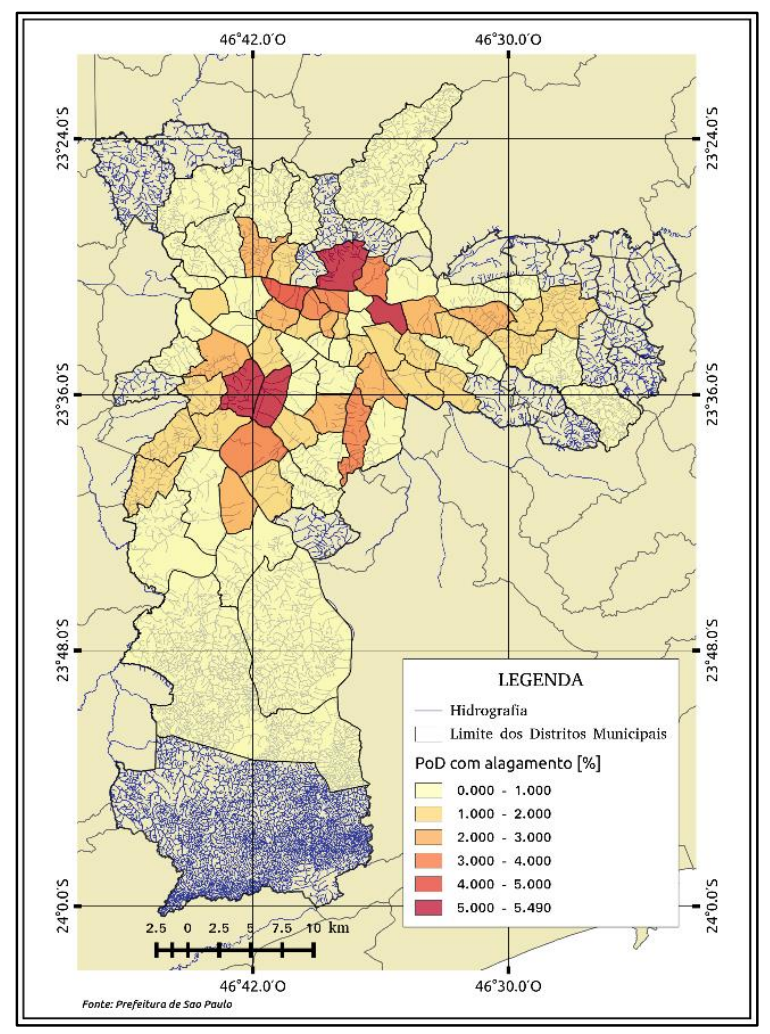

b) POD: Eventos sem alagamento

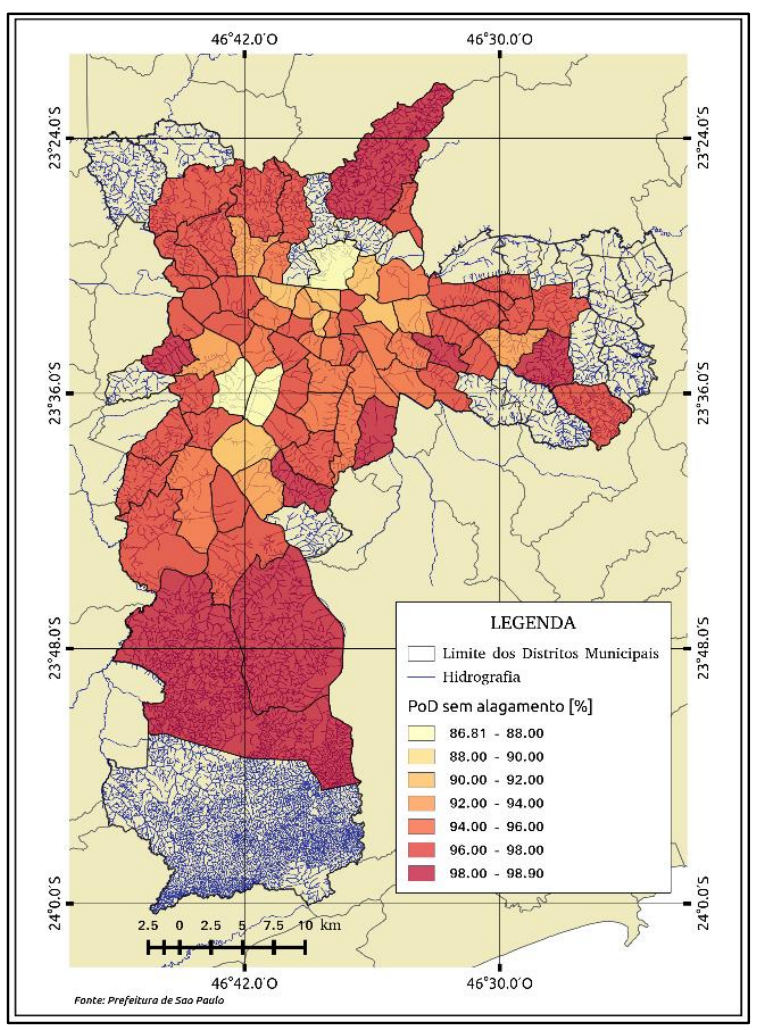

Figura 5.18. Mapas do índice de validação POD para eventos a) com alagamento e b) sem alagamento nos bairros da cidade de São Paulo 
a) FAR: Eventos com alagamento

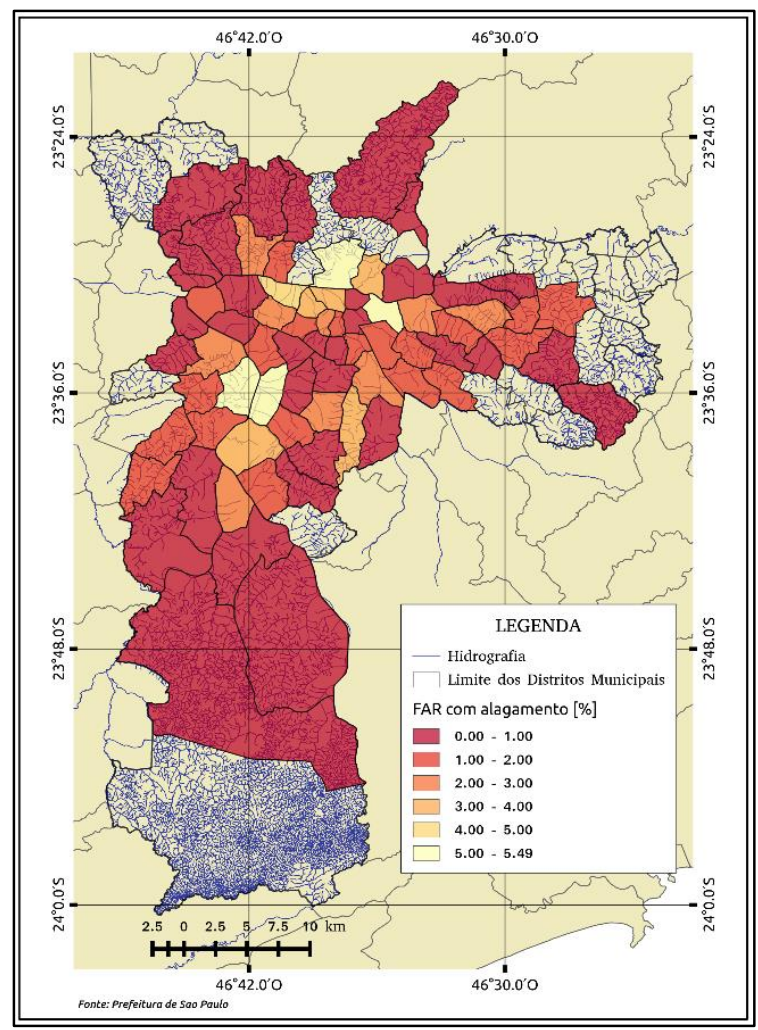

b) FAR: Eventos sem alagamento

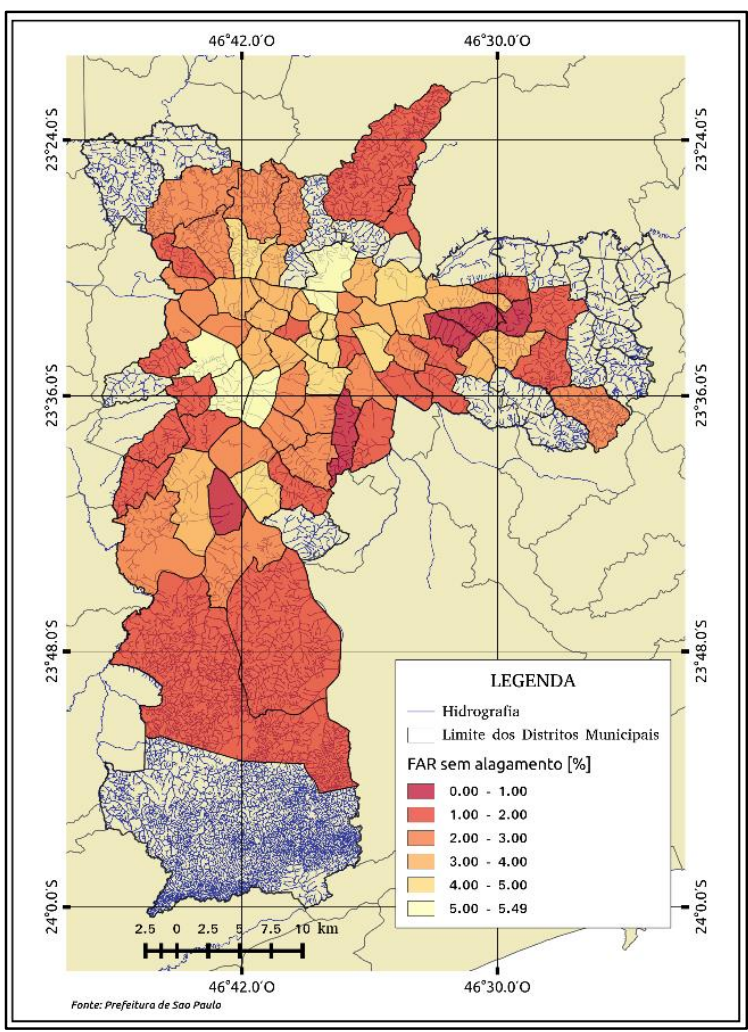

Figura 5.19. Mapas do índice de validação FAR para eventos a) com alagamento e b) sem alagamento nos bairros da cidade de São Paulo

Existe uma grande diferença entre ambos casos sendo notável que o modelo consegue prever eventos sem alagamento o que pode estar associado com o número de amostras, neste caso os eventos de alagamento registrados só no ano 2015, que é muito menor comparado com os eventos sem alagamento. 


\section{Conclusões}

O objetivo deste projeto foi caracterizar pela primeira vez as chuvas estimadas pelo radar meteorológico Doppler de dupla polarização Banda S (SPOL) do DAEE/FCTH durante eventos de alagamento ou não na cidade de São Paulo para cada bairro a partir de analises estatísticas e comparações entre as variáveis de chuva acumulada no dia, taxa de precipitação, duração da chuva e fração da área de chuva nos bairros, com o propósito de prever eventos de alagamento. A seguir são apresentadas as principais conclusões obtidas a partir dos dados do ano 2015:

O controle de qualidade feito nos registros de dados dos pluviômetros para o ano 2015 conforme aos critérios de avaliação, mostrou que 41 postos pluviométricos foram desconsiderados na comparação e avaliação da variação da chuva com as estimativas de precipitação do radar.

As comparações das estimativas de precipitação do radar meteorológico de São Paulo com as medidas dos pluviômetros da rede telemétrica do DAEE mostraram que o ajuste para escala temporal de 1 dia obtive uma correlação de 0,8 para 1 hora foi de 0,7 e para escala temporal de 10 minutos foi de 0,4 . Por conseguinte, a escala de 1 dia foi a que apresentou melhor estimativa de precipitação que a escala de 1 hora e 10 minutos. Nos três casos, conforme ao ajuste linear, houve subestimativa da precipitação em relação ao registrado pelo radar por possuir inclinação inferior a reta 1:1. Observou-se também, que o ajuste para cada um dos pluviômetros com as estimativas do radar obteve uma correlação média de 0,6, uma correlação mínima de 0,5 e máximo de 0,7 o que indica apenas uma relação linear moderada entre as variáveis.

Em relação as distribuições de probabilidade para cada bairro as seguintes características foram observadas:

- A forma da curva das distribuições de probabilidade ao ser uma distribuição normal, permitiu de forma aproximada calcular a probabilidade de ocorrência ou não de alagamento com relação aos parâmetros da média e o desvio padrão 
populacional. Porém, tem-se bairros onde as distribuições não foram calculadas por ter registrado um só dia com evento de alagamento no ano.

- Na análise das PDFs a chuva acumulada em 24 horas se observou que para os 79 bairros analisados, a probabilidade média de ocorrer eventos com alagamento foi de $28 \%$ para volumes de chuva maior que $27 \mathrm{~mm}$. Observou-se que o bairro de Jabaquara obtive o valor mínimo de chuva acumulada que foi de $20 \mathrm{~mm}$ e probabilidade de ocorrência de alagamento de $51 \%$, e o volume de chuva máximo se registrou em Itaim Paulista com $45 \mathrm{~mm}$ e probabilidade de alagamento de $78 \%$. Mostrou-se também, que os bairros de Jardim Helena, Vila Curuçá, Grajaú, Jaraguá, Bom Retiro e Santana são os bairros com maior vulnerabilidade tendo como probabilidade de alagamento entre os 10 e $20 \mathrm{~mm} / \mathrm{h}$.

- Em relação ás PDF da taxa de precipitação, os alagamentos são mais propensos a ocorrer ao atingir precipitações maiores que $30 \mathrm{~mm} / \mathrm{h}$, como valor médio de todos os bairros, com probabilidade de $26 \%$. Ademais, se observou que bairros como Vila Formosa, Jose Bonifácio e Guaianases obtiveram taxa de precipitação máxima de $50 \mathrm{~mm} / \mathrm{h}$ com probabilidade média de ocorrência de alagamento de 49\% e precipitação mínima de $10 \mathrm{~mm} / \mathrm{h}$ nos bairros de Grajau e Jaraguá com probabilidade média de $60 \%$.

- Em termos de fração da área de chuva foram analisados 73 bairros para precipitações maiores que $30 \mathrm{~mm} / \mathrm{h}$ e 68 bairros para precipitações maiores que $50 \mathrm{~mm} / \mathrm{h}$. Observou-se que a probabilidade média da fração de chuva com precipitações maior que $30 \mathrm{~mm} / \mathrm{h}$ foi de $21 \%$ para ocupar uma área média de $27 \%$. A fração de chuva mínimo e máximo dentro deste intervalo foram de $2 \%$ com o 100\% de probabilidade de ocorrência (bairro de Tremembé) e 56\% de área com $7 \%$ de probabilidade (bairro de Jaguaré), respectivamente. No caso de precipitações maiores que $50 \mathrm{~mm} / \mathrm{h}$, a probabilidade média da fração de chuva foi de $27 \%$ para ocupar ao redor de $26 \%$ da área do bairro. Neste caso, a fração de chuva mínimo e máximo foram de $2 \%$ com $96 \%$ de probabilidade de ocorrência (bairro de Parelheiros) e $89 \%$ da área com $29 \%$ de probabilidade (bairro de Socorro), respectivamente. 
Comparando as variáveis de duração da chuva e chuva acumulada em 24 horas a intervalos de 10 mm de chuva a cada 1 hora, observou-se que com relação a duração não foi possível encontrar um padrão médio, pois a chuva tinha duração de 20 minutos mínimo a 23 horas máximo. Quanto a chuva acumulada, foram calculados os padrões de probabilidade para os possíveis bairros, onde, na média, os eventos de alagamento estavam associados a chuvas acumuladas maiores que $33 \mathrm{~mm}$, mínimo de $20 \mathrm{~mm}$ e máximo de $60 \mathrm{~mm}$ de chuva. E ao comparar a taxa de precipitação e chuva acumulada por intervalos de $10 \mathrm{~mm}$ de chuva a cada $10 \mathrm{~mm} / \mathrm{h}$, nota-se que os eventos de alagamentos estavam relacionados a precipitações maiores que $29 \mathrm{~mm} / \mathrm{h}$, mínimo de $10 \mathrm{~mm} / \mathrm{h}$ e máximo de $60 \mathrm{~mm} / \mathrm{h}$.

Correlacionando as distribuições de probabilidade e eventos de alagamento, observou-se que bairros localizados na proximidade dos rios Tietê e Pinheiros e região central da cidade de São Paulo apresentaram maior probabilidade de ocorrência de alagamento com volumes de chuva mais baixos do que a média de $30 \mathrm{~mm}$ por dia e também registram maior recorrência de pontos de alagamento, por exemplo 37 vezes no bairro de Bom Retiro. Já na zona sul, foram registrados o maior volume de chuva, ou seja, $2.300 \mathrm{~mm}$ no bairro de Parelheiros, porém com a menor frequência de dias com alagamentos.

Finalmente foi desenvolvido um modelo de regressão logística binaria com o propósito de prever eventos de alagamento para cada bairro. O modelo usa as variáveis chuva acumulada no dia, taxa de precipitação máxima e duração da chuva como parâmetros de entrada. Para a construção do modelo foi utilizado de forma aleatória $75 \%$ dos dados de precipitação e os $25 \%$ remanescentes foram utilizados para validação. Para validar a eficiência do modelo desenvolvido para cada bairro, foi aplicado o teste da tabela de contingência que calcula a probabilidade de detecção e taxa de falso alarme para os casos de alagamento e não alagamento.

- Para os eventos de alagamento a probabilidade de detecção obtive uma média de $1,15 \%$ e taxa de falso alarme médio de $0,6 \%$, a POD e FAR mínimo foram de $1,1 \%$ e a POD máximo foi de $5,5 \%$ e FAR de $4,4 \%$.

- Para os eventos sem alagamento a probabilidade de detecção média foi de $95,7 \%$ e FAR médio de 2,5\%, os valores mínimos obtidos para os dois índices foram de 
POD de $86,8 \%$ e FAR de $1,1 \%$ e a POD e FAR máximo foram de $99 \%$ e 5,5\%, respectivamente.

Baseado nestes índices, observa-se que o modelo de regressão funciona muito bem para eventos de não alagamento, ou seja, POD médio de 96\% e FAR médio de 2,5\%, já para os eventos de alagamento não foi possível obter resultados satisfatórios. Este resultado pode estar associado com o número de amostras de alagamento que é muito menor que os eventos sem alagamento. O recomendável seria analisar anos seguintes ao ano de estudo, e que permita melhorar a probabilidade de ocorrência de eventos de alagamentos nos bairros da cidade de São Paulo. 


\section{Referências Bibliográficas}

Ahnert, P. (2011). National Weather Service Flash Flood Warning Program. Early Warning for Flash Floods, 6-16

Akaike. (1974). A new look at statistical model identification. (AU-19, Org.). IEEE Transactions on Automatic Control.

Anagnostou, E. N. (2004). A convective/stratiform precipitation classification algorithm for volume scanning weather radar observations. Meteorological Applications, 11(4), 291300. https://doi.org/10.1017/S1350482704001409

Ávila, A., Pinto, H., \& Nery, L. (2007). Uso de dados de radar e de satélites meteorológicos em modelos de previsão de chuvas intensas em centros urbanos. Anais XIII Simpósio Brasileiro de Sensoriamento Remoto, Florianópolis,Brasil, 4815-4817. https://doi.org/11.15.19.35/doc/4815-4817

Barros, M., \& Braga JR, B. (1992). São Paulo Flood Warning System: Integrating Different Levels of Data Quality and Availability. 2nd. International. Symposium on Hydrological, Applications of Weather Radar. Hannover, Alemanha.

Barros, M. T. L., \& Conde, F. (2017). Urban Flood Warning System Social Benefits. In World Environmental and Water Resources Congress 2017 (p. 12-23).

Battan, L. J. (1973). Radar Observation of the Atmosphere. Chicago: University of Chicago Press.

Belachsen, I., Marra, F., Peleg, N., \& Morin, E. (2017). Convective rainfall in a dry climate: relations with synoptic systems and flash-flood generation in the Dead Sea region. Hydrology and Earth System Sciences, 21, 5165-5180.

Bohren, C. F., \& Clothiaux, E. E. (2006). Fundamentals of Atmospheric Radiation: An Introduction with 400 Problems. John Wiley \& Sons.

Boni, G., Ferraris, L., Giannoni, F., Roth, G., \& Rudari, R. (2007). Flood probability analysis for un-gauged watersheds by means of a simple distributed hydrologic model. Advances in Water Resources, 30(10), 2135-2144. https://doi.org/10.1016/j.advwatres.2006.08.009

Bung, D., Oertel, M., Schlenkhoff, A., \& Schlurmann, T. (2011). Flash Flood Awareness and Prevention in Germany. Early Warning for Flash Floods, 34-40.

CENAD-Centro Nacional de Gerenciamento de Riscos e Desastres. (2014). Anuário brasileiro de desastres naturais: 2013. Brasília. 
Centro Nacional de Monitoramento e Alerta de Desastres Naturais - CEMADEN. Municípios monitorados: São Paulo. Recuperado de https://www.cemaden.gov.br/oalerta/. Acceso em 2018

CGE - Centro de Gerenciamento de Emergências. Alagamentos. Recuperado de https://www.cgesp.org/v3/index.jsp. Acceso em 2016

Chau, K. T., \& Chan, J. E. (2005). Regional bias of landslide data in generating susceptibility maps using logistic regression: Case of Hong Kong Island. Landslides, 2(4), 280-290. https://doi.org/10.1007/s10346-005-0024-X

Chaurasia, A., \& Harel, O. (2012). Using AIC in multiple linear regression framework with multiply imputed data. Health Services and Outcomes Research Methodology, 12(2-3), 219-233. https://doi.org/10.1007/s10742-012-0088-8

Collier, C. G. (2007). Flash flood forecasting: What are the limits of predictability? Quarterly Journal of the Royal ..., 133(October), 937-948. https://doi.org/10.1002/qj

Cook, D., Dixon, P., Duckworth, W. M., Kaiser, M. S., Koehler, K., Meeker, W. Q., \& Stephenson, W. R. (2000). Binary Response and Logistic Regression Analysis. In Beyond Traditional Statistical Methods. Iowa.

Cyr, I. (2014). Estimation of Z-R relationship and comparative analysis of precipitation data from colocated rain-gauge, vertical radar and disdrometer. The Norwegian University for Science and Technology (NTNU).

Dutta, D., Sharma, S., Kannan, B. A. M., Venketswarlu, S., Gairola, R. M., Rao, T. N., \& Viswanathan, G. (2012). Sensitivity of Z-R relations and spatial variability of error in a Doppler Weather Radar measured rain intensity. Indian Journal \& Space Physics, 41(August), 448-460.

Farias, J. F. da S. (2009). Previsão de chuva a curtíssimo prazo na área de abrangência do radar meteorológico de São Paulo. Universidade de São Paulo.

Farias, J. F. da S., \& Filho, A. J. P. (2013). Previsão de chuva a curtíssimo prazo na área de abrangência do radar meteorológico de São Paulo. Revista Brasileira de Meteorologia, 28(2), 199-209. https://doi.org/10.1590/S0102-77862013000200009

Fawcett, T. (2006). An introduction to ROC analysis. Pattern Recognition Letters, 27(8), 861-874. https://doi.org/10.1016/j.patrec.2005.10.010

Fiorentino, M., Manfreda, S., \& Iacobellis, V. (2007). Peak runoff contributing area as hydrological signature of the probability distribution of floods. Advances in Water Resources, 30, 2123-2134. https://doi.org/10.1016/j.advwatres.2006.11.017

Gonçalves, M. F. (2009). Previsão de chuva com auxílio de radar de tempo visando a um sistema de alerta antecipado de cheias em áreas urbanas. Universidade de São Paulo. 
González-Rouco, J. F., Jiménez, J. L., Quesada, V., \& Valero, F. (2001). Quality Control and Homogeneity of Precipitation Data in the Southwest of Europe. Journal of Climate, 14(5), 964-978. https://doi.org/10.1175/15200442(2001)014<0964:QCAHOP>2.0.CO;2

Gruntfest, E., \& Handmer, J. (1999). Coping With Flash Floods NATO Science Series.

Hamada, A., Arakawa, O., \& Yatagai, A. (2011). An automated quality control method for daily rain-gauge data. Global Environmental Research, 15, 183-192. Recuperado de http://www.airies.or.jp/journal_15-2eng.html

Hanson, L. S., \& Vogel, R. (2008). The Probability Distribution of Daily Rainfall in the United States. World Environmental and Water Resources Congress 2008, 1-10. https://doi.org/10.1061/40976(316)585

Hirata, E., Abrantes, M., Camargo, A. P., \& Quintanilha, J. A. (2013). Mapeamento dinâmico e colaborativo de alagamentos na cidade de São Paulo. Boletim de Ciências Geodésicas, $602-623$.

Horton, R. E. (1940). an Approach Toward a Physical Interpretation of Infiltration-Capacity. Soil Science Society of America Journal, 5, 399-417. Recuperado de https://dl.sciencesocieties.org/publications/sssaj/abstracts/5/C/SS00500C0399

IBGE. Instituto Brasilero de Geografia e Estatística. Recuperado de https://www.ibge.gov.br/. Acceso em 2017

Johnson, R. A., \& Wichern, D. W. (2007). Applied Multivariate Statistical Analysis.

Krajewski, W. F., \& Smith, J. A. (2002). Radar hydrology: Rainfall estimation. Advances in Water Resources, 25(8-12), 1387-1394. https://doi.org/10.1016/S03091708(02)00062-3

Libertino, A., Allamano, P., Claps, P., Cremonini, R., \& Laio, F. (2015). Radar Estimation of Intense Rainfall Rates through Adaptive Calibration of the Z-R Relation. Atmosphere, 6(10), 1559-1577. https://doi.org/10.3390/atmos6101559

Liechti, K., Panziera, L., Germann, U., \& Zappa, M. (2013). Flash-flood early warning using weather radar data: from nowcasting to forecasting. Hydrology and Earth System Sciences Discussions, 10(1), 1289-1331. https://doi.org/10.5194/hessd-10-1289-2013

Marshall, J. S., \& Palmer, W. M. (1948). The Distribution of Raindrops with Size. Journal of Meteorology, 5, 165-166.

Montopoli, M., \& Marzano, F. S. (2011). Meteorological Radar Systems. In Integrated Ground-Based Observing Systems: Applications for Climate, Meteorology and Civil Protection (p. 33-58). https://doi.org/10.1007/978-3-642-12968-1 
Morales, C. A. (2015). Exploring the use of mini-radars for high-resolution QPE in São Paulo - Brazil. In 37th Conference on Radar Meteorology. Oklahoma: American Meteorological Society.

Morales, C. A., Testud, J., Javelle, P., Moreau, E., Rocha Filho, K., \& Conde, F. (2017). ChuvaOnline:A X-Band Radar Network Used for High Spatial and Temporal Rainfall Monitoring. In 38th Conference on Radar Meteorology. Chicago, Illinois/EUA: American Meteorological Society.

Naccarato, K. P. (2006). Análise das características dos relâmpagos na Região Sudeste do Brasil. Instituto Nacional de Pesquisas Espaciais (INPE).

Oliveira, A. P., \& Silva Dias, P. L. (1982). Aspectos observacionais da brisa marítima em São Paulo. In Congresso Brasileiro de Meteorologia (p. 2). Pelotas.

Oliveira, C. P. M., da Silva, C. V. ., Sosnoski, A. S. K. B., Bozzini, P. L., Rossi, D. M., Uemura, S., \& Conde, F. (2014). Warning System Based on Real-Time Flood Forecasts in São Paulo, Brazil. In International Conference on Flood Management (p. 1-12).

Oliveira, R. A. J. (2017). Characteristics and error modeling of GPM satellite rainfall estimates during chuva campaign in Brazil. Instituto Nacional de Pesquisas Espaciais INPE. Recuperado de http://urlib.net/8JMKD3MGP3W34P/3NU3598

Parzen, E. (1962). On Estimation of a Probability Density Function and Mode. The Annals of Mathematical Statistics, 33(3), 1065-1076.

Paula, G. A. (2013). Modelos de Regressão com apoio computacional. Sao Paulo: Instituto de Matemática e Estatística-Universidade de São Paulo. Recuperado de http://www.ime.usp.br/ giapaula/livro.pdf

Paz, A. R. da, \& Collischonn, W. (2011). Avaliação de estimativas de campos de precipitação para modelagem hidrológica distribuída. Revista Brasileira de Meteorologia, 26(1), 109-120. https://doi.org/10.1590/S0102-77862011000100010

Pereira Filho, A. J. (1999). Radar measurements of tropical summer convection: urban feedback on flash floods. 29th International Conference on Radar meteorology.

Pereira Filho, A. J., Barros, M. T. L., Hallak, R., \& Gandu, A. W. (2004). Enchentes na região metropolitana de São Paulo: aspectos de mesoescala e a avaliação de impactos. In XIII Congresso Brasileiro de Meteorologia (p. 28-93). Fortaleza, Brazil.

Pereira Filho, A. J., Haas, R., \& Ambrizzi, T. (2002). Caracterização de eventos de enchente na Bacia do Alto Tietê por meio do radar meteorológico e da modelagem numérica de mesoescala. In Congresso Brasileiro de Meteorologia (p. 2864-2873). Foz do Iguaçu, PR.

Pereira Filho, A. J., Massambani, O., Hallak, R., Karam, H. H., \& Paulo, S. (2000). A Hydrometeorological Forecast System for the Metropolitan Area of São Paulo. In Symposium on Nowcasting and Very Short Range Forecasting. 
Pereira Filho, A. J., \& Silva, F. D. S. (2005). The Morphology of Tropical Rainfall Systems and their Hydrological Significance. 32Nd Conference on Radar Meteorology.

Recuperado de http://ams.confex.com/ams/32Rad11Meso/techprogram/paper_96859.htm

Pisani, A. (1995). Avaliação dos Dados do Radar Meteorológico de São Paulo para Aplicação em Hidrologia. Universidade de São Paulo.

Queiroz, A. P. (2008). Monitoramento e previsão imediata de tempestades severas usando dados de radar. Instituto Nacional de Pesquisas Espaciais - INPE.

Rasyid, A. R., Bhandary, N. P., \& Yatabe, R. (2016). Performance of frequency ratio and logistic regression model in creating GIS based landslides susceptibility map at Lompobattang Mountain, Indonesia. Geoenvironmental Disasters, 3(1), 19. https://doi.org/10.1186/s40677-016-0053-x

Reboita, M. S., Gan, M. A., Rocha, R. P. da, \& Ambrizzi, T. (2010). Regimes de precipitação na América do Sul: uma revisão bibliográfica. Revista Brasileira de Meteorologia, 25(2), 185-204. https://doi.org/10.1590/S0102-77862010000200004

Richards, W. G., \& Crozier, C. L. (2010). Precipitation measurement with a C - band weather radar in southern Ontario. Atmosphere-Ocean, 5900. https://doi.org/10.1080/07055900.1983.9649160

Rinehart, R. E. (1997). RADAR for Meteorologists. Rinehart Publications.

Rocha Filho, K., Conde, F., \& Andrioli, C. P. (2013). Correção em tempo real da precipitação estimada por uma radar metrológico com uma rede de superfície. In XX Simpósio Brasileiro de Recursos Hídricos. Bento Gonçalves.

Rocha Filho, K., Conde, F., \& Andrioli, C. P. (2015). Estimativas de Precipitação no Leste de São Paulo com Radar de Dupla Polarização. In XXI Simposio Brasileiro de Recursos Hidricos (p. 1-8).

Ryzhkov, A. V., Giangrande, S. E., \& Schuur, T. J. (2005). Rainfall Estimation with a Polarimetric Prototype of WSR-88D. Journal of Applied Meteorology, 44(4), 502-515. https://doi.org/10.1175/JAM2213.1

Sampson, E. S. (2008). The correlation between soil permeability and flooding in the Northeast Sector of the Dog River Watershed. Caspion, 1-7. Recuperado de http://www.biology-online.org/dictionary/Cytoplasm

Santos, L. L. dos. (2009). Modelos Hidráulicos-Hidrológicos: Conceitos e Aplicações. Revista Brasileira de Geografia Física, 2(3), 1-19. Recuperado de https://periodicos.ufpe.br/revistas/rbgfe/article/view/232624/26638

SELEX System Integration. (2010). Hydrological Products. In Rainbow 5. Products and Algorithms (p. 113-124). 
Seliga, T., \& Bringi, V. (1978). Differential reflectivity and differential phase shift: Applications in radar meteorology. Radio Science, 271-275.

Seliga, T. A., \& Bringi, V. N. (2018). Differential reflectivity and differential phase shift: Applications in radar meteorology. Radio Science, 13(2), 271-275. https://doi.org/10.1029/RS013i002p00271

Šercl, P. (2011). The Robust Method for an Estimate of Runoff caused by Torrential Rainfall and a Proposal of a Warning System. Early Warning for Flash Floods, 76-81.

Silva, F. D. D. S., Pereira Filho, A. J., \& Hallak, R. (2009). Classificação de sistemas meteorológicos e comparação da precipitação estimada pelo radar e medida pela rede telemétrica na bacia hidrográfica do alto Tietê. Revista Brasileira de Meteorologia, 24(3), 292-307. https://doi.org/10.1590/S0102-77862009000300004

Steiner, M., \& Smith, J. A. (1998). Convective versus stratiform rainfall: An icemicrophysical and kinematic conceptual model. Atmospheric Research, 317-326.

Steiner, M., Smith, J. a., Burges, S. J., Alonso, C. V., \& Darden, R. W. (1999). Effect of bias adjustment and rain gauge data quality control on radar rainfall estimation. Water Resources Research, 35(8), 2487. https://doi.org/10.1029/1999WR900142

Tarboton, D. G. (2003). Rainfall-Runoff Processes. (N. W. S. COMET, Org.), Methods in cell biology (Vol. 1). Utah: Utah State University. https://doi.org/10.1061/(ASCE)IR.1943-4774.0000380

Tucci, C. E. M. (2005). Modelos hidrológicos ( $2^{\circ}$ ed). Editora da UFRGS.

Ulbrich, C. W., \& Lee, L. G. (1999). Rainfall measurement error by WSR-88D radars due to variations in Z-R law parameters and the radar constant. Journal of Atmospheric and Oceanic Technology, 16(8), 1017-1024. https://doi.org/10.1175/15200426(1999)016<1017:RMEBWR>2.0.CO;2

Vemado, F. (2012). Análise da circulação de brisa marítima e seus impactos sobre a precipitação na Região Metropolitana de São Paulo por meio do modelo ARPS. https://doi.org/10.1017/CBO9781107415324.004

Yuter, S. (2003). Precipitation Radar. Encyclopedia of Atmospheric Sciences, 1833-1851. https://doi.org/10.1016/B978-0-12-382225-3.00328-5

Zhu, D., Xuan, Y., \& Cluckie, I. (2014). Hydrological appraisal of operational weather radar rainfall estimates in the context of different modelling structures. Hydrology and Earth System Sciences, 18(1), 257-272. https://doi.org/10.5194/hess-18-257-2014

Zrnic, D. S., \& Ryzhkov, A. V. (1999). Polarimetry for Weather Surveillance Radars. Bulletin of the American Meteorological Society, 80(3), 389-406. https://doi.org/10.1175/1520-0477(1999)080<0389:PFWSR>2.0.CO;2 


\section{Apêndices}

\section{A1.Descrição do controle de qualidade dos postos pluviométricos}

Os postos pluviométricos representados em cor vermelho representam os postos que não foram considerados nos analises do estudo.

\begin{tabular}{|c|c|c|c|c|c|c|c|c|c|}
\hline \multirow[b]{2}{*}{ No } & \multicolumn{9}{|c|}{$\begin{array}{l}\text { Tabela A1.1. Características dos resultados obtidos no controle de qualidade dos postos } \\
\text { pluviométricos da cidade de São Paulo durante o ano } 2015\end{array}$} \\
\hline & Pluviómetro & $\begin{array}{c}\text { Media } \\
{[\mathrm{mm}]}\end{array}$ & $\begin{array}{c}\text { Desvio } \\
\text { Padrão } \\
\text { [mm] }\end{array}$ & $\begin{array}{l}\text { Máx. } \\
\text { [mm] }\end{array}$ & $\begin{array}{l}\text { Mín. } \\
\text { [mm] }\end{array}$ & $\begin{array}{c}\text { Num. } \\
\text { dados } \\
\text { negativos }\end{array}$ & $\begin{array}{c}\text { Num. de } \\
\text { dados sem } \\
\text { informação }\end{array}$ & $\begin{array}{l}\text { Registros } \\
\text { com zeros }\end{array}$ & $\begin{array}{c}\text { Num. de } \\
\text { registros } \\
\text { com valores } \\
\text { constantes }\end{array}$ \\
\hline 1 & 11 & 0,0256 & 0,2934 & 17 & 0 & 0 & 0 & 50852 & 1 \\
\hline 2 & 143 & 0,0167 & 0,4882 & 19,8 & -9 & 84 & 0 & 50606 & 1 \\
\hline 3 & 149 & 0,0291 & 0,3138 & 24,4 & 0 & 0 & 0 & 50607 & 0 \\
\hline 4 & 157 & 0,0322 & 0,6170 & 48,2 & 0 & 0 & 0 & 51894 & 0 \\
\hline 5 & 168 & 0,0248 & 0,3027 & 17 & $-0,8$ & 1 & 0 & 50858 & 0 \\
\hline 6 & 273 & 0,0319 & 0,3752 & 22,8 & $-13,88$ & 2 & 0 & 50498 & 0 \\
\hline 7 & 275 & 0,0160 & 0,5267 & 18,8 & -9 & 90 & 0 & 50631 & 0 \\
\hline 8 & 277 & 0,0246 & 0,2675 & 16,8 & $-0,4$ & 2 & 0 & 50734 & 0 \\
\hline 9 & 279 & 0,0354 & 0,3452 & 14,8 & $-0,2$ & 2 & 0 & 50439 & 0 \\
\hline 10 & 280 & 0,0192 & 0,5028 & 19,8 & -9 & 88 & 0 & 50425 & 1 \\
\hline 11 & 282 & 0,0240 & 0,2567 & 12 & -9 & 2 & 0 & 50741 & 0 \\
\hline 12 & 283 & 0,0195 & 0,5496 & 24,8 & -9 & 89 & 0 & 50639 & 0 \\
\hline 13 & 284 & 0,0280 & 0,4419 & 52 & $-51,8$ & 3 & 0 & 50647 & 1 \\
\hline 14 & 296 & 0,0356 & 0,3888 & 18,8 & $-0,2$ & 1 & 0 & 50621 & 0 \\
\hline 15 & 346 & 0,0277 & 0,2900 & 13,6 & 0 & 0 & 0 & 50326 & 0 \\
\hline 16 & 347 & 0,0334 & 0,3775 & 19,8 & -9 & 1 & 0 & 50510 & 0 \\
\hline 17 & 397 & 0,0338 & 0,3785 & 20,2 & -9 & 4 & 0 & 50483 & 0 \\
\hline 18 & 405 & 0,0296 & 0,3266 & 14 & $-9,74$ & 3 & 0 & 50655 & 1 \\
\hline 19 & 413 & 0,0301 & 0,3415 & 21,8 & 0 & 0 & 0 & 50709 & 0 \\
\hline 20 & 508 & $-1,5136$ & 3,3944 & 16,2 & -9 & 8933 & 0 & 42239 & 0 \\
\hline 21 & 511 & 0,0317 & 0,4070 & 19,6 & $-48,48$ & 205 & 0 & 50130 & 1 \\
\hline 22 & 523 & $-0,0200$ & 0,7960 & 28,5 & -9 & 307 & 0 & 50642 & 0 \\
\hline 23 & 527 & 0,0311 & 0,3482 & 20,4 & $-0,4$ & 1 & 0 & 50607 & 0 \\
\hline 24 & 528 & 0,0327 & 0,4822 & 30,6 & $-0,2$ & 1 & 0 & 51346 & 0 \\
\hline 25 & 563 & 0,0335 & 0,3820 & 22,6 & $-0,2$ & 1 & 0 & 50556 & 0 \\
\hline 26 & 580 & 0,0263 & 0,3010 & 17,4 & 0 & 0 & 0 & 50624 & 1 \\
\hline 27 & 1000350 & 0,0291 & 0,3031 & 13 & $-5,4$ & 3 & 0 & 50488 & 0 \\
\hline 28 & 1000360 & 0,0271 & 0,5061 & 23,8 & -9 & 54 & 0 & 50447 & 0 \\
\hline 29 & 1000370 & 0,0278 & 0,4149 & 15 & -9 & 34 & 0 & 50261 & 0 \\
\hline
\end{tabular}




\begin{tabular}{|c|c|c|c|c|c|c|c|c|c|}
\hline No & Pluviómetro & $\begin{array}{l}\text { Media } \\
{[\mathrm{mm}]}\end{array}$ & $\begin{array}{c}\text { Desvio } \\
\text { Padrão } \\
{[\mathrm{mm}]}\end{array}$ & $\begin{array}{l}\text { Máx. } \\
\text { [mm] }\end{array}$ & $\begin{array}{l}\text { Mín. } \\
\text { [mm] }\end{array}$ & $\begin{array}{c}\text { Num. } \\
\text { dados } \\
\text { negativos }\end{array}$ & $\begin{array}{c}\text { Num. de } \\
\text { dados sem } \\
\text { informação }\end{array}$ & $\begin{array}{l}\text { Registros } \\
\text { com zeros }\end{array}$ & $\begin{array}{l}\text { Num. de } \\
\text { registros } \\
\text { com valores } \\
\text { constantes }\end{array}$ \\
\hline 30 & 1000380 & 0,0266 & 0,3471 & 17,4 & -9 & 15 & 0 & 50397 & 0 \\
\hline 31 & 1000410 & 0,0282 & 0,2671 & 18,6 & $-0,4$ & 1 & 0 & 50320 & 1 \\
\hline 32 & 1000430 & 0,0255 & 0,3150 & 19,2 & $-13,81$ & 194 & 0 & 50354 & 0 \\
\hline 33 & 1000440 & 0,0278 & 0,4164 & 17 & -9 & 23 & 0 & 50543 & 0 \\
\hline 34 & 1000450 & 0,0276 & 0,4392 & 21,2 & -9 & 23 & 0 & 50660 & 0 \\
\hline 35 & 1000470 & 0,0320 & 0,3626 & 21,6 & 0 & 0 & 0 & 50625 & 0 \\
\hline 36 & 1000480 & 0,0302 & 0,4104 & 20,2 & -9 & 19 & 0 & 50445 & 0 \\
\hline 37 & 1000490 & 0,0283 & 0,3483 & 15,6 & -9 & 13 & 0 & 50456 & 0 \\
\hline 38 & 1000500 & 0,0322 & 0,3173 & 15,6 & $-0,2$ & 1 & 0 & 50441 & 0 \\
\hline 39 & 1000510 & 0,0200 & 0,2013 & 10,6 & $-0,2$ & 1 & 0 & 50486 & 0 \\
\hline 40 & 1000550 & 0,0285 & 0,3568 & 14,6 & -9 & 14 & 0 & 50471 & 0 \\
\hline 41 & 1000640 & 0,0320 & 0,3626 & 21,6 & 0 & 0 & 0 & 50625 & 0 \\
\hline 42 & 1000790 & 0,0328 & 0,3576 & 27,4 & 0 & 0 & 0 & 50523 & 0 \\
\hline 43 & 1000814 & $-0,0011$ & 0,7638 & 48 & -39 & 207 & 0 & 50410 & 0 \\
\hline 44 & 1000817 & 0,0250 & 0,2632 & 16 & $-0,6$ & 2 & 0 & 50617 & 0 \\
\hline 45 & 1000837 & 0,0304 & 0,3148 & 17,5 & 0 & 0 & 0 & 50813 & 0 \\
\hline 46 & 1000838 & 0,0179 & 0,2080 & 14,8 & 0 & 0 & 0 & 50968 & 1 \\
\hline 47 & 1000839 & 0,0272 & 0,2822 & 13 & 0 & 0 & 0 & 50731 & 1 \\
\hline 48 & 1000843 & 0,0328 & 0,3475 & 13,8 & 0 & 0 & 0 & 50595 & 0 \\
\hline 49 & 1000845 & 0,0316 & 0,3247 & 13 & 0 & 0 & 0 & 50721 & 1 \\
\hline 50 & 1000846 & 0,0206 & 0,2515 & 11 & 0 & 0 & 0 & 51184 & 0 \\
\hline 51 & 1000847 & 0,0319 & 0,3694 & 20,6 & 0 & 0 & 0 & 50717 & 0 \\
\hline 52 & 1000851 & 0,0302 & 0,3419 & 18 & -9 & 2 & 0 & 50594 & 0 \\
\hline 53 & 1000853 & 0,0304 & 0,3152 & 15,4 & 0 & 0 & 0 & 50513 & 0 \\
\hline 54 & 1000858 & 0,0309 & 0,3494 & 16,2 & 0 & 0 & 0 & 50703 & 0 \\
\hline 55 & 1000861 & 0,0392 & 1,5196 & 22,95 & $-14,3$ & 406 & 0 & 49971 & 0 \\
\hline 56 & 1000863 & 0,0259 & 0,3499 & 17,2 & $-37,4$ & 1 & 0 & 50758 & 0 \\
\hline 57 & 1000865 & 0,0288 & 0,2975 & 13,8 & $-0,2$ & 1 & 0 & 50714 & 0 \\
\hline 58 & 1000868 & 0,0309 & 0,3186 & 15,8 & 0 & 0 & 0 & 50578 & 0 \\
\hline 59 & 1000879 & 0,0254 & 0,4259 & 18 & -9 & 37 & 0 & 50576 & 0 \\
\hline \multirow[t]{5}{*}{60} & 1000883 & 0,0255 & 0,2991 & 20,6 & $-0,2$ & 1 & 0 & 50839 & 0 \\
\hline & TOTAL & $\mathbf{0 , 0 7 8 2}$ & & & & 10872 & $\mathbf{0}$ & & 11 \\
\hline & MEDIA & 0,0013 & 0,4427 & 19,829 & $-6,8168$ & 181,2 & 0 & $\mathbf{5 0 4 7 6 , 1}$ & \\
\hline & MAX. & $\mathbf{0 , 0 3 9 2}$ & 3,3944 & 52,0 & $\mathbf{0 , 0}$ & 8933 & 0 & 51894 & 1 \\
\hline & MIN. & $-1,5136$ & 0,2013 & 10,6 & $-51,8$ & 0 & 0 & 42239 & $\mathbf{0}$ \\
\hline
\end{tabular}


A2.Descrição das estadísticas gerais das escalas temporais de 10 minutos, 1 hora e 1 dia na comparação da precipitação registrada pelos pluviômetros e o radar

POD: Probabilidade de Detecção

FAR: Taxa de Falso Alarme

TSC: Taxa de Sucesso Critico

SR: Taxa de Sucesso

\begin{tabular}{|c|c|c|c|c|c|c|c|c|c|c|c|c|c|c|c|c|c|}
\hline \multirow[b]{2}{*}{ No } & \multicolumn{17}{|c|}{ Tabela A2.1. Características estadísticas gerais para escala temporal de 10 minutos } \\
\hline & Posto & $\operatorname{maxp}$ & sump & $\operatorname{maxr}$ & sumr & Dif & $\mathbf{R 2}$ & declive & Sem Inf & POD & FAR & TSC & SR & BIAS & sd & vies & RMSE \\
\hline 1 & 1000470 & 21,6 & 1681 & 3,64 & 1549,40 & 131,60 & 0,61 & 0,99 & 33654 & 0,34 & 0,05 & 0,33 & 0,95 & 0,35 & 0,24 & 0,00 & 0,24 \\
\hline 2 & 1000640 & & & 13,64 & 1549,40 & 1,60 & 0,61 & & 654 & & 0,05 & 33 & 0,95 &, 35 &, 24 & 0,00 & 0,24 \\
\hline 3 & 1000790 & & 24,4 & 14,54 & 1450,00 & 274,40 & & & 33654 & & & & & 0,37 & 0,24 & 0,01 & 0,24 \\
\hline 4 & 1000837 & 17,5 & 1600 & 13,54 & 1393,15 & 206,85 & 0,55 & 0,85 & 3654 & 0,29 & 0,04 & 28 & 0,96 & 0,30 & 0,24 & 0,00 & 0,24 \\
\hline 5 & 1000838 & & 942 & 12,91 & 1354,12 & $-412,12$ & 0,49 & 55 & 33654 & 28 & 0,04 & 28 & 0,96 & 0,29 & 0,19 & $-0,01$ &, 19 \\
\hline 6 & 1000839 & 1 & 1431,6 & 14,81 & 1496,77 & $-65,17$ & 0,55 & 0,70 & 33654 & 0,30 & 0,05 & 0,29 & 0,95 & 0,31 & 0,22 & 0,00 & 0,22 \\
\hline 7 & 1000843 & 13,8 & 1725,8 & 13,04 & 1455,72 & 270,08 & 0,60 & 0,96 & 33654 & & 0,06 & 0,30 & 0,94 &, 33 & 0,23 & 0,01 & \\
\hline 8 & 1000845 & & & & & & & & & & & & & & & & \\
\hline 9 & 1000846 & 11 & 1081 & 11,67 & 1501,79 & $-420,79$ & 0,47 & 0,62 & 33654 & & 0,04 & 0,24 & 0,96 & 0,25 & 0,21 & $-0,01$ & 0,21 \\
\hline 10 & 1000847 & 20,6 & 1675,8 & 14,76 & 1373,22 & 302,58 & 0,62 & 1,03 & 33654 & 0,32 & 0,04 & 0,32 & 0,96 & 0,34 & 0,25 & 0,01 & 0,25 \\
\hline 11 & 1000853 & 15,4 & 1599,6 & 13,28 & 1522,96 & 76,64 & 0,67 & 0,90 & 33654 & 0,35 & 0,06 & 0,34 & 0,94 & 0,37 & 0,19 & 0,00 & 0,19 \\
\hline 12 & 1000858 & & 1625,4 & 13,02 & 1510,89 & 114,51 & 0,62 & & 33654 & & & & & & & & \\
\hline 13 & 1000868 & 15,8 & 1624,6 & 18,04 & 1463,32 & 161,28 & 0,58 & 0,83 & 33654 & 0,33 & 0,04 & 0,32 & 0,96 & 0,34 & 0,23 & 0,00 & 0,23 \\
\hline 14 & 11 & 17 & 1348 & 12,81 & 1476,44 & $-128,44$ & 0,59 & 0,83 & 33654 & 0,27 & 0,05 & 0,27 & 0,95 & 0,29 & 0,20 & 0,00 & 0,20 \\
\hline 15 & 149 & & 1530,6 & 19,55 & 1378,41 & 152,19 & 0,5 & & 3654 & & 06 & & &, 36 & 0,23 & 0,00 & 0,23 \\
\hline 16 & 157 & 48,2 & 1690,2 & 17,41 & 1534,54 & 155,66 & 0,03 & & 33654 & & & & & 0,11 & & 0,00 & 0,64 \\
\hline 17 & 346 & & 1455,8 & 16,83 & 1413,60 & 42,20 & 0,52 & & 33654 & & & & & 0,25 & & & 0,21 \\
\hline 18 & 413 & 21,8 & 1583,8 & 12,64 & 1426,82 & 156,98 & 0,37 & 0,73 & 33654 & 0,30 & 0,04 & 0,30 & 0,96 & 0,31 & 0,29 & 0,00 & 0,29 \\
\hline 19 & 580 & 17,4 & 1384,8 & 17,75 & 1393,70 & $-8,90$ & 0,47 & & 33654 & & & & & 0,35 & 0,23 & & 0,23 \\
\hline & MÉDIA & 19,16 & 1528,78 & 14,48 & 1454,61 & 74,17 & $\mathbf{0 , 5 3}$ & & 33654,00 & & & & & 0,31 & & & \\
\hline & SD & 8,25 & 215,17 & & 63,68 & 206,98 & 0,14 & 0,18 & $\mathbf{0 , 0 0}$ & 0,06 & 0,03 & 0,06 & 0,03 & 0,06 & 0,10 & 0,00 & 0,10 \\
\hline & MAX & 48,20 & 1725,80 & 19,55 & 1549,40 & 302,58 & 0,67 & 1,03 & 33654,00 & 0,35 & 0,19 & 0,35 & 0,98 & 0,37 & 0,64 & 0,01 & 0,64 \\
\hline
\end{tabular}


Tabela A2.2. Características estadísticas gerais para escala temporal de 1 hora

\begin{tabular}{|c|c|c|c|c|c|c|c|c|c|c|c|c|c|c|c|c|}
\hline \multirow[b]{2}{*}{ No } & \multicolumn{16}{|c|}{ Tabela A2.2. Características estadísticas gerais para escala temporal de 1 hora } \\
\hline & Posto & $\operatorname{maxp}$ & sump & $\operatorname{maxr}$ & sumr & Dif & $\mathbf{R 2}$ & declive & POD & FAR & TSC & SR & BIAS & sd & vies & RMSE \\
\hline 1 & 1000470 & 50,2 & 1681 & 36,06 & 1549,40 & 131,60 & 0,78 & 1,09 & 0,47 & 0,20 & 0,42 & 0,80 & 0,59 & 0,72 & 0,02 & 0,72 \\
\hline 2 & 1000640 & 50,2 & 1681 & 36,06 & 1549,40 & 131,60 & 0,78 & 1,09 & 0,47 & 0,20 & 0,42 & 0,80 & 0,59 & 0,72 & 0,02 & 0,72 \\
\hline 3 & 1000790 & 68,8 & 1724,4 & 45,10 & 1450,00 & 274,40 & 0,72 & 1,14 & 0,47 & 0,16 & 0,43 & 0,84 & 0,56 & 0,82 & 0,03 & 0,82 \\
\hline 4 & 1000837 & 39,75 & 1600 & 41,02 & 1393,15 & 206,85 & 0,63 & 0,99 & 0,40 & 0,14 & 0,37 & 0,86 & 0,46 & 0,82 & 0,02 & 0,82 \\
\hline 5 & 1000838 & 28 & 942 & 26,90 & 1354,12 & $-412,12$ & 0,66 & 0,67 & 0,42 & 0,11 & 0,39 & 0,89 & 0,47 & 0,57 & $-0,05$ & 0,57 \\
\hline 6 & 1000839 & 29 & 1431,6 & 32,87 & 1496,77 & $-65,17$ & 0,73 & 0,85 & 0,40 & 0,16 & 0,37 & 0,84 & 0,48 & 0,63 & $-0,01$ & 0,63 \\
\hline 7 & 1000843 & 32,4 & 1725,8 & 26,75 & 1455,72 & 270,08 & 0,78 & 1,16 & 0,43 & 0,16 & 0,39 & 0,84 & 0,50 & 0,69 & 0,03 & 0,69 \\
\hline 8 & 1000845 & 31 & 1661,5 & 32,41 & 1393,36 & 268,14 & 0,66 & 1,06 & 0,44 & 0,16 & 0,41 & 0,84 & 0,52 & 0,80 & 0,03 & 0,80 \\
\hline 9 & 1000846 & 36 & 1081 & 25,75 & 1501,79 & $-420,79$ & 0,66 & 0,80 & 0,33 & 0,10 & 0,32 & 0,90 & 0,36 & 0,69 & $-0,05$ & 0,69 \\
\hline 10 & 1000847 & 70,4 & 1675,8 & 48,63 & 1373,22 & 302,58 & 0,68 & 1,15 & 0,44 & 0,14 & 0,41 & 0,86 & 0,51 & 0,92 & 0,03 & 0,92 \\
\hline 11 & 1000853 & 45,2 & 1599,6 & 40,39 & 1522,96 & 76,64 & 0,84 & 1,02 & 0,47 & 0,19 & 0,42 & 0,81 & 0,58 & 0,53 & 0,01 & 0,53 \\
\hline 13 & 1000868 & 37,6 & 1624,6 & 45,47 & 1463,32 & 161,28 & 0,68 & 0,94 & 0,44 & 0,14 & 0,41 & 0,86 & 0,51 & 0,75 & 0,02 & 0,75 \\
\hline 14 & 11 & 40,6 & 1348 & 33,68 & 1476,44 & $-128,44$ & 0,79 & 0,90 & 0,39 & 0,14 & 0,37 & 0,86 & 0,46 & 0,55 & $-0,01$ & 0,55 \\
\hline 15 & 149 & 37,4 & 1530,6 & 29,28 & 1378,41 & 152,19 & 0,75 & 1,06 & 0,45 & 0,17 & 0,42 & 0,83 & 0,54 & 0,63 & 0,02 & 0,63 \\
\hline 16 & 157 & 48,2 & 1690,2 & 43,91 & 1534,54 & 155,66 & 0,79 & 1,05 & 0,40 & 0,11 & 0,38 & 0,89 & 0,45 & 0,69 & 0,02 & 0,69 \\
\hline 17 & 346 & 32,9 & 1455,8 & 23,47 & 1413,60 & 42,20 & 0,71 & 1,05 & 0,38 & 0,07 & 0,37 & 0,93 & 0,41 & 0,67 & 0,00 & 0,67 \\
\hline 18 & 413 & 39,6 & 1583,8 & 31,69 & 1426,82 & 156,98 & 0,62 & 1,01 & 0,42 & 0,14 & 0,39 & 0,86 & 0,49 & 0,84 & 0,02 & 0,84 \\
\hline \multirow[t]{4}{*}{19} & 580 & 48,4 & 1384,8 & 51,40 & 1393,70 & $-8,90$ & 0,67 & 0,87 & 0,48 & 0,23 & 0,42 & 0,77 & 0,62 & 0,72 & 0,00 & 0,72 \\
\hline & MEDIA & 42,23 & 1528,78 & 36,07 & 1454,61 & 74,17 & 0,72 & 1,00 & 0,43 & 0,15 & $\mathbf{0 , 3 9}$ & $\mathbf{0 , 8 5}$ & 0,51 & 0,71 & $\mathbf{0 , 0 1}$ & 0,71 \\
\hline & SD & 11,84 & 215,17 & 8,17 & 63,68 & 206,98 & $\mathbf{0 , 0 7}$ & 0,13 & 0,04 & 0,04 & $\mathbf{0 , 0 3}$ & 0,04 & 0,07 & 0,10 & $\mathbf{0 , 0 2}$ & 0,10 \\
\hline & MAX & $\mathbf{7 0 , 4 0}$ & 1725,80 & 51,40 & 1549,40 & 302,58 & $\mathbf{0 , 8 4}$ & 1,16 & 0,48 & 0,23 & $\mathbf{0 , 4 3}$ & $\mathbf{0 , 9 3}$ & 0,62 & 0,92 & $\mathbf{0 , 0 3}$ & 0,92 \\
\hline
\end{tabular}




\begin{tabular}{|c|c|c|c|c|c|c|c|c|c|c|c|c|c|c|c|c|}
\hline \multirow[b]{2}{*}{ No } & \multicolumn{16}{|c|}{ Tabela A2.3. Características estadísticas gerais para escala temporal de 1 dia } \\
\hline & Posto & $\operatorname{maxp}$ & sump & $\operatorname{maxr}$ & sumr & Dif & $\mathbf{R 2}$ & declive & POD & FAR & TSC & SR & BIAS & sd & vies & RMSE \\
\hline 1 & 1000470 & 89,4 & 1681 & 363,39 & 9296,40 & $-7615,40$ & 0,85 & 0,17 & 0,85 & 0,16 & 0,73 & 0,84 & 1,01 & 51,80 & $-20,86$ & 51,73 \\
\hline 2 & 1000640 & 4 & 1681 & 363,39 & 9296,40 & $-7615,40$ & 0,85 & 0,17 & 0,85 & 0,16 & 0,73 & 0,84 & 1,01 & 51,80 & $-20,86$ & 51,73 \\
\hline 3 & 1000790 & 98 & 1 & 400,70 & 8700,00 & $-6975,60$ & 0,82 & 0,19 & 0,85 & & 0,76 & 0,88 & 0,97 & 47,61 & $-19,11$ & 47,55 \\
\hline 4 & 1000837 & 73,75 & 1600 & 421,78 & 8358,88 & $-6758,88$ & 0,77 & 0,17 & 0,77 & 0,13 & 0,69 & 0,87 & 0,88 & 49,02 & $-18,52$ & 48,95 \\
\hline 5 & 1000838 & 58,2 & 942 & 439,62 & 8124,74 & $-7182,74$ & 0,78 & 0,11 & 0,76 & 0,08 & 0,71 & 0,92 & 0,82 & 50,09 & $-19,68$ & 50,02 \\
\hline 6 & 1000839 & 70,4 & 1431,6 & 538,46 & 8980,62 & $-7549,02$ & 0,83 & 0,15 & 0,73 & 0,16 & 0,64 & 0,84 & 0,86 & 52,99 & $-20,68$ & 52,92 \\
\hline 7 & 1000843 & 69,4 & 1725,8 & 362,27 & 8734,33 & $-7008,53$ & 0,86 & 0,18 & 0,70 & 0,13 & 0,64 & 0,88 & 0,80 & 47,07 & $-19,20$ & 47,01 \\
\hline 8 & 1000845 & & & & & & 0,77 & & & & & & & & & 4,36 \\
\hline 9 & 1000846 & 67,8 & 1081 & 335,65 & 9010,71 & $-7929,71$ & 0,73 & 0,13 & 0,63 & & 0,60 & 0,93 & 0,67 & 51,81 & $-21,73$ & 51,74 \\
\hline 10 & 1000847 & 80,6 & 1675,8 & 388,11 & 8239,30 & $-6563,50$ & 0,75 & 0,18 & 0,76 & 0,10 & 0,70 & 0,90 & 0,84 & 47,17 & $-17,98$ & 47,11 \\
\hline 11 & 1000853 & 69 & 1599,6 & 396,37 & 9137,76 & $-7538,16$ & 0,89 & 0,17 & 0,79 & 0,13 & 0,71 & 0,87 & 0,91 & 52,60 & $-20,65$ & 52,52 \\
\hline 12 & 1000858 & & & & 9065,37 & & 0,87 & & & & & & & & & 49,27 \\
\hline 13 & 1000868 & & 1624,6 & 369,51 & 8779,93 & $-7155,33$ & 0,81 & 0,17 & 0,80 & 0,13 & 0,71 & 0,87 & 0,92 & 48,40 & $-19,60$ & 48,33 \\
\hline 14 & 11 & 55,2 & 1348 & 436,90 & 8858,61 & $-7510,61$ & 0,86 & 0,15 & 0,73 & 0,09 & 0,68 & 0,91 & 0,80 & 49,71 & $-20,58$ & 49,64 \\
\hline 15 & 149 & 100,2 & 1530,6 & 407,72 & 8270,46 & $-6739,86$ & 0,85 & 18 & 84 & 13 & 0,75 & 0,87 &, 96 & 45,34 & $-18,47$ & 45,28 \\
\hline 16 & 157 & & 1690,2 & 360,76 & 9207,22 & $-7517,02$ & 0,84 & & & & 0,67 & 0,89 & 0,82 & 50,34 & $-20,59$ & 50,28 \\
\hline 17 & 346 & 61,8 & 1455,8 & 370,83 & 8481,61 & $-7025,81$ & 0,80 & & 0,73 & 0,09 & 0,68 & 0,91 & 0,80 & 46,36 & $-19,25$ & 46,30 \\
\hline 18 & 413 & 62 & 1583,8 & 413,46 & 8560,92 & $-6977,12$ & 0,78 & 0,16 & 0,76 & 0,14 & 0,67 & 0,86 & 0,88 & 49,55 & $-19,12$ & 49,48 \\
\hline 19 & 580 & & 1384,8 & 356,58 & 8362,23 & $-6977,43$ & 0,84 & 0,15 & 0,87 & 0,28 & 0,65 & 0,72 & 1,20 & 48,12 & $-19,12$ & 48,06 \\
\hline & MEDIA & 73,29 & 1528,78 & 390,99 & 8727,67 & $-7198,88$ & 0,82 & 0,17 & 0,77 & $\mathbf{0 , 1 3}$ & 0,69 & $\mathbf{0 , 8 7}$ & $\mathbf{0 , 8 9}$ & 49,13 & $-19,72$ & 49,07 \\
\hline & SD & 12,95 & 215,17 & 47,79 & 382,09 & 383,69 & 0,04 & 0,02 & 0,06 & 0,04 & $\mathbf{0 , 0 4}$ & 0,04 & 0,11 & 2,44 & 1,05 & 2,44 \\
\hline & MAX & 100,20 & 1725,80 & 538,46 & 9296,40 & $-6563,50$ & 0,89 & 0,19 & 0,87 & 0,28 & 0,76 & 0,93 & 1,20 & 52,99 & $-17,98$ & 52,92 \\
\hline
\end{tabular}


A3.Descrição das principais características espaciais e temporais da precipitação e resultados obtidos dos analise estatísticos dos bairros da cidade de São Paulo.

\begin{tabular}{|c|c|c|c|c|c|c|}
\hline & Tabela A3.1. C & $\begin{array}{l}\text { racterísticas esp } \\
\text { los bairros da c }\end{array}$ & $\begin{array}{l}\text { aciais e t } \\
\text { dade de }\end{array}$ & $\begin{array}{l}\text { emporais das c } \\
\text { São Paulo dura }\end{array}$ & $\begin{array}{l}\text { huvas e even } \\
\text { nte o ano } 201\end{array}$ & $\begin{array}{l}\text { os de alagamento } \\
5\end{array}$ \\
\hline No & Bairro & $\begin{array}{c}\text { Chuva } \\
\text { acumulada total } \\
\text { no ano } \\
{[\mathbf{m m}]}\end{array}$ & $\begin{array}{l}\text { R máx. } \\
{[\mathbf{m m} / \mathbf{h}]}\end{array}$ & $\begin{array}{l}\text { Duração média } \\
\text { [min] }\end{array}$ & $\begin{array}{l}\text { Número dias } \\
\text { alagamento }\end{array}$ & $\begin{array}{c}\text { Média acumulada } \\
\text { antes do alagamento } \\
{[\mathrm{mm}]}\end{array}$ \\
\hline 1 & Agua Rasa & 1604,90 & 99,49 & 545,93 & 12 & 13,75 \\
\hline 2 & Alto de Pinheiros & 1448,79 & 88,63 & 522,13 & 6 & 8,74 \\
\hline 3 & Anhanguera & 1503,11 & 49,26 & 559,65 & 1 & 5,51 \\
\hline 4 & Aricanduva & 1609,62 & 74,31 & 558,05 & 11 & 6,58 \\
\hline 5 & Artur Alvim & 1459,73 & 82,34 & 529,77 & 5 & 8,48 \\
\hline 6 & Barra Funda & 1397,44 & 48,58 & 526,42 & 27 & 9,37 \\
\hline 7 & Bela Vista & 1415,46 & 64,75 & 514,71 & 15 & 6,04 \\
\hline 8 & Belém & 1613,69 & 181,63 & 515,58 & 32 & 10,36 \\
\hline 9 & Bom Retiro & 1401,65 & 64,37 & 522,96 & 33 & 10,21 \\
\hline 11 & Brás & 1603,22 & 83,54 & 557,41 & 8 & 10,88 \\
\hline 10 & Brasilândia & 1498,16 & 70,14 & 480,88 & 10 & 10,47 \\
\hline 12 & Butantã & 1478,22 & 84,14 & 562,78 & 28 & 9,76 \\
\hline 13 & Cachoeirinha & 1587,12 & 67,90 & 547,56 & 8 & 10,44 \\
\hline 14 & Cambuci & 1506,35 & 74,51 & 520,96 & 10 & 9,95 \\
\hline 15 & Campo Belo & 1529,86 & 83,99 & 512,53 & 13 & 7,85 \\
\hline 16 & Campo Grande & 1439,05 & 102,14 & 522,96 & 21 & 7,67 \\
\hline 17 & Campo Limpo & 1659,81 & 76,14 & 516,82 & 8 & 14,27 \\
\hline 18 & Cangaiba & 1423,05 & 61,79 & 545,57 & 3 & 8,82 \\
\hline 19 & Capão Redondo & 1675,03 & 88,25 & 521,70 & 6 & 19,32 \\
\hline 20 & Carrão & 1604,92 & 80,35 & 544,34 & 3 & 11,79 \\
\hline 21 & Casa Verde & 1463,91 & 60,10 & 513,66 & 2 & 13,91 \\
\hline 22 & Cidade Ademar & 1490,48 & 58,89 & 551,10 & 5 & 5,26 \\
\hline 23 & Cidade Dutra & 1591,78 & 72,46 & 595,12 & 9 & 9,47 \\
\hline 24 & Cidade Líder & 1583,36 & 63,94 & 586,07 & 15 & 6,49 \\
\hline 25 & Consolação & 1422,85 & 65,66 & 509,76 & 9 & 12,61 \\
\hline 26 & Cursino & 1608,79 & 71,29 & 575,50 & 13 & 10,74 \\
\hline 27 & $\begin{array}{l}\text { Ermelino } \\
\text { Matarazzo }\end{array}$ & 1334,16 & 51,59 & 513,63 & 1 & 0,13 \\
\hline 28 & Freguesia do $\mathrm{O}$ & 1508,55 & 49,79 & 542,91 & 22 & 8,12 \\
\hline 29 & Grajau & 1844,08 & 83,91 & 636,46 & 3 & 14,69 \\
\hline 30 & Guaianases & 1436,41 & 71,45 & 538,60 & 2 & 4,57 \\
\hline 31 & Iguatemi & 1468,71 & 58,23 & 621,95 & 9 & 8,26 \\
\hline 32 & Ipiranga & 1668,23 & 110,13 & 577,47 & 16 & 10,95 \\
\hline 33 & Itaim Bibi & 1478,55 & 76,81 & 509,51 & 39 & 7,83 \\
\hline 34 & Itaim Paulista & 1490,92 & 85,73 & 541,79 & 2 & 22,16 \\
\hline
\end{tabular}




\begin{tabular}{|c|c|c|c|c|c|c|}
\hline No & Bairro & $\begin{array}{c}\text { Chuva } \\
\text { acumulada total } \\
\text { no ano } \\
{[\mathrm{mm}]}\end{array}$ & $\begin{array}{l}\text { R máx. } \\
{[\mathrm{mm} / \mathrm{h}]}\end{array}$ & $\begin{array}{c}\text { Duração média } \\
\text { [min] }\end{array}$ & $\begin{array}{l}\text { Número dias } \\
\text { alagamento }\end{array}$ & $\begin{array}{l}\text { Média acumulada } \\
\text { antes do alagamento } \\
{[\mathrm{mm}]}\end{array}$ \\
\hline 35 & Itaquera & 1465,07 & 79,68 & 560,57 & 7 & 9,27 \\
\hline 36 & Jabaquara & 1512,31 & 65,55 & 542,93 & 7 & 8,88 \\
\hline 37 & Jacana & 1546,36 & 59,21 & 524,71 & 3 & 15,94 \\
\hline 38 & Jaguará & 1448,01 & 71,83 & 484,03 & 6 & 10,15 \\
\hline 39 & Jaguaré & 1452,83 & 86,71 & 498,93 & 7 & 8,37 \\
\hline 40 & Jaraguá & 1552,79 & 44,46 & 584,14 & 7 & 8,17 \\
\hline 41 & Jardim Ângela & 1843,14 & 138,77 & 581,75 & 6 & 8,50 \\
\hline 42 & Jardim Helena & 1528,41 & 73,27 & 529,77 & 1 & 10,91 \\
\hline 43 & Jardim Paulista & 1425,24 & 50,42 & 527,23 & 11 & 7,27 \\
\hline 44 & Jardim São Luís & 1630,58 & 87,59 & 541,43 & 12 & 12,65 \\
\hline 45 & Jose Bonifácio & 1480,52 & 58,12 & 580,39 & 3 & 7,43 \\
\hline 46 & Lajeado & 1453,67 & 111,54 & 526,90 & 1 & 0,10 \\
\hline 47 & Lapa & 1469,10 & 63,31 & 530,12 & 12 & 13,21 \\
\hline 48 & Liberdade & 1452,32 & 73,41 & 486,40 & 16 & 8,14 \\
\hline 49 & Limão & 1432,18 & 48,95 & 493,95 & 16 & 8,46 \\
\hline 50 & Mandaqui & 1604,73 & 58,39 & 538,38 & 1 & 0,14 \\
\hline 51 & Moema & 1455,52 & 82,65 & 542,13 & 10 & 8,11 \\
\hline 52 & Mooca & 1619,93 & 190,60 & 554,22 & 21 & 9,79 \\
\hline 53 & Morumbi & 1507,29 & 89,71 & 552,80 & 40 & 9,36 \\
\hline 54 & Parelheiros & 2312,41 & 241,71 & 705,56 & 3 & 14,97 \\
\hline 55 & Pari & 1498,22 & 69,99 & 472,07 & 6 & 5,97 \\
\hline 56 & Parque do Carmo & 1536,66 & 67,66 & 587,13 & 4 & 10,51 \\
\hline 57 & Penha & 1525,51 & 74,20 & 573,54 & 11 & 9,75 \\
\hline 58 & Perdizes & 1435,79 & 60,05 & 513,95 & 20 & 10,39 \\
\hline 59 & Perus & 1535,73 & 59,22 & 569,87 & 1 & 0,00 \\
\hline 60 & Pinheiros & 1447,97 & 70,67 & 519,11 & 16 & 10,65 \\
\hline 61 & Pirituba & 1540,41 & 54,79 & 553,49 & 8 & 9,48 \\
\hline 62 & Ponte Rasa & 1411,51 & 72,52 & 525,06 & 3 & 11,61 \\
\hline 63 & Raposo Tavares & 1576,15 & 89,36 & 485,25 & 2 & 18,59 \\
\hline 64 & Republica & 1382,32 & 60,52 & 491,83 & 26 & 8,25 \\
\hline 65 & Rio Pequeno & 1451,01 & 62,14 & 509,87 & 4 & 7,68 \\
\hline 66 & Sacomã & 1604,47 & 56,93 & 567,13 & 5 & 8,59 \\
\hline 67 & Santa Cecilia & 1384,97 & 80,57 & 520,36 & 24 & 10,31 \\
\hline 68 & Santana & 1569,94 & 46,05 & 542,89 & 41 & 9,37 \\
\hline 69 & Santo Amaro & 1559,81 & 83,00 & 539,26 & 21 & 9,43 \\
\hline 70 & São Domingos & 1495,99 & 68,11 & 530,51 & 5 & 18,09 \\
\hline 71 & São Lucas & 1598,82 & 69,70 & 573,72 & 8 & 14,93 \\
\hline 72 & São Miguel & 1430,52 & 78,10 & 539,41 & 1 & 0,39 \\
\hline
\end{tabular}




\begin{tabular}{|c|c|c|c|c|c|c|}
\hline No & Bairro & $\begin{array}{c}\text { Chuva } \\
\text { acumulada total } \\
\text { no ano } \\
{[\mathrm{mm}]}\end{array}$ & $\begin{array}{l}\text { R máx. } \\
{[\mathrm{mm} / \mathrm{h}]}\end{array}$ & $\begin{array}{l}\text { Duração média } \\
\text { [min] }\end{array}$ & $\begin{array}{l}\text { Número dias } \\
\text { alagamento }\end{array}$ & $\begin{array}{l}\text { Média acumulada } \\
\text { antes do alagamento } \\
{[\mathrm{mm}]}\end{array}$ \\
\hline 73 & Saúde & 1542,40 & 79,24 & 498,78 & 14 & 6,73 \\
\hline 74 & Se & 1428,61 & 68,35 & 458,85 & 19 & 8,61 \\
\hline 75 & Socorro & 1468,37 & 108,18 & 528,61 & 8 & 7,80 \\
\hline 76 & Tatuapé & 1611,76 & 89,97 & 520,79 & 19 & 10,45 \\
\hline 77 & Tremembé & 1866,67 & 51,82 & 618,17 & 4 & 12,53 \\
\hline 78 & Tucuruvi & 1589,30 & 55,39 & 514,37 & 2 & 21,10 \\
\hline 79 & Vila Andrade & 1555,65 & 76,16 & 508,13 & 10 & 11,26 \\
\hline 80 & Vila Curuçá & 1466,90 & 102,72 & 525,29 & 1 & 21,75 \\
\hline 81 & Vila Formosa & 1634,26 & 81,85 & 557,47 & 3 & 10,38 \\
\hline 82 & Vila Guilherme & 1600,06 & 52,42 & 489,01 & 26 & 9,90 \\
\hline 83 & Vila Jacuí & 1371,40 & 79,92 & 525,37 & 1 & 0,27 \\
\hline 84 & Vila Leopoldina & 1463,25 & 89,71 & 480,60 & 11 & 9,39 \\
\hline 86 & Vila Maria & 1502,06 & 98,25 & 532,95 & 17 & 7,24 \\
\hline 85 & Vila Mariana & 1545,95 & 78,54 & 517,79 & 16 & 10,49 \\
\hline 87 & Vila Matilde & 1576,57 & 85,17 & 570,74 & 9 & 9,80 \\
\hline 88 & Vila Prudente & 1651,67 & 83,92 & 562,30 & 6 & 8,45 \\
\hline \multirow[t]{3}{*}{89} & Vila Sonia & 1517,60 & 115,49 & 505,24 & 10 & 11,45 \\
\hline & MÉDIA & 1532,82 & 78,68 & 537,72 & 11 & 9,74 \\
\hline & $\boldsymbol{\sigma}$ & 129,06 & 29,62 & 37,85 & 9,5 & 4,31 \\
\hline
\end{tabular}


Tabela A3.2. PDF da Taxa de precipitação dos bairros da cidade de São Paulo durante o ano 2015

\begin{tabular}{|c|c|c|c|c|}
\hline \multirow[b]{2}{*}{ No } & \\
\hline & Bairro & Probabilidade [\%] & $\begin{array}{l}\text { Taxa de precipitação media } \\
{[\mathrm{mm} / \mathrm{h}]}\end{array}$ & Desvio Padrão \\
\hline 1 & Agua Rasa & 19,19 & 28,65 & 20,59 \\
\hline 2 & Alto de Pinheiros & 14,44 & 43,14 & 27,47 \\
\hline 3 & Anhanguera & & & \\
\hline 4 & Aricanduva & 23,7 & 37,67 & 16,58 \\
\hline 5 & Artur Alvim & 28,15 & 46,59 & 13,87 \\
\hline 6 & Barra Funda & 32,05 & 25,53 & 12,10 \\
\hline 7 & Bela Vista & 20,2 & 30,37 & 19,53 \\
\hline 8 & Belém & 11,98 & 33,29 & 33,17 \\
\hline 9 & Bom Retiro & 26,55 & 21,80 & 14,75 \\
\hline 10 & Brás & 19,43 & 33,57 & 20,33 \\
\hline 11 & Brasilândia & 23,66 & 26,09 & 16,61 \\
\hline 12 & Butantã & 22,7 & 25,39 & 17,33 \\
\hline 13 & Cachoeirinha & 19,67 & 29,43 & 20,08 \\
\hline 14 & Cambuci & 17,29 & 39,38 & 22,89 \\
\hline 15 & Campo Belo & 15,77 & 44,22 & 25,13 \\
\hline 16 & Campo Grande & 17,44 & 25,79 & 22,69 \\
\hline 17 & Campo Limpo & 20,73 & 43,68 & 19,03 \\
\hline 18 & Cangaiba & 90,81 & 28,84 & 2,97 \\
\hline 19 & Capao Redondo & 13,98 & 44,94 & 28,40 \\
\hline 20 & Carrão & 15,2 & 50,68 & 26,08 \\
\hline 21 & Casa Verde & 13,39 & 32,68 & 29,66 \\
\hline 22 & Cidade Ademar & & & \\
\hline 23 & Cidade Dutra & 19,14 & 23,14 & 20,65 \\
\hline 24 & Cidade Lider & 23,32 & 33,26 & 16,86 \\
\hline 25 & Cidade Tiradentes & & & \\
\hline 26 & Consolação & 29,84 & 26,80 & 13,05 \\
\hline 27 & Cursino & 24,27 & 38,24 & 16,18 \\
\hline 28 & Ermelino Matarazzo & & & \\
\hline 29 & Freguesia do 0 & 28,21 & 24,95 & 13,84 \\
\hline 30 & Grajau & 75,68 & 14,04 & 4,28 \\
\hline 31 & Guaianases & 84,29 & 54,15 & 3,53 \\
\hline 32 & Iguatemi & 23,89 & 22,73 & 16,45 \\
\hline 33 & Ipiranga & 14,32 & 45,50 & 27,71 \\
\hline 34 & Itaim Bibi & 22,47 & 28,25 & 17,51 \\
\hline 35 & Itaim Paulista & 70,67 & 49,01 & 4,76 \\
\hline 36 & Itaquera & 16,51 & 43,93 & 24,00 \\
\hline 37 & Jabaquara & 28,19 & 28,34 & 13,85 \\
\hline 38 & Jaçanã & 59,44 & 36,35 & 6,01 \\
\hline
\end{tabular}




\begin{tabular}{|c|c|c|c|c|}
\hline No & Bairro & Probabilidade [\%] & $\begin{array}{l}\text { Taxa de precipitação media } \\
{[\mathrm{mm} / \mathrm{h}]}\end{array}$ & Desvio Padrão \\
\hline 39 & Jaguará & 13,81 & 44,03 & 28,75 \\
\hline 40 & Jaguaré & 13,02 & 43,58 & 30,49 \\
\hline 41 & Jaraguá & 45,21 & 16,12 & 8,32 \\
\hline 42 & Jardim Ângela & 16,44 & 39,87 & 24,10 \\
\hline 43 & Jardim Helena & & & \\
\hline 44 & Jardim Paulista & 24,99 & 29,47 & 15,70 \\
\hline 45 & Jardim São Luís & 17,76 & 30,27 & 22,27 \\
\hline 46 & Jose Bonifácio & 47,88 & 52,61 & 7,79 \\
\hline 47 & Lajeado & & & \\
\hline 48 & Lapa & 22,25 & 29,66 & 17,70 \\
\hline 49 & Liberdade & 19,65 & 38,80 & 20,10 \\
\hline 50 & Limão & 31,61 & 26,69 & 12,28 \\
\hline 51 & Mandaqui & & & \\
\hline 52 & Marsilac & & & \\
\hline 53 & Moema & 15,07 & 42,41 & 26,32 \\
\hline 54 & Mooca & 9,55 & 41,55 & 41,66 \\
\hline 55 & Morumbi & 20,15 & 28,74 & 19,58 \\
\hline 56 & Parelheiros & 67,29 & 11,34 & 5,10 \\
\hline 57 & Pari & 18,12 & 36,07 & 21,83 \\
\hline 58 & Parque do Carmo & 25,86 & 48,92 & 15,15 \\
\hline 59 & Pedreira & & & \\
\hline 60 & Penha & 18,05 & 36,87 & 21,91 \\
\hline 61 & Perdizes & 28,15 & 27,19 & 13,87 \\
\hline 62 & Perus & & & \\
\hline 63 & Pinheiros & 21 & 29,73 & 18,78 \\
\hline 64 & Pirituba & 27,16 & 30,22 & 14,40 \\
\hline 65 & Ponte Rasa & 56,94 & 50,76 & 6,34 \\
\hline 66 & Raposo Tavares & 24,1 & 29,29 & 16,30 \\
\hline 67 & Republica & 29,18 & 25,68 & 13,36 \\
\hline 68 & Rio Pequeno & 14,18 & 30,95 & 27,99 \\
\hline 69 & Sacomã & 30,11 & 31,84 & 12,93 \\
\hline 70 & Santa Cecilia & 32,28 & 22,25 & 12,01 \\
\hline 71 & Santana & 33,95 & 19,39 & 11,38 \\
\hline 72 & Santo Amaro & 18,45 & 32,45 & 21,43 \\
\hline 73 & São Domingos & 24,71 & 26,37 & 15,88 \\
\hline 74 & São Lucas & 23,36 & 29,87 & 16,83 \\
\hline 75 & São Mateus & & & \\
\hline 76 & São Miguel & & & \\
\hline 77 & São Rafael & & & \\
\hline 78 & Sapopemba & & & \\
\hline
\end{tabular}




\begin{tabular}{|c|c|c|c|c|}
\hline No & Bairro & Probabilidade [\%] & $\begin{array}{l}\text { Taxa de precipitação media } \\
{[\mathrm{mm} / \mathrm{h}]}\end{array}$ & Desvio Padrão \\
\hline 79 & Saúde & 17,61 & 47,39 & 22,47 \\
\hline 80 & Se & 24,3 & 27,25 & 16,16 \\
\hline 81 & Socorro & 11,87 & 33,11 & 33,48 \\
\hline 82 & Tatuapé & 16,18 & 34,59 & 24,49 \\
\hline 83 & Tremembé & 33,29 & 23,92 & 11,63 \\
\hline 84 & Tucuruvi & 92,7 & 30,33 & 2,79 \\
\hline 85 & Vila Andrade & 19,58 & 34,70 & 20,16 \\
\hline 86 & Vila Curuca & & & \\
\hline 87 & Vila Formosa & 14,45 & 55,34 & 27,45 \\
\hline 88 & Vila Guilherme & 29,57 & 27,05 & 13,17 \\
\hline 89 & Vila Jacuí & & & \\
\hline 90 & Vila Leopoldina & 16,47 & 41,16 & 24,05 \\
\hline 91 & Vila Maria & 20,32 & 28,41 & 19,42 \\
\hline 92 & Vila Mariana & 15,57 & 43,07 & 25,46 \\
\hline 93 & Vila Matilde & 16,53 & 45,82 & 23,97 \\
\hline 94 & Vila Medeiros & & & \\
\hline 95 & Vila Prudente & 16,22 & 45,72 & 24,43 \\
\hline \multirow[t]{3}{*}{96} & Vila Sonia & 12,27 & 51,21 & 32,38 \\
\hline & MÉDIA & 27,01 & 34,33 & 18,61 \\
\hline & $\sigma$ & 18,02 & $\mathbf{9 , 8 2}$ & $\mathbf{7 , 8 6}$ \\
\hline
\end{tabular}




\begin{tabular}{|c|c|c|c|c|}
\hline \multirow[b]{2}{*}{ No } & \multicolumn{4}{|c|}{$\begin{array}{l}\text { Tabela A3.3. PDF da chuva acumulada nos bairros da cidade de São Paulo durante o } \\
\text { ano } 2015\end{array}$} \\
\hline & Bairro & Probabilidade [\%] & Chuva acumulada media [mm] & Desvio padrão \\
\hline 1 & Agua Rasa & 24,51 & 34,67 & 16,01 \\
\hline 2 & Alto de Pinheiros & 52,99 & 36,00 & 6,92 \\
\hline 3 & Anhanguera & & & \\
\hline 4 & Aricanduva & 26,27 & 31,03 & 14,91 \\
\hline 5 & Artur Alvim & 22,14 & 34,37 & 17,78 \\
\hline 6 & Barra Funda & 24,61 & 27,95 & 15,95 \\
\hline 7 & Bela Vista & 22,89 & 26,29 & 17,19 \\
\hline 8 & Belém & 22,76 & 27,75 & 17,29 \\
\hline 9 & Bom Retiro & 26,16 & 24,69 & 14,97 \\
\hline 10 & Brás & 21,25 & 33,28 & 18,55 \\
\hline 11 & Brasilândia & 19,44 & 29,89 & 20,31 \\
\hline 12 & Butantã & 27,77 & 24,09 & 14,07 \\
\hline 13 & Cachoeirinha & 23,63 & 29,83 & 16,63 \\
\hline 14 & Cambuci & 28,73 & 27,12 & 13,58 \\
\hline 15 & Campo Belo & 25,45 & 32,27 & 15,40 \\
\hline 16 & Campo Grande & 21,54 & 25,36 & 18,29 \\
\hline 17 & Campo Limpo & 32,51 & 39,49 & 11,92 \\
\hline 18 & Cangaiba & 17,18 & 34,03 & 23,04 \\
\hline 19 & Capão Redondo & 19,97 & 36,66 & 19,76 \\
\hline 20 & Carrão & 32,4 & 29,62 & 11,96 \\
\hline 21 & Casa Verde & 11,78 & 31,99 & 33,74 \\
\hline 22 & Cidade Ademar & & & \\
\hline 23 & Cidade Dutra & 16,05 & 32,00 & 24,69 \\
\hline 24 & Cidade Líder & 31,87 & 27,55 & 12,17 \\
\hline 25 & Cidade Tiradentes & & & \\
\hline 26 & Consolação & 18,41 & 38,77 & 21,48 \\
\hline 27 & Cursino & 26,69 & 33,36 & 14,66 \\
\hline 28 & $\begin{array}{l}\text { Ermelino } \\
\text { Matarazzo }\end{array}$ & & & \\
\hline 29 & Freguesia do $\mathrm{O}$ & 23,95 & 25,78 & 16,40 \\
\hline 30 & Grajau & 22,57 & 28,84 & 17,44 \\
\hline 31 & Guaianases & 25,93 & 29,96 & 15,11 \\
\hline 32 & Iguatemi & 40,57 & 23,82 & 9,39 \\
\hline 33 & Ipiranga & 13,92 & 34,93 & 28,51 \\
\hline 34 & Itaim Bibi & 29,29 & 22,63 & 13,31 \\
\hline 35 & Itaim Paulista & 78,21 & 51,18 & 4,06 \\
\hline 36 & Itaquera & 21,4 & 36,55 & 18,42 \\
\hline 37 & Jabaquara & 50,93 & 22,65 & 7,26 \\
\hline 38 & Jacana & 45,62 & 32,81 & 8,24 \\
\hline
\end{tabular}




\begin{tabular}{|c|c|c|c|c|}
\hline No & Bairro & Probabilidade [\%] & Chuva acumulada media [mm] & Desvio padrão \\
\hline 39 & Jaguará & 19,57 & 34,09 & 20,18 \\
\hline 40 & Jaguaré & 25,69 & 29,98 & 15,26 \\
\hline 41 & Jaraguá & 31,06 & 23,11 & 12,51 \\
\hline 42 & Jardim Ângela & 25,33 & 35,06 & 15,48 \\
\hline 43 & Jardim Helena & & 43,53 & \\
\hline 44 & Jardim Paulista & 23,44 & 25,02 & 16,77 \\
\hline 45 & Jardim São Luís & 21,52 & 32,94 & 18,31 \\
\hline 46 & Jose Bonifácio & 48,37 & 30,21 & 7,70 \\
\hline 47 & Lajeado & & 37,60 & \\
\hline 48 & Lapa & 18,78 & 31,96 & 21,04 \\
\hline 49 & Liberdade & 20,87 & 35,62 & 18,89 \\
\hline 50 & Limão & 25,28 & 27,62 & 15,51 \\
\hline 51 & Mandaqui & & 23,71 & \\
\hline 52 & Marsilac & & & \\
\hline 53 & Moema & 23,27 & 29,51 & 16,90 \\
\hline 54 & Mooca & 15,87 & 32,75 & 24,97 \\
\hline 55 & Morumbi & 28,01 & 23,51 & 13,95 \\
\hline 56 & Parelheiros & 21,66 & 29,97 & 18,19 \\
\hline 57 & Pari & 21,13 & 34,60 & 18,66 \\
\hline 58 & Parque do Carmo & 27,51 & 32,43 & 14,21 \\
\hline 59 & Pedreira & & & \\
\hline 60 & Penha & 34,94 & 32,07 & 11,04 \\
\hline 61 & Perdizes & 21,43 & 29,10 & 18,39 \\
\hline 62 & Perus & & & \\
\hline 63 & Pinheiros & 25,9 & 26,98 & 15,13 \\
\hline 64 & Pirituba & 22,47 & 38,98 & 17,51 \\
\hline 65 & Ponte Rasa & 23,32 & 35,21 & 16,86 \\
\hline 66 & Raposo Tavares & 24,54 & 47,22 & 15,99 \\
\hline 67 & Republica & 26,61 & 24,69 & 14,71 \\
\hline 68 & Rio Pequeno & 15,9 & 46,03 & 24,92 \\
\hline 69 & Sacomã & 60,55 & 28,28 & 5,87 \\
\hline 70 & Santa Cecilia & 26,83 & 25,71 & 14,58 \\
\hline 71 & Santana & 29,1 & 22,95 & 13,40 \\
\hline 72 & Santo Amaro & 26,21 & 29,68 & 14,94 \\
\hline 73 & São Domingos & 22,09 & 40,89 & 17,83 \\
\hline 74 & São Lucas & 15,91 & 32,20 & 24,91 \\
\hline 75 & São Mateus & & & \\
\hline 76 & São Miguel & & 25,01 & \\
\hline 77 & São Rafael & & & \\
\hline 78 & Sapopemba & & & \\
\hline
\end{tabular}




\begin{tabular}{|c|c|c|c|c|}
\hline No & Bairro & Probabilidade [\%] & Chuva acumulada media [mm] & Desvio padrão \\
\hline 79 & Saúde & 27 & 31,74 & 14,49 \\
\hline 80 & Se & 24,55 & 26,99 & 15,99 \\
\hline 81 & Socorro & 15,14 & 33,96 & 26,20 \\
\hline 82 & Tatuapé & 23,29 & 30,16 & 16,88 \\
\hline 83 & Tremembé & 100 & 33,10 & 0,66 \\
\hline 84 & Tucuruvi & 40,8 & 48,37 & 9,33 \\
\hline 85 & Vila Andrade & 32,89 & 38,00 & 11,77 \\
\hline 86 & Vila Curuca & & & \\
\hline 87 & Vila Formosa & 57,53 & 41,71 & 6,26 \\
\hline 88 & Vila Guilherme & 26,31 & 25,55 & 14,89 \\
\hline 89 & Vila Jacuí & & & \\
\hline 90 & Vila Leopoldina & 25,71 & 31,78 & 15,24 \\
\hline 91 & Vila Maria & 25,36 & 26,72 & 15,46 \\
\hline 92 & Vila Mariana & 26,25 & 30,65 & 14,92 \\
\hline 93 & Vila Matilde & 46,52 & 32,22 & 8,06 \\
\hline 94 & Vila Medeiros & & & \\
\hline 95 & Vila Prudente & 9,76 & 37,76 & 40,79 \\
\hline \multirow[t]{3}{*}{96} & Vila Sonia & 20,63 & 37,42 & 19,12 \\
\hline & MÉDIA & 28,16 & 31,82 & 16,13 \\
\hline & $\sigma$ & 13,96 & 6,1 & 6,1 \\
\hline
\end{tabular}


Tabela A3.4. PDF da fração da área de chuva para precipitações maiores que $30 \mathrm{~mm} / \mathrm{h}$ e $50 \mathrm{~mm} / \mathrm{h}$ dos bairros da cidade de São Paulo durante o ano 2015

\begin{tabular}{|c|c|c|c|c|c|c|c|}
\hline \multirow[b]{2}{*}{ No } & \multirow[b]{2}{*}{ Bairro } & \multicolumn{3}{|c|}{$\mathrm{R}>30 \mathrm{~mm} / \mathrm{h}$} & \multicolumn{3}{|c|}{$\mathrm{R}>50 \mathrm{~mm} / \mathrm{h}$} \\
\hline & & Prob [\%] & Média & Sd & Prob [\%] & Média & Sd \\
\hline 1 & Agua Rasa & 21,510 & 0,187 & 0,183 & 52,020 & 0,121 & 0,071 \\
\hline 2 & Alto de Pinheiros & 13,230 & 0,195 & 0,300 & 7,500 & 0,389 & 0,531 \\
\hline 3 & Anhanguera & & & & & & \\
\hline 4 & Aricanduva & 17,460 & 0,336 & 0,227 & 27,680 & 0,260 & 0,141 \\
\hline 5 & Artur Alvim & 13,410 & 0,365 & 0,296 & 25,120 & 0,214 & 0,156 \\
\hline 6 & Barra Funda & 16,210 & 0,278 & 0,244 & 37,570 & 0,131 & 0,102 \\
\hline 7 & Bela Vista & 19,870 & 0,280 & 0,199 & 17,950 & 0,253 & 0,220 \\
\hline 8 & Belém & 22,930 & 0,194 & 0,172 & 69,860 & 0,070 & 0,048 \\
\hline 9 & Bom Retiro & 18,210 & 0,227 & 0,217 & 13,150 & 0,234 & 0,302 \\
\hline 10 & Brás & 12,820 & 0,297 & 0,310 & 12,920 & 0,580 & 0,307 \\
\hline 11 & Brasilândia & 13,120 & 0,296 & 0,303 & 23,170 & 0,357 & 0,170 \\
\hline 12 & Butantã & 20,050 & 0,123 & 0,197 & 14,840 & 0,146 & 0,267 \\
\hline 13 & Cachoeirinha & 13,300 & 0,252 & 0,299 & 12,260 & 0,189 & 0,324 \\
\hline 14 & Cambuci & 60,390 & 0,125 & 0,059 & & 0,167 & \\
\hline 15 & Campo Belo & 15,340 & 0,202 & 0,258 & 11,430 & 0,251 & 0,348 \\
\hline 16 & Campo Grande & 10,160 & 0,241 & 0,392 & 10,070 & 0,690 & 0,395 \\
\hline 17 & Campo Limpo & 15,270 & 0,307 & 0,260 & 19,060 & 0,283 & 0,207 \\
\hline 18 & Cangaiba & 20,660 & 0,203 & 0,191 & 26,810 & 0,125 & 0,146 \\
\hline 19 & Capão Redondo & 19,650 & 0,145 & 0,201 & 45,040 & 0,068 & 0,084 \\
\hline 20 & Carrão & 15,360 & 0,297 & 0,258 & 19,440 & 0,156 & 0,203 \\
\hline 21 & Casa Verde & & & & & & \\
\hline 22 & Cidade Ademar & & & & & & \\
\hline 23 & Cidade Dutra & 20,260 & 0,152 & 0,195 & 18,200 & 0,201 & 0,217 \\
\hline 24 & Cidade Líder & 21,410 & 0,174 & 0,184 & 30,410 & 0,123 & 0,128 \\
\hline 25 & Consolação & 9,880 & 0,533 & 0,403 & 18,670 & 0,317 & 0,212 \\
\hline 26 & Cursino & 74,070 & 0,049 & 0,044 & & & \\
\hline 27 & Ermelino Matarazzo & & & & & & \\
\hline 28 & Freguesia do $\mathrm{O}$ & 16,660 & 0,232 & 0,238 & 17,830 & 0,233 & 0,222 \\
\hline 29 & Grajau & 50,500 & 0,061 & 0,073 & 70,990 & 0,072 & 0,047 \\
\hline 30 & Guaianases & 10,860 & 0,502 & 0,366 & 12,420 & 0,468 & 0,320 \\
\hline 31 & Iguatemi & 44,330 & 0,042 & 0,085 & & 0,054 & \\
\hline 32 & Ipiranga & 20,050 & 0,147 & 0,197 & 63,670 & 0,350 & 0,055 \\
\hline 33 & Itaim Bibi & 14,540 & 0,192 & 0,273 & 13,850 & 0,508 & 0,287 \\
\hline 34 & Itaim Paulista & 13,050 & 0,356 & 0,304 & 26,450 & 0,243 & 0,148 \\
\hline 35 & Itaquera & 11,550 & 0,317 & 0,344 & 11,900 & 0,546 & 0,334 \\
\hline 36 & Jabaquara & & & & & & \\
\hline
\end{tabular}




\begin{tabular}{|c|c|c|c|c|c|c|c|}
\hline \multirow[b]{2}{*}{ No } & \multirow[b]{2}{*}{ Bairro } & \multicolumn{3}{|c|}{$\mathrm{R}>30 \mathrm{~mm} / \mathrm{h}$} & \multicolumn{3}{|c|}{$\mathrm{R}>50 \mathrm{~mm} / \mathrm{h}$} \\
\hline & & Prob [\%] & Média & Sd & Prob [\%] & Média & Sd \\
\hline 37 & Jacana & 21,690 & 0,248 & 0,182 & 31,090 & 0,149 & 0,125 \\
\hline 38 & Jaguará & 10,550 & 0,503 & 0,377 & 11,010 & 0,418 & 0,361 \\
\hline 39 & Jaguaré & 6,760 & 0,563 & 0,589 & & 0,833 & \\
\hline 40 & Jaraguá & 55,630 & 0,052 & 0,065 & 62,210 & 0,037 & 0,057 \\
\hline 41 & Jardim Ângela & 12,260 & 0,347 & 0,324 & 12,990 & 0,322 & 0,306 \\
\hline 42 & Jardim Helena & 18,900 & 0,247 & 0,209 & 25,460 & 0,106 & 0,154 \\
\hline 43 & Jardim Paulista & & & & & & \\
\hline 44 & Jardim São Luís & 11,170 & 0,315 & 0,356 & 10,490 & 0,330 & 0,379 \\
\hline 45 & Jose Bonifácio & 18,250 & 0,435 & 0,217 & 55,220 & 0,464 & 0,066 \\
\hline 46 & Lajeado & 10,510 & 0,407 & 0,378 & 11,970 & 0,433 & 0,332 \\
\hline 47 & Lapa & 27,040 & 0,173 & 0,145 & 64,360 & 0,103 & 0,054 \\
\hline 48 & Liberdade & 12,710 & 0,418 & 0,312 & 17,570 & 0,229 & 0,225 \\
\hline 49 & Limão & 14,610 & 0,231 & 0,272 & 22,410 & 0,204 & 0,176 \\
\hline 50 & Mandaqui & & & & & & \\
\hline 51 & Marsilac & & & & & & \\
\hline 52 & Moema & & & & & & \\
\hline 53 & Mooca & 16,340 & 0,288 & 0,243 & 22,950 & 0,205 & 0,171 \\
\hline 54 & Morumbi & 18,780 & 0,175 & 0,210 & 18,370 & 0,190 & 0,215 \\
\hline 55 & Parelheiros & 80,600 & 0,036 & 0,038 & 95,770 & 0,021 & 0,025 \\
\hline 56 & Pari & 13,810 & 0,366 & 0,287 & 20,660 & 0,229 & 0,191 \\
\hline 57 & Parque do Carmo & 14,520 & 0,261 & 0,273 & 15,390 & 0,224 & 0,258 \\
\hline 58 & Penha & 17,300 & 0,224 & 0,229 & 18,980 & 0,134 & 0,208 \\
\hline 59 & Perdizes & 12,210 & 0,325 & 0,326 & 41,690 & 0,117 & 0,091 \\
\hline 60 & Perus & & & & & & \\
\hline 61 & Pinheiros & 9,130 & 0,426 & 0,436 & 9,140 & 0,484 & 0,436 \\
\hline 62 & Pirituba & 15,550 & 0,240 & 0,255 & 30,310 & 0,140 & 0,128 \\
\hline 63 & Ponte Rasa & 12,480 & 0,282 & 0,318 & 21,280 & 0,228 & 0,185 \\
\hline 64 & Raposo Tavares & & & & & & \\
\hline 65 & Republica & 16,430 & 0,431 & 0,241 & 22,160 & 0,231 & 0,178 \\
\hline 66 & Rio Pequeno & 8,920 & 0,485 & 0,446 & 15,550 & 0,452 & 0,255 \\
\hline 67 & Sacomã & 20,330 & 0,175 & 0,194 & 39,530 & 0,130 & 0,097 \\
\hline 68 & Santa Cecilia & 14,740 & 0,230 & 0,269 & 9,600 & 0,264 & 0,414 \\
\hline 69 & Santana & 19,960 & 0,193 & 0,198 & 20,460 & 0,156 & 0,193 \\
\hline 70 & Santo Amaro & 13,710 & 0,174 & 0,290 & 11,220 & 0,266 & 0,354 \\
\hline 71 & São Domingos & 9,600 & 0,434 & 0,415 & 21,230 & 0,303 & 0,186 \\
\hline 72 & São Lucas & 16,470 & 0,289 & 0,240 & 20,860 & 0,244 & 0,189 \\
\hline 73 & São Mateus & & & & & & \\
\hline 74 & São Miguel & & & & & & \\
\hline
\end{tabular}




\begin{tabular}{|c|c|c|c|c|c|c|c|}
\hline \multirow[b]{2}{*}{ No } & \multirow[b]{2}{*}{ Bairro } & \multicolumn{3}{|c|}{$\mathrm{R}>30 \mathrm{~mm} / \mathrm{h}$} & \multicolumn{3}{|c|}{$\mathrm{R}>50 \mathrm{~mm} / \mathrm{h}$} \\
\hline & & Prob [\%] & Média & Sd & Prob [\%] & Média & Sd \\
\hline 75 & Sapopemba & & & & & & \\
\hline 76 & Saúde & & & & & & \\
\hline 77 & Se & 13,070 & 0,483 & 0,304 & 13,170 & 0,458 & 0,302 \\
\hline 78 & Socorro & 8,490 & 0,459 & 0,469 & 29,390 & 0,893 & 0,133 \\
\hline 79 & Tatuapé & 15,640 & 0,293 & 0,253 & 17,790 & 0,170 & 0,222 \\
\hline 80 & Tremembé & 100,000 & 0,016 & 0,003 & & & \\
\hline 81 & Tucuruvi & & & & & & \\
\hline 82 & Vila Andrade & 20,700 & 0,182 & 0,191 & 23,620 & 0,171 & 0,166 \\
\hline 83 & Vila Curuçá & 10,740 & 0,349 & 0,370 & 30,560 & 0,427 & 0,127 \\
\hline 84 & Vila Formosa & 53,120 & 0,080 & 0,069 & 95,240 & 0,030 & 0,025 \\
\hline 85 & Vila Guilherme & 15,020 & 0,325 & 0,264 & 20,830 & 0,179 & 0,189 \\
\hline 86 & Vila Jacuí & & & & & & \\
\hline 87 & Vila Leopoldina & 9,270 & 0,555 & 0,430 & 10,350 & 0,476 & 0,384 \\
\hline 88 & Vila Maria & 17,250 & 0,229 & 0,229 & 24,290 & 0,129 & 0,162 \\
\hline 89 & Vila Mariana & 21,490 & 0,244 & 0,183 & 35,340 & 0,132 & 0,109 \\
\hline 90 & Vila Matilde & 14,200 & 0,233 & 0,279 & 15,970 & 0,244 & 0,248 \\
\hline & MÉDIA & 20,768 & 0,267 & 0,255 & 26,864 & 0,264 & 0,207 \\
\hline & $\sigma$ & 17,087 & 0,130 & 0,108 & 19,518 & $\mathbf{0 , 1 7 7}$ & $\mathbf{0 , 1 1 1}$ \\
\hline
\end{tabular}


A4.Descrição dos resultados obtidos nas principais estatísticas categóricas na análise do modelo de regressão logística binária para os bairros da cidade de São Paulo.

\begin{tabular}{|c|c|c|c|c|c|}
\hline \multirow[b]{3}{*}{ No } & \multicolumn{5}{|c|}{$\begin{array}{l}\text { Tabela A4.1. Características de avaliação do modelo de regressão logística binária } \\
\text { para eventos com e sem alagamento nos bairros da cidade de São Paulo }\end{array}$} \\
\hline & \multirow[b]{2}{*}{ Bairro } & \multicolumn{2}{|c|}{ Com Alagamento } & \multicolumn{2}{|c|}{ Sem alagamento } \\
\hline & & POD & FAR & POD & FAR \\
\hline 1 & Agua Rasa & 1,1 & 1,1 & 95,6 & 2,2 \\
\hline 2 & Alto de Pinheiros & 0 & 0 & 97,83 & 2,17 \\
\hline 3 & Aricanduva & 0 & 0 & 96,7 & 3,3 \\
\hline 4 & Artur Alvim & 1,1 & 2,2 & 96,7 & 0 \\
\hline 5 & Barra Funda & 4,4 & 1,1 & 91,21 & 3,3 \\
\hline 6 & Bela Vista & 0 & 0 & 95,65 & 4,35 \\
\hline 7 & Belém & 5,49 & 1,1 & 90,11 & 3,3 \\
\hline 8 & Bom Retiro & 3,3 & 0 & 91,21 & 5,49 \\
\hline 9 & Brás & 0 & 1,1 & 96,7 & 2,2 \\
\hline 10 & Brasilândia & 0 & 0 & 97,8 & 2,2 \\
\hline 11 & Butantã & 2,2 & 0 & 92,31 & 5,49 \\
\hline 12 & Cachoeirinha & 0 & 0 & 97,8 & 2,2 \\
\hline 13 & Cambuci & 1,1 & 0 & 97,8 & 1,1 \\
\hline 14 & Campo Belo & 1,1 & 0 & 96,7 & 2,2 \\
\hline 15 & Campo Grande & 1,1 & 1,1 & 93,41 & 4,4 \\
\hline 16 & Campo Limpo & 1,1 & 1,1 & 96,7 & 1,1 \\
\hline 17 & Capão Redondo & 1,09 & 0 & 97,83 & 1,09 \\
\hline 18 & Carrão & 1,1 & 2,2 & 96,7 & 0 \\
\hline 19 & Cidade Ademar & 0 & 0 & 98,9 & 1,1 \\
\hline 20 & Cidade Dutra & 0 & 0 & 97,8 & 2,2 \\
\hline 21 & Cidade Líder & 1,09 & 2,17 & 93,48 & 3,26 \\
\hline 22 & Consolação & 1,1 & 1,1 & 96,7 & 1,1 \\
\hline 23 & Cursino & 3,3 & 1,1 & 95,6 & 0 \\
\hline 24 & Freguesia do $\mathrm{O}$ & 2,17 & 0 & 93,48 & 4,35 \\
\hline 25 & Grajau & 0 & 0 & 98,9 & 1,1 \\
\hline 26 & Iguatemi & 0 & 0 & 97,8 & 2,2 \\
\hline 27 & Ipiranga & 2,2 & 0 & 95,6 & 2,2 \\
\hline 28 & Itaim Bibi & 5,43 & 2,17 & 86,96 & 5,43 \\
\hline 29 & Itaquera & 1,09 & 1,09 & 96,74 & 1,09 \\
\hline 30 & Jabaquara & 0 & 0 & 97,83 & 2,17 \\
\hline 31 & Jacana & 0 & 1,1 & 97,8 & 1,1 \\
\hline 32 & Jaguará & 0 & 0 & 97,83 & 2,17 \\
\hline 33 & Jaguaré & 0 & 0 & 97,83 & 2,17 \\
\hline 34 & Jaraguá & 0 & 1,09 & 96,74 & 2,17 \\
\hline 35 & Jardim Ângela & 0 & 0 & 97,83 & 2,17 \\
\hline 36 & Jardim Paulista & 0 & 0 & 96,7 & 3,3 \\
\hline
\end{tabular}




\begin{tabular}{|c|c|c|c|c|c|}
\hline \multirow[b]{2}{*}{ No } & \multirow[b]{2}{*}{ Bairro } & \multicolumn{2}{|c|}{ Com Alagamento } & \multicolumn{2}{|c|}{ Sem alagamento } \\
\hline & & POD & FAR & POD & FAR \\
\hline 37 & Jardim São Luís & 0 & 1,1 & 95,6 & 3,3 \\
\hline 38 & Lapa & 0 & 0 & 96,7 & 3,3 \\
\hline 39 & Liberdade & 0 & 1,1 & 94,51 & 4,4 \\
\hline 40 & Limão & 1,1 & 1,1 & 94,51 & 3,3 \\
\hline 41 & Moema & 0 & 0 & 97,8 & 2,2 \\
\hline 42 & Mooca & 1,1 & 0 & 94,51 & 4,4 \\
\hline 43 & Morumbi & 5,49 & 1,1 & 87,91 & 5,49 \\
\hline 44 & Parelheiros & 0 & 0 & 98,9 & 1,1 \\
\hline 45 & Pari & 0 & 0 & 97,83 & 2,17 \\
\hline 46 & Parque do Carmo & 0 & 0 & 98,9 & 1,1 \\
\hline 47 & Penha & 0 & 0 & 96,7 & 3,3 \\
\hline 48 & Perdizes & 2,2 & 0 & 94,51 & 3,3 \\
\hline 49 & Pinheiros & 1,1 & 1,1 & 94,51 & 3,3 \\
\hline 50 & Pirituba & 0 & 0 & 97,8 & 2,2 \\
\hline 51 & Ponte Rasa & 0 & 1,1 & 97,8 & 1,1 \\
\hline 52 & Republica & 2,2 & 2,2 & 91,21 & 4,4 \\
\hline 53 & Rio Pequeno & 0 & 0 & 98,9 & 1,1 \\
\hline 54 & Sacomã & 0 & 0 & 98,9 & 1,1 \\
\hline 55 & Santa Cecilia & 3,3 & 0 & 93,41 & 3,3 \\
\hline 56 & Santana & 5,49 & 2,2 & 86,81 & 5,49 \\
\hline 57 & Santo Amaro & 3,3 & 4,4 & 90,11 & 2,2 \\
\hline 58 & São Domingos & 0 & 1,1 & 97,8 & 1,1 \\
\hline 59 & São Lucas & 1,1 & 0 & 97,8 & 1,1 \\
\hline 60 & Saúde & 2,17 & 1,09 & 94,57 & 2,17 \\
\hline 61 & Se & 1,1 & 0 & 94,51 & 4,4 \\
\hline 62 & Socorro & 2,2 & 0 & 97,8 & 0 \\
\hline 63 & Tatuapé & 2,2 & 2,2 & 92,31 & 3,3 \\
\hline 64 & Tremembé & 0 & 0 & 98,9 & 1,1 \\
\hline 65 & Vila Andrade & 1,1 & 1,1 & 96,7 & 1,1 \\
\hline 66 & Vila Formosa & 0 & 0 & 98,9 & 1,1 \\
\hline 67 & Vila Guilherme & 3,3 & 2,2 & 91,21 & 3,3 \\
\hline 68 & Vila Leopoldina & 1,1 & 0 & 96,7 & 2,2 \\
\hline 69 & Vila Maria & 0 & 1,1 & 94,51 & 4,4 \\
\hline 70 & Vila Mariana & 0 & 0 & 95,6 & 4,4 \\
\hline 71 & Vila Matilde & 2,2 & 0 & 97,8 & 0 \\
\hline 72 & Vila Prudente & 1,09 & 2,17 & 95,65 & 1,09 \\
\hline 73 & Vila Sonia & 1,1 & 0 & 97,8 & 1,1 \\
\hline & MÉDIA & 1,16 & $\mathbf{0 , 6 5}$ & 95,75 & 2,45 \\
\hline & $\sigma$ & 1,51 & $\mathbf{0 , 8 9}$ & $\mathbf{2 , 8 9}$ & 1,48 \\
\hline
\end{tabular}

